Short-Term Operational Forecasts of Trafficability

George Mason, Richard Ahlvin, and John Green

October 2001 
The contents of this report are not to be used for advertising, publication, or promotional purposes. Citation of trade names does not constitute an official endorsement or approval of the use of such commercial products.

The findings of this report are not to be construed as an official Department of the Army position, unless so designated by other authorized documents. 


\section{Short-Term Operational Forecasts of Trafficability}

by George Mason, Richard Ahlvin, John Green

Geotechnical and Structures Laboratory

U.S. Army Engineer Research and Development Center 3909 Halls Ferry Road

Vicksburg, MS 39180-6199

Final report

Approved for public release; distribution is unlimited 


\section{Contents}

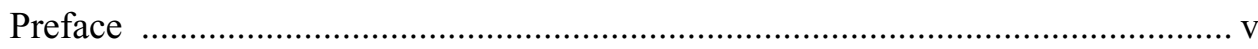

Conversion Factors, Non-SI to SI Units of Measurement ..................................... vi

Executive Summary ............................................................................................ vii

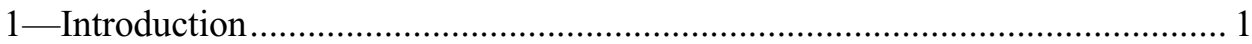

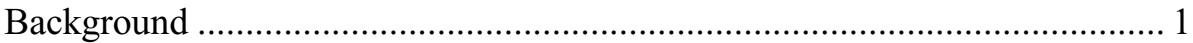

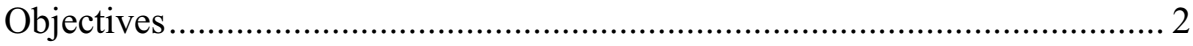

Scope

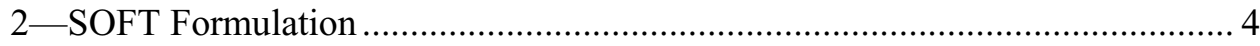

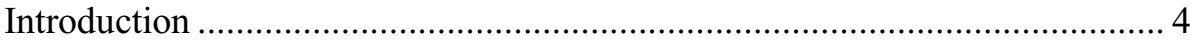

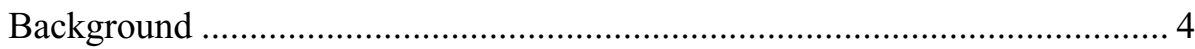

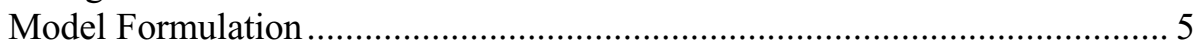

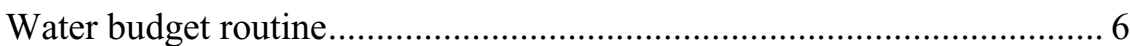

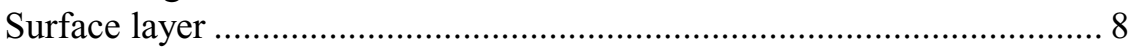

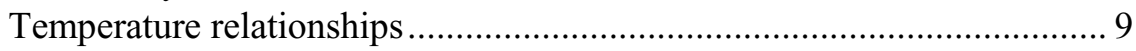

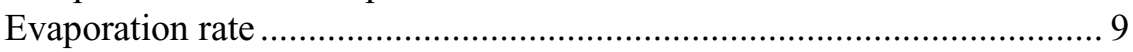

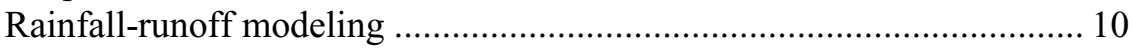

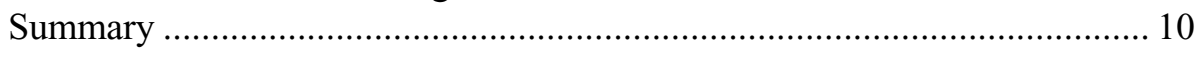

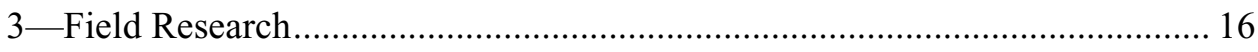

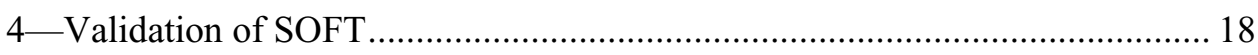

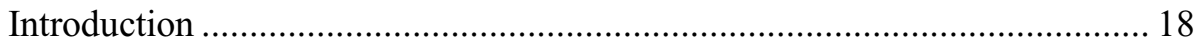

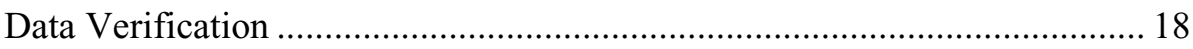

5-Real-Time Mobility Model ..................................................................... 21

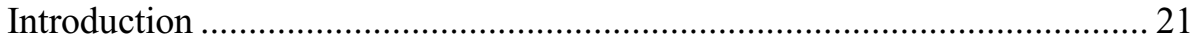

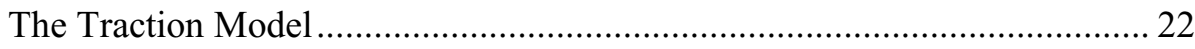

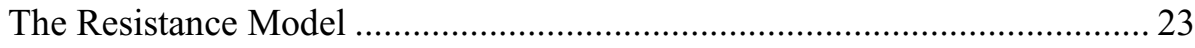

The Application Programmers' Interface …................................................ 24

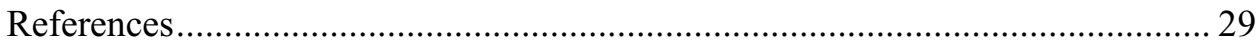

Tables 1-9

Plates 1-22

Appendix A: SOFT API for SAF Model ....................................................... A1

Appendix B: Real-Time Mobility API for SAF …………................................. 
Appendix C: Real-Time Mobility DATA File for SAF …….............................

Appendix D: Laboratory Data..................................................................... D1

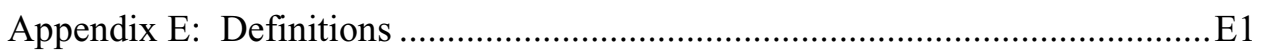

SF 298 


\section{Preface}

This report describes models developed to predict moisture migration in soil for the purpose of predicting vehicle trafficability and determining tractive force and speed relationships for vehicles.

The study reported herein was conducted at the U.S. Army Engineer Research and Development Center (ERDC), Geotechnical and Structures Laboratory (GSL), Mobility Systems Division (MSD), Vicksburg, MS, under U.S. Army Corps of Engineers RDT\&E 6.2 Research. Technical transfer of the code and additional research regarding temporal and spatial stability of code was also conducted under RDT\&E Research.

The study was conducted by GSL under the general supervision of Dr. Michael J. O'Connor, Director, and under the direct supervision of Dr. David Horner, Chief, Mobility Systems Branch (MSB).

The field test program was directed by Mr. Dennis Moore, MSB, GSL. Messrs. Richard Tennant and David McClurg, MSB, provided field test support. Messrs. Richard Ahlvin, George Mason, and John Green developed the programs and algorithms. Messrs. Mason, Ahlvin, and Green prepared this report.

At the time of publication of this report, Dr. James R. Houston was Director of ERDC, and COL John W. Morris III, EN, was Commander and Executive Director.

The contents of this report are not to be used for advertising, publication, or promotional purposes. Citation of trade names does not constitute an official endorsement or approval of the use of such commercial products. 


\section{Conversion Factors, Non-SI to SI Units of Measurement}

\begin{tabular}{||l|l|l||}
\hline Multiply & By & To Obtain \\
\hline \hline cubic feet & 0.02831685 & cubic meters \\
\hline feet & 0.3048 & meters \\
\hline gallons (U.S. liquid) & 0.003785412 & cubic meters \\
\hline $\begin{array}{l}\text { horsepower (550 foot-pounds } \\
\text { force per second) }\end{array}$ & 745.6999 & watts \\
\hline inches & 25.4 & millimeters \\
\hline miles (U.S. statute) & 1.609347 & kilometers \\
\hline pounds (mass) & 0.4535924 & kilograms \\
\hline $\begin{array}{l}\text { pounds (force) per square } \\
\text { inch }\end{array}$ & 0.006894757 & megapascals \\
\hline pound (force) per foot & 14.5939 & newtons per meter \\
\hline square feet & 0.09290304 & square meters \\
\hline square inches & 0.00064516 & square meters \\
\hline square miles & $2,589,998$ & square meters \\
\hline square yards & 0.8361274 & square meters \\
\hline tons & 907.1847 & kilograms \\
\hline yards & 0.9144 & meters \\
\hline \hline
\end{tabular}




\section{Executive Summary}

The primary objective of this study was to extend current state of the art for predicting temporal changes in soil strength as it relates to vehicle traction. A secondary objective was to develop an algorithm which could be included in highresolution combat models for improvement of modeling weather effects on mobility. To this end, the algorithms developed in this study were included in the Semiautomated Forces (SAF) models, specifically JointSAF 5.4. This provided an approach to evaluating combat models in the context of weather effects on mobility.

Two models are developed. The first is the Short-Term Operational Forecasts of Trafficability (SOFT) model. The second Real-Time Mobility (RTM) Model is a vehicle movement model which reacts to continuous changes in soil strength. A model run with SOFT under heavy rainfall conditions of $0.10 \mathrm{in} . / \mathrm{hr}$ of rain with a clayey silt soil type (ML) is shown following this paragraph. In this scenario, neither runoff nor evaporation were introduced. Soil strength drops rapidly from a hard packed materiel of 625-cone index to an area that will cause immobilization of many military vehicles within a 23 -hr period. The SOFT is a layered model, and predictions were made for the surface, for 3- to 6-in., and 9- to 12-in. ${ }^{1}$ layers. The table provided with the following figure indicates the soil strength at which an M1A1 main battle tank and a Grizzly mine plow vehicle will become immobilized.

\footnotetext{
${ }^{1}$ A table for converting non-SI units of measurement to SI units is presented on page vi.
} 


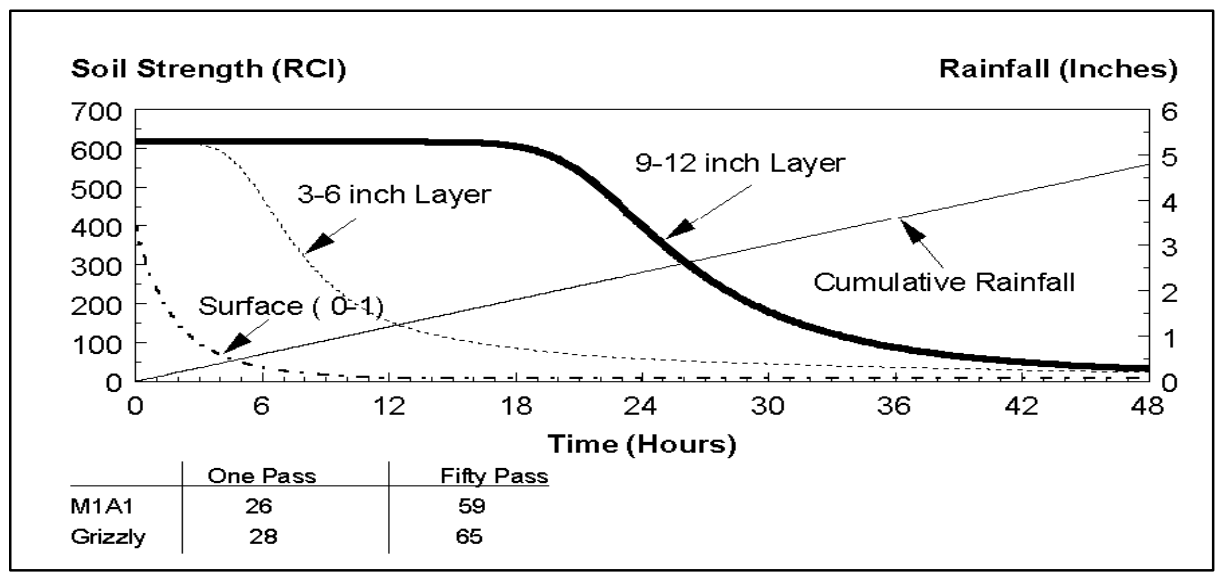

Simulated variations with soil strength with climate conditions

To evaluate algorithms adopted from past climatic studies and those used in this report, study sites were selected and monitored. The predicted versus measured percent moisture content for surface readings at Fort Leonard Wood, Missouri, are shown in the illustration following this paragraph. The computations were made for a 3-month period and compared to field measurements by the U.S. Geological Service (USGS). Percent moisture content, measured as a function of the weight of the soil, is plotted on the first y-axis. Rainfall in centimeters is plotted on the second y-axis. Rainfall is illustrated by the bar graph. The continuous line illustrates the predictions. The points are measured values in irregular intervals. This plot represents the surface layer and illustrates a good agreement for the model predictions.

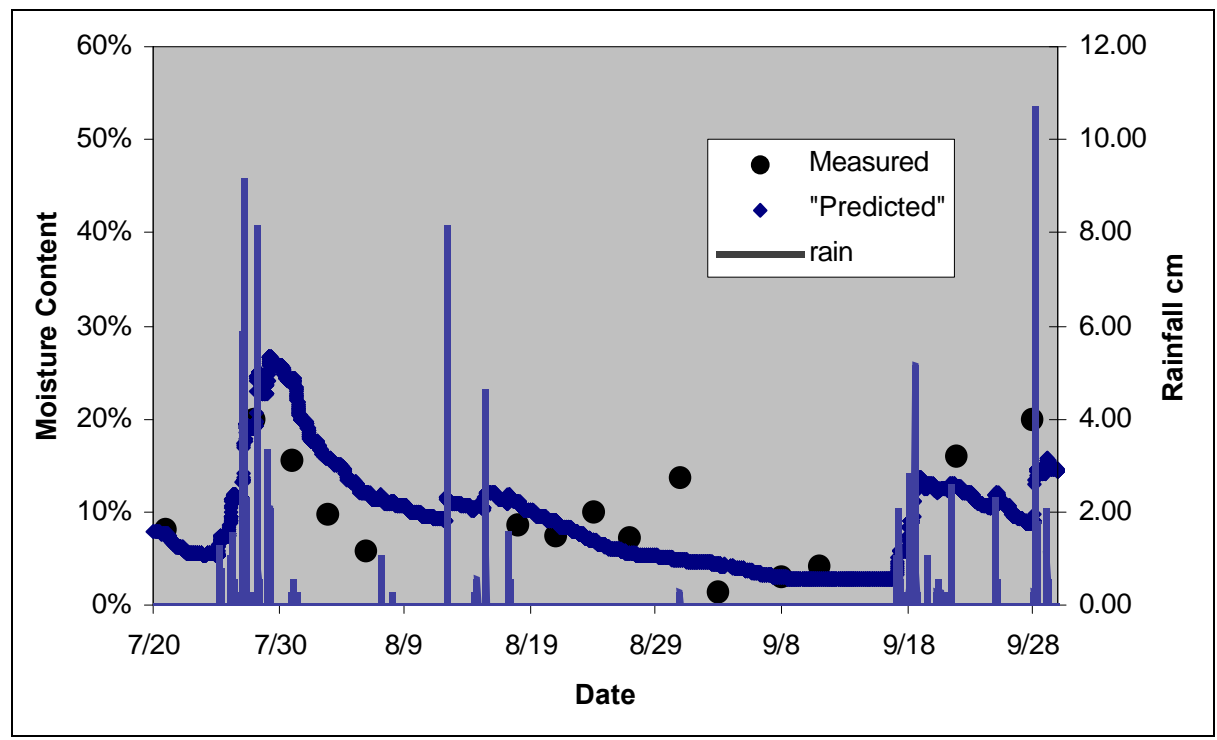

Predicted versus measured moisture content 


\section{Introduction}

\section{Background}

On November 30, 1994, Major General Joe N. Ballard, U.S. Army (Headquarters, Department of the Army 1989), detailed the requirements for collection and dissemination of information required for U.S. Army Engineer terrain teams to determine the weather requirements for current models used by the U.S. Army Corps of Engineers to forecast vehicle trafficability. These requirements included the collection of data from a weather station. Substantial issues still existed regarding the virtual and constructive environments and the approach to implementation of the Operational Requirements Doctrine (ORD) for the live environment.

a. What are the time constraints for predicting soil moisture?

b. How do these time constraints correlate with respect to the size of the military unit that is modeled?

c. What is the range in depths required for predicting mobility?

d. What depths of moisture influence wet-slippery conditions for mobility?

e. How does vegetation and slope impact these predictions?

f. Are these mobility models integrated into current training models?

The Army's weather collection and forecasting program is entitled Integrated Meteorological System (IMETS). The IMETS provides forecasts of weather conditions. The IMETS program will be supplemented with tactical field weather stations such as the Tactical Meteorology Station (TACMET) or Automatic Meteorological Sensor System (AMSS). These weather stations will transmit information that consists of:

a. Wind speed and direction.

b. Temperature.

c. Humidity.

d. Barometric pressure.

e. Rainfall rate and amount. 
f. Soil temperature and moisture.

g. Solar radiation.

h. Illumination.

The U.S. Army Engineer Research and Development Center (ERDC) was funded to research algorithms pertaining to Short-Term Operational Forecasts relative to vehicle mobility. This workunit is an extension of previous research in which the Soil Moisture-Strength Prediction (SMSP) system was developed.

The SMSP predicts daily forecasts of ground strength for purposes related to trafficability. The short-term forecasting was created to extend the SMSP algorithms to consider temporal changes in moisture content of the soil at intervals of hours and minutes. These short-term forecasts were developed to support efforts in the live and virtual environment included in this report as Appendices A through E.

\section{Objectives}

The main objective of this study was to develop and verify a model that predicts short-term moisture migration in a soil, which ultimately affects vehicle mobility. The report will describe in two major areas: the first is development of a model to predict moisture/soil strength in short time and spatial increments, the second is development of a vehicle mobility model which will give quick answers to reductions in speed due to rapid soil strength changes. The validation tests utilized three soil types; a clay, silt, and sandy clay at various compacted states. The soil areas were measured during actual rainfall events and artificial rainfall events. The artificial events were considered to induce more rapid changes in the soil moisture. A model was written and integrated into the Semi-Automated Forces (SAF) environment to replicate the soil behavior.

Two basic models were developed. The first model, Short-Term Operational Forecasts of Trafficability (SOFT), was a soil physics model, defining moisture changes of the soil with respect to long-term and short-term weather changes. The SOFT model extended the Soil Moisture-Strength Prediction (SMSPII) algorithms described by (Morris 1994). The SOFT model extended the SMSPII model, which operated at $24-\mathrm{hr}$ time intervals and $15-\mathrm{cm}$ (6-in.) spatial intervals to include changes in the time intervals of $1 \mathrm{~min}$ and spatial intervals of $1 \mathrm{~cm}$. The SOFT also includes a modified evaporation model. The second model, the Real Time Mobility Model (RTM), is a vehicle traction model from the soil parameter outputs of the SOFT. These models are supported through additional coding which transfer information within the high-resolution combat model JointSAF. The output of SOFT is moisture content and soil strength (in terms of Rating Cone Index (RCI)) for the surface and subsurface layers. Figure 1 illustrates the various models and data dictionaries required to run the RTM and SOFT. The box confines those models which run internal to SAF as libraries of concurrently run executables. The NATO Reference Mobility Model (NRMM) main module is run external to SAF to provide preprocessed output of vehicle information. This preprocessing of information is conducted to reduce run time requirements. 


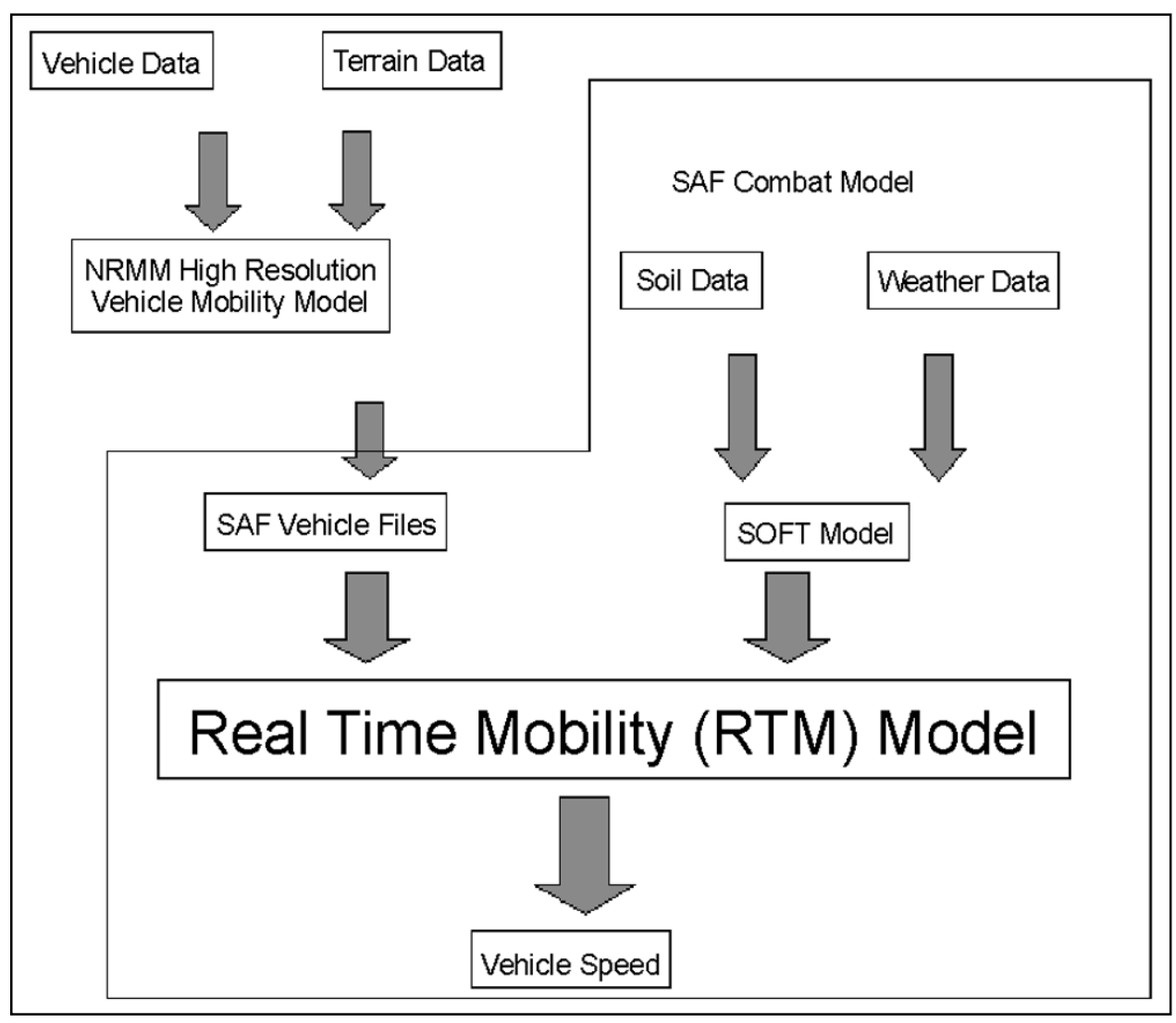

Figure 1. Flowchart of SOFT integration with RTM in SAF

\section{Scope}

The requirements necessary to achieve the objectives of this assessment were as follows:

a. Laboratory data were collected at each site for soil information to include specific gravity, clay content, Atterberg limits, and moisture content by weight.

$b$. At each site, density, cone index, and moisture were recorded at varying time intervals.

c. An Application Programmers' Interface (API) was written for the SOFT model.

d. An API for mobility, which reads output from SOFT, and predicts vehicle speed. 


\section{SOFT Formulation}

\section{Introduction}

A model entitled SOFT is proposed for the prediction of dynamic changes in the physical properties of soils. These physical properties are then used to predict a soil strength measurement (cone index). The cone index calculation is used to predict trafficability of wheeled and tracked vehicles. The model predicts cone index as a function of moisture migration through a layered soil at discrete time and spatial intervals. The prediction is performed for intervals of $30 \mathrm{~min}$ or less and vertical spatial intervals of $1 \mathrm{~cm}$.

The soil strength is defined in terms of cone index as a function of soil type, moisture content by weight, and soil density. Soil strength is predicted to a depth of $30 \mathrm{~cm}$ at varying intervals. The model includes algorithms for sorptivity of the surface, migration of the wetness front, and runoff during nonfreezing periods. The SOFT model is imbedded in a standalone program called Hydrosim (Mason 2000). The Hydrosim uses SOFT to dynamically change soil strength and moisture content attributes in the terrain database within the SAF model for the Compact Terrain DataBase (CTDB) version 7.0.

Two vehicle files were created using NRMM to model a generic wheeled and tracked vehicle. This study illustrates a method of dynamically changing moisture content of the soil within the SAF, while effecting movement rates of vehicles. The vehicle database for the tracked vehicle includes plow forces as a function of soil strength and soil type. These were preprocessed forces as derived from the NRMM (Farr et al. 1991).

\section{Background}

Mobility and countermobility predictions for regional areas of the world require knowledge of terrain and the vehicle system. The soil strength required to sustain traffic can be measured with a cone penetrometer. The cone penetrometer has been considered the standard for predicting vehicle trafficability for the U.S. Army since the late 1940's. The soil strength will change based upon the physical state of the soil, including whether the soil is frozen or in some state of freezing/thawing (Bekker 1969). The information on the strength of the soil in terms of Rating Cone Index (RCI) is then used to predict the maximum vehicle 
speed using existing traction models for high-resolution models (Haley, Jurkat, and Brady 1979).

High-resolution combat models have been developed which require accurate predictions of a maximum vehicle speed as a function of terrain and weather. The Hydrosim model developed by the Defense Modeling and Simulation Office (Cornish and Li 1998) used preprocessed data to define saturated zones in the terrain. Environmental Change Notices (ECN) were used to dynamically modify terrain attributes from one soil moisture state to another. These new attributes were added to the CTDB's Polygon Attribute Tables (PAT) which were used to define a new speed of the vehicle. Four soil states were identified by the Hydrosim 1 work (dry, average, wet, and wet-slippery). This version of Hydrosim worked with files generated from ARC INFO which delineated saturated areas based on slope. To this end, Hydrosim categorized areas of the CTDB, defining areas in terms of their level of saturation during various weather conditions external to the weather editors within the combat model.

The Hydrosim model was extended (Mason 2000) to include a model that changed soil strength directly, as a function of changing weather conditions within the JointSAF. The SOFT model was developed to predict the changes in moisture content of the soil. A particular requirement for SOFT was the need to provide soil strength information to model a mine plow vehicle. This required modeling changes in soil strength with depth to predict both traction and plowing forces.

The integration of a soil physics model into Hydrosim provided predictive capability of continuous changes in simulated conditions on the battlefield. The SOFT model was directed at the time and spatial resolution defined in JointSAF. This required modifications of the current soil moisture codes to accommodate the higher temporal and spatial resolutions. The algorithms developed in this study include unsaturated conditions of the soil and do not include snow cover, frozen, freezing, or thawing ground.

\section{Model Formulation}

The SOFT model formulation relates in situ soil strength variations to the physical properties of the soil (i.e., soil type, moisture content, overburden pressure, and density of the soil). Equation 1, as given by the RCI rating, gives an empirical relationship between soil moisture by weight and the bearing capacity of the soils, as defined by Morris (1994).

$$
R C I=e^{[a-b \ln (m)]}
$$

where

$$
R C I=\text { soil strength in terms of Rating Cone Index }
$$



$a, b=$ coefficients specified for each Unified Soil Classification System (USCS) soil type (Table 1)
$m=$ moisture content ( percent (weight (soil/water))

The relationship between moisture content in weight (as opposed to volumetric moisture content) and the dry density of the soil is given in Equation 2.

$$
\gamma_{d}=\frac{S G_{s}}{S+m G_{s}} \gamma_{w}
$$

where

$$
\begin{aligned}
\gamma_{\mathrm{d}} & =\text { dry unit weight of soil }\left(\mathrm{lb} / \mathrm{ft}^{3}\right) \\
\gamma_{\mathrm{w}} & =\text { unit weight of water }\left(\mathrm{lb} / \mathrm{ft}^{3}\right) \\
S & =\text { percent saturation } \\
G_{S} & =\text { specific gravity of solids }
\end{aligned}
$$

The relationship of moisture content of the soil and dry density is given in Equation 3.

$$
m=\frac{V_{w} \gamma_{w}}{V_{s} \gamma_{d}}
$$

where

$$
\begin{aligned}
& V_{w}=\text { volume of water }\left(\mathrm{ft}^{3}\right) \\
& V_{S}=\text { volume of solids (constant) }\left(\mathrm{ft}^{3}\right)
\end{aligned}
$$

Density of the soil is required to determine moisture content by weight and to compute soil strength. The interdependencies of density and volumetric movement of water directly determine soil strength relative to traction of a vehicle.

\section{Water budget routine}

The expected values of $\gamma_{d}$ are given in Table 1 for various soil types. The volume of water in the soil at any time is determined with a water budget routine as given in Equation 4.

$$
V_{w[t, d]}=V_{w[t-1, d]}+\partial V_{w[t, d]}
$$

where

$$
t=\text { time }(\mathrm{sec})
$$




$$
d=\text { distance }(\mathrm{cm})
$$

Given a multilayer system as shown in Figure 2, the volume of water at each interval can be computed as given in Equation 5.

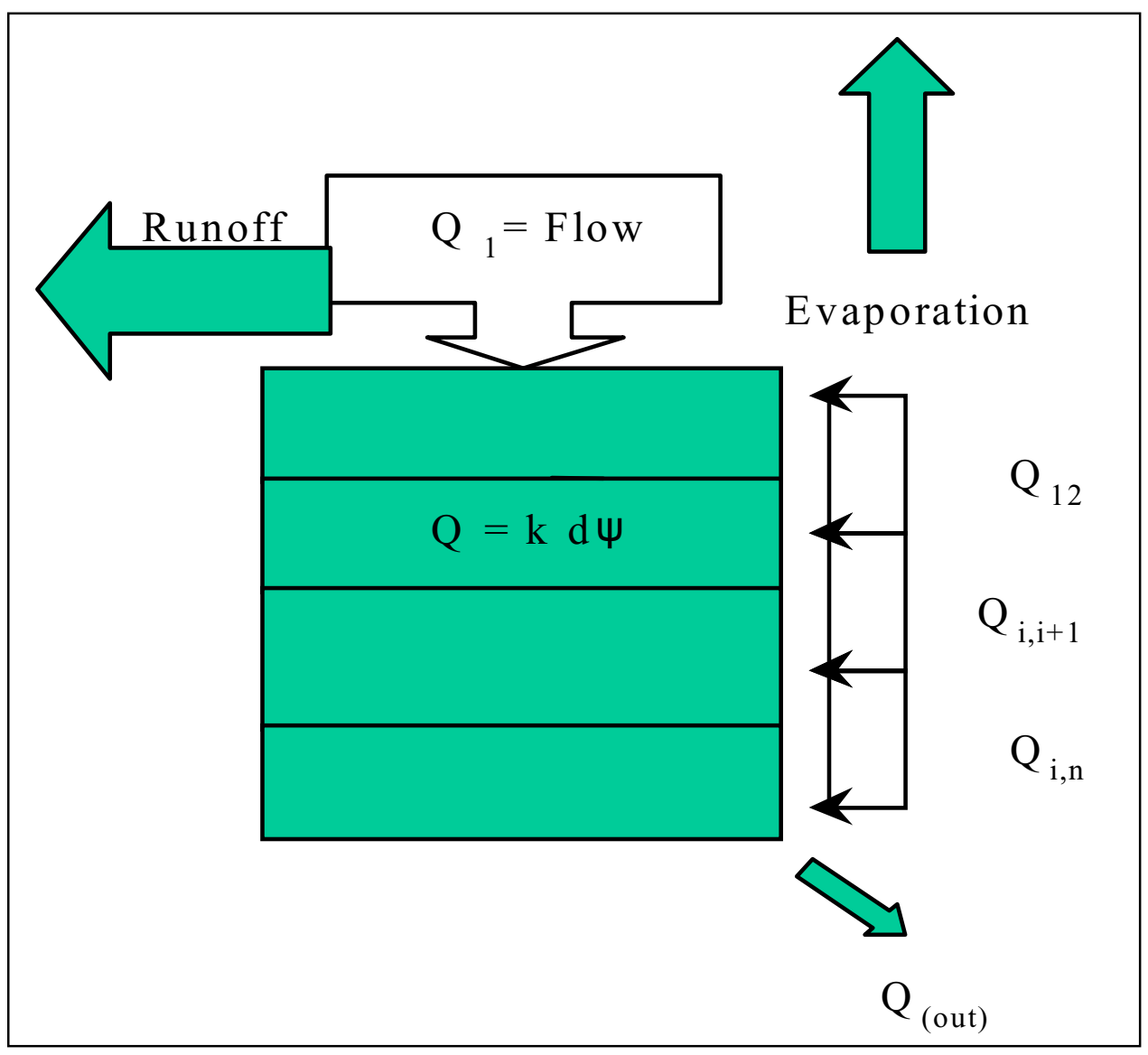

Figure 2. Multilayered soil system

Equation 5 splits the computations into three discrete computations. The first computation is for the change in the volume of water in the surface layer. The second computation for change in water volume can be subdivided into multiple layers. The third computation represents the change in the volume of water in the $\mathrm{n}^{\text {th }}$ layer where the drainage into the soil and the water table is the only controlling factor. The Sellers (Sellers et al. 1986) equation is modified in Equation 5 with the term $\mathrm{d}$ to account for variations of the soil depth. 


$$
\begin{aligned}
& \partial V_{w[t, 1]} \approx \partial V_{w[t-1,1]}-\left(Q_{(1,2)} \frac{d_{1}}{d_{2}}+E+R\right) \partial t \\
& \partial V_{w[t, i]} \approx \partial V_{w[t-1, i]}-\left(Q_{(i, i-1)} \frac{d_{i-1}}{d_{i}}+Q_{(i, i+1)} \frac{d_{i}}{d_{i+1}}\right) \partial t \\
& \partial V_{w[t, n]} \approx\left(Q_{(i-1, i)} \frac{d_{i-1}}{d_{i}}-Q_{(\text {out })}\right) \partial t
\end{aligned}
$$

where

$$
\begin{aligned}
& Q=\text { flow through a layer (LT-1) } \\
& E=\text { evaporation at the near surface (LT-1) } \\
& R=\text { runoff of the surface Layer (L) }
\end{aligned}
$$

The term $(Q)$ accounts for flow between two consecutive layers of soil, including flow of water up or down in the system. The highest value of the flow is restricted to the saturated permeability of the soil as given in Table 1 . The flow is a function of pressure and permeability of the soil. The change in pressure between consecutive layers of soil controls the direction of the flow. The change in flow between layers is given in Equation 6 as a function of relative permeability and pressure.

$$
\partial Q=2 K_{r}\left(\frac{\partial \psi_{i, i+1}}{d_{i}+d_{i+1}}+1\right)
$$

where

$$
\begin{aligned}
K_{r} & =\text { relative permeability }(\mathrm{cm} / \mathrm{sec}) \\
\psi & =\text { bubbling pressure head }(\mathrm{cm})
\end{aligned}
$$

The bubbling pressure can be measured in the field with a tensiometer and the saturated permeability with a permeameter. The relationship between moisture content, bubbling pressure, and permeability is given by Clapp and Hornberger (1978) in Equations 7 and 8, where the coefficients for $\beta$ are given in Table 1. Plates 1 and 2 illustrate the relationships between the physical properties of a soil and permeability. Plate 2 illustrates the relationship between $\mathrm{S}$ and $\psi$.

$$
\begin{aligned}
& K_{r}=K_{s} S^{(2 \beta+3)} \\
& \psi_{r}=\psi_{s} S_{i}^{-\beta}
\end{aligned}
$$

where 


$$
\beta=\text { empirical coefficient from Table } 1
$$

Rada, Schwarz, and Witczak (1989) used these relationships to address issues of migration of moisture in a road's subgrade for purposes of defining seasonal road deterioration.

The equation for the output flow $\mathrm{Q}_{\mathrm{r}}$ from the final layer is given by Equation 9 (Sellers et al. 1986) as:

$$
Q_{r}=\sin (s) K_{r}
$$

where $s=$ slope of the terrain $(\%)$.

The slope for this equation is based on digital elevation data. $Q_{r}$ assumes the soil layer (r) extends to the water table.

\section{Surface layer}

From a slipperiness standpoint, researchers are often concerned with only the surface layer of soil. This is particularly true when we consider short-term forecasts of less than 1 day in a region where dry weather has prevailed. When the precipitation events occur, slippery conditions on the surface reduce mobility considerably. To predict surface slippery conditions, a sorptivity term is introduced. Sorptivity is a measure of the surface layers ability to absorb or release water. Computation of the sorptivity of the surface layer will define the amount of water the soil will take in over small increments of time. The equation for sorptivity as given by Clapp and Hornberger (1978) is shown in Equation 10 for zero pressure. Zero pressure indicates that there is no head or standing water to influence permeation.

$$
\Omega=\left(2 \mathrm{~K}_{\mathrm{s}} \psi_{s} S\right)^{1 / 2}\left(1-W_{i}\right)
$$

where

$$
\begin{aligned}
\Omega & =\text { sorptivity at surface pressure of } 0\left(\mathrm{~cm} / \mathrm{sec}^{0.5}\right) \\
S & =\text { saturation }(\%) \\
W_{i} & =\text { moisture content }
\end{aligned}
$$

The sorptivity is related to volume of water absorbed by the soil per unit time. Equation 11 expresses sorptivity, permeability, and time as a function of flow into the surface (Sellers et al. 1986).

$$
\partial V_{1}=\Omega \partial t^{1 / 2}+K_{r[1]} \partial t
$$




\section{Temperature relationships}

The viscosity of water is affected by temperature. This relationship is illustrated in Plate 1 . The relationship between permeability at temperature $T$ was fitted for this report to data given by Spangler and Handy (1984). Equation 12 is the resulting fitted formula.

$$
K_{20 . C}=\frac{\mu T}{\mu_{20^{\circ} \mathrm{C}}} K_{T}
$$

\section{Evaporation rate}

The evaporation rate used for this model was designed around the input data available in the SAF environment. The initial derivation of the Penman model, given in Equation 13, Penman (1948), appeared adequate for this experiment.

The more advanced energy balance equations require inputs of solar radiance and cloud cover.

$$
E=C^{*}\left(e_{s}-e_{a}\right) u_{2}^{0.76}
$$

where

$$
\begin{aligned}
E & =\text { evaporation rate (millimeters } / \text { minute) } \\
e_{s} & =\text { saturated vapor pressure }(\mathrm{Pa}) \\
u_{2} & =\text { wind velocity at } 2 \mathrm{~m} \text { above the ground }(\mathrm{m} / \mathrm{sec}) \\
e_{a} & =\text { vapor pressure (millibars) } \\
C & =\text { constant }
\end{aligned}
$$

The vapor pressure at the surface $e_{s}$ is a function of the percent saturation (S) of the surface. The relationship between atmospheric vapor pressure and saturated vapor pressure as a function of relative humidity is given in Equation 14.

$$
E=C^{*} e_{a}^{*}(1-h) u_{2}^{0.76}
$$

where $h=$ relative humidity $\mathrm{e}_{\mathrm{a}} / \mathrm{e}_{\mathrm{s}}$. Rate of evaporation is used in a time dependent model. Pan evaporation rates were used to correlate predicted and measured evaporation rates and compute the constant $\mathrm{C}$. The constant $\mathrm{C}$ was computed at $1 * 10^{-5}$. 


\section{Rainfall-runoff modeling}

Runoff coefficients were used for rural areas (Schwab et al. 1971) as given in Table 2. The coefficients are applied against the precipitation rate before interception of the ground. Equation 15 gives the new precipitation rate.

$$
P=P A-C P A
$$

where

$$
\begin{aligned}
& P=\text { precipitation rate }(\mathrm{LT}-1) \\
& A=\text { area of polygon } \\
& C=\text { runoff coefficient }
\end{aligned}
$$

\section{Summary}

A flowchart for the algorithms above is given in Figure 3. A short-term forecasting algorithm is presented that provides a method to dynamically change soil strength. The static parameters required to run this model are presented in Table 1. Parameters for Table 1 are taken from Rada, Schwarz, and Witczak 1989. These are included in the API. The model accounts for tensions of the soil during seasonal changes in weather which create negative pore pressures that can be measured with field instruments such as tension meters. Positive pore pressures associated with confined aquifers, dynamic loading of the soil, or other pressures are not considered in this formulation. The SOFT model provides a simple method for predicting moisture migration in undisturbed surface layer soils. 


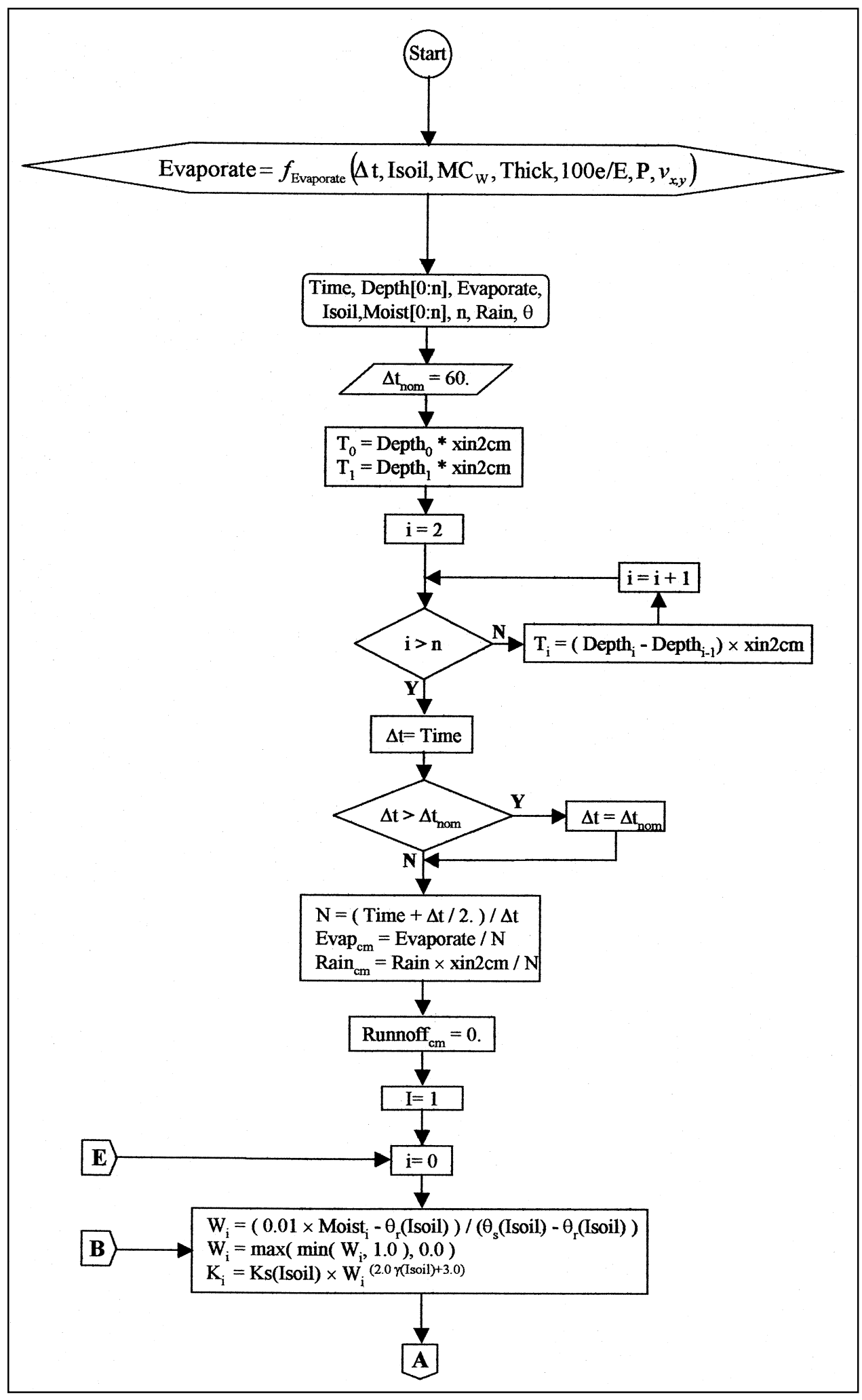

Figure 3. Flowchart of SOFT (page 1 of 4) 


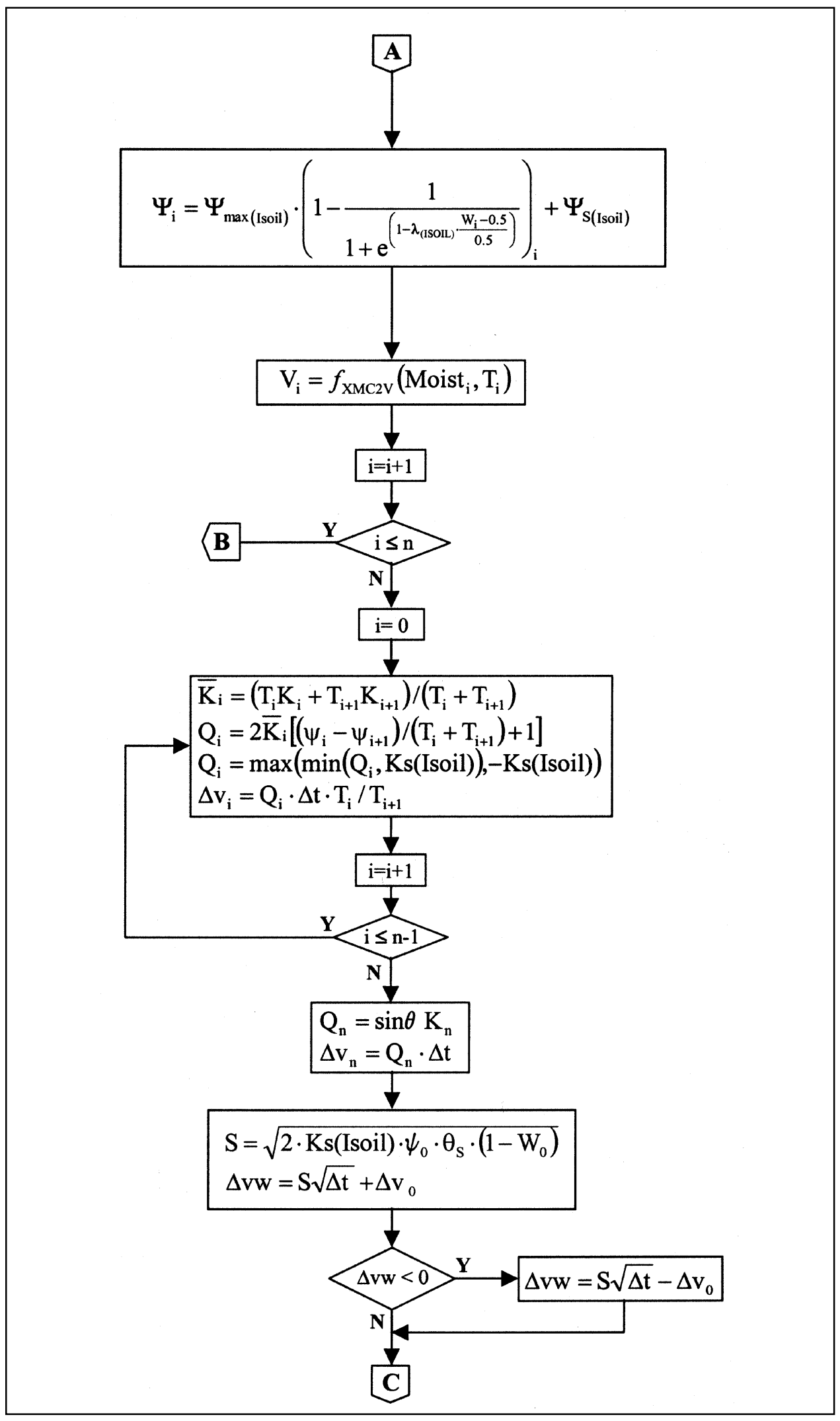

Figure 3. (page 2 of 4 ) 


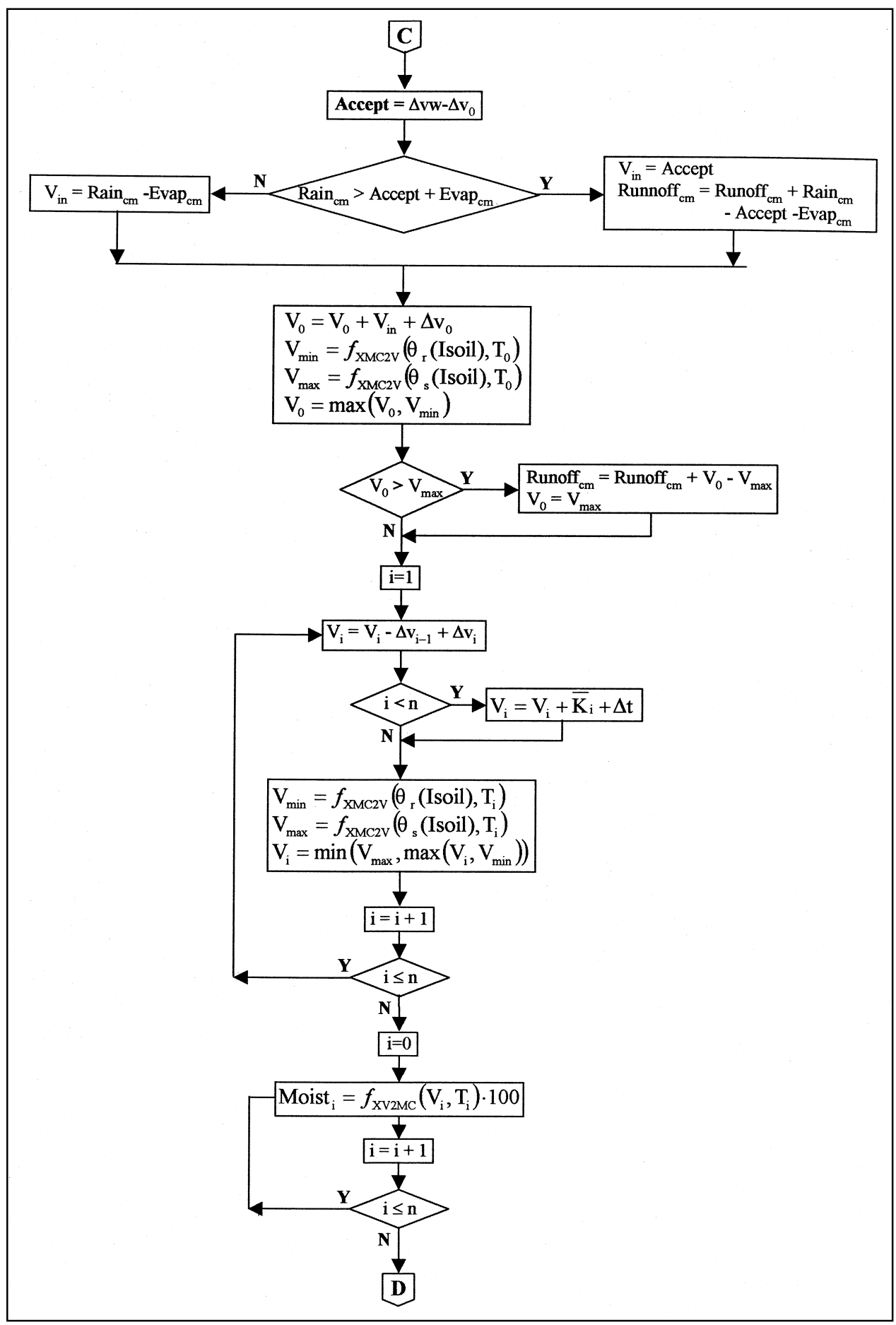

Figure 3. (page 3 of 4 ) 


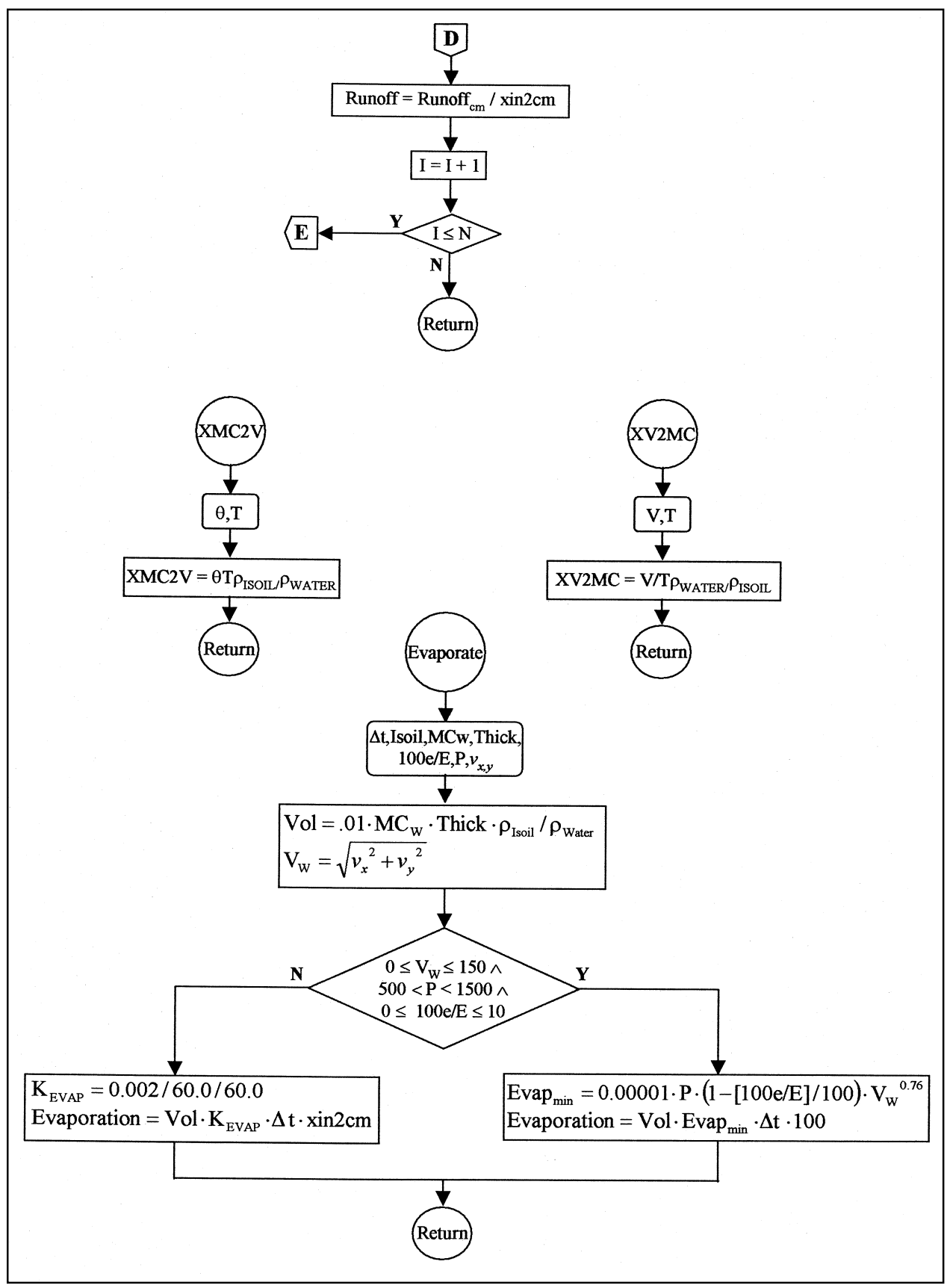

Figure 3. (page 4 of 4 ) 


\section{Field Research}

\section{Introduction}

A limited validation effort was conducted to test the equations implemented for SOFT against field data collected at the U.S. Army Engineer Research and Development Center (ERDC), Vicksburg, Mississippi, and Fort Leonard Wood, Missouri. Sites were spilt between long-term and short-term research. Short-term testing was based on artificial flooding of areas to evaluate how quickly soil strength would change as a function of worst-case conditions. Long-term test sites were built around existing weather stations. The weather station data were supplemented with periodic testing of soil strength. In both cases, model results were compared to test data. This section details the methods used at each site to collect data.

Two sites at Vicksburg, MS, were flooded. Soil strength and moisture content was monitored on varying time intervals. Gradations and pictures of each site are included in Appendix D of this report. The time intervals were recorded and soil strength was measured with a 0.2 -in. cone penetrometer.

Site 1 (entitled Poor House property) was located on a soil classified as low plasticity silt (ML). The site was located in an area on the east side of ERDC. Permeability at the site was recorded with a hygrometer and plotted on Plate 3. Plate 3 suggests the permeability of the soil surface, at saturation, is near $9 \times$ $10^{-5} \mathrm{~cm} / \mathrm{sec}$. The Poor House property site was primarily a fill material with fairly uniform soil strength and density when measured in the initial condition.

Approximately 3 in. of surface material was removed, prior to any testing, to ensure minimal runoff and remove surface vegetation and debris. The area was flooded with approximately 2 in. of water and cone indexes were taken after $2.5 \mathrm{hr}$ and then after $24 \mathrm{hr}$.

Cone penetrometer measurements at Site 1 are illustrated in Table 3. Twenty measurements were made from the surface to a depth of $18 \mathrm{in.} \mathrm{The} \mathrm{highest,}$ lowest, first standard and second standard deviations, and average cone value from measured values are provided in Table 3 . These values represent the initial strength of the soil. The initial predicted cone index is defined from the model by adjusting the empirical coefficients such that the average initial measured cone index and predicted values for depth were similar. Plate 4 illustrates the high, low, and predicted values of the cone index as derived from 10 cone readings in 
the left side of the Poor House property test section. The measured moisture content readings at the surface were between 17 and 18 percent of dry weight. The site was located on fill material, and the cone readings were relatively weak.

Table 4 presents initial empirical coefficients inputted for model prediction. The average hydraulic conductivity of the soil was measured at $4.8 \times 10^{-3} \mathrm{~cm} / \mathrm{sec}$ for the first 6 in. and $4.5 \times 10^{-3} \mathrm{~cm} / \mathrm{sec}$ for the 6- to 12 -in. layer. Plate 3 illustrates the flow measured during a $30-\mathrm{min}$ test series. A $10-\mathrm{cm}$ head of water was applied. The defined input permeability was varied based on field measurements from $5 \times 10^{-4} \mathrm{~cm} / \mathrm{sec}$ to $9 \times 10^{-5} \mathrm{~cm} / \mathrm{sec}$. Similar variations were defined in Table 4. For example, tests were conducted to determine density. Density readings were measured with a Hvorslev Sampler. Dry density measurements averaged $71 \mathrm{lb} / \mathrm{ft}^{3}$ with a standard deviation of $12 \mathrm{lb} / \mathrm{ft}^{3}$.

The variations in initial conditions for the ERDC site were used to suggest similar expected variations of the soil physical properties at the Fort Leonard Wood Site (Site 2). No direct measurements of permeability were made at Fort Leonard Wood. The expected variations in initial conditions are defined in Table 5. Moreover, cone index readings were not collected at Leonard Wood.

Predicted and measured values were compared based on the moisture content, and the average values for the empirical coefficients in Table 1 were redefined in Table 4 such that the initial condition matched for Site 1 (Table 5). The coefficients for Site 2 were also modified to match initial conditions (Table 5). Tables 4 and 5 define a distribution of data within expected ranges. The nominal value defines the numeric value used to predict the initial condition. The mean value is based on the defined distribution type. In each case, a triangular distribution was used. The difference between the nominal and mean value are indicative of the skewness of the distribution. 


\section{Validation of SOFT}

\section{Introduction}

The field tests were concentrated on validation of the SOFT model. The SOFT validation effort was split between verification of field data and validation of the components of the model. The model components included:

\section{a. Evaporation.}

b. Dry density/moisture relationship.

c. Volumetric water content versus water content by weight.

d. Rapid flux of water through media.

e. Long-term movement of water through media.

\section{Data Verification}

Initial verification of the model occurred using a flooded field at Poor House property (Site 1) located at ERDC. The top 3 in. of material was removed with a dozer. Twenty sets of cone penetrometer readings were made using a 0.2-in. cone and a 750 dial to allow for follow-on tests or the area would contain water. The cones were punched after the earth was removed. Variations in soil strength are indicated with depth in Plate 4. A set of moisture contents/soil strengths from the prediction model was mapped to these initial conditions. Table 6 provides the initial conditions for the SOFT model. Predicted versus measured cone index readings are given in Table 3 and plotted in Plate 4. These initial conditions had significant effect on predicted temporal changes in the soil. If initial conditions were defined at too low a moisture content, the time required for the water to flow through the media was rapid and saturation would occur in a rapid manner. Likewise, if the initial condition for the soil was too dry and the respective initial soil strength defined too high, the time for the water travel through the soil was excessive. Defining the initial sequence of moisture contents and respective soil strengths between the standard deviations provided the most reasonable answer.

The entire Site 1 was flooded with a 2-in. depth of water. A water truck was kept onsite during the investigation to assure the water level was constant. Cones were punched into the ground every $2.5 \mathrm{hr}$. Data from these cones are given in 
Table 7. The data are plotted in Plates 5 and 6. For the initial conditions, variations in the cone index readings appeared significant between a depth of 1 and 4 in. The model was run at 60 -sec time intervals. Predicted and measured differed at the surface down to $2 \mathrm{in}$. The model computed rapid absorption on the surface. Initial model predictions were calibrated (initial moisture content was varied within expected ranges) such that the average predicted cone indexes fell between the measured high and low values for $2 \mathrm{in}$. down to $14 \mathrm{in}$. At the end of $2.5 \mathrm{hr}$, cones were punched again and plotted in Plate 5, and these cones indicated good correlations.

The area was then left overnight and at the end of a 24 -hr period cones were punched again. The predicted versus measured results are tabulated in Table 8 with Plate 6 illustrating plots of these data. In this series of plots, the surface layer appeared to overlay correctly on the predicted measurements. However, seepage of water into the 5- to 14-in. layer was less than the measured.

Model results from Poor House property were extended to examine results from the Fort Leonard Wood data set. The Fort Leonard Wood experiment was different in as much as only weather station data were collected along with moisture content of the soil. For this program, data collected between July 14 and September 12, 1999, were examined. Plate 7 illustrates wind speed and humidity versus time. Humidity remained relatively high with wind speeds averaging 2 to $3 \mathrm{~m} / \mathrm{sec}$. Plots of wind speed and rainfall are given in Plate 8 . Since SOFT does not include a freezing model, those times of the year where temperatures dropped below $32{ }^{\circ} \mathrm{F}$ were excluded. Table 9 defines the initial conditions used for the model runs.

Predicted and measured evaporation rates are plotted on Plate 9 for nighttime events. Plate 10 illustrates daytime evaporation rates. Both daytime and nighttime evaporation rates were plotted on Plate 11. Pan evaporation rates were used. Prediction of the evaporation rate was conducted using Equation 13. Predicted versus measured is illustrated on Plate 12. There appears to be a good correlation between the predicted and measured values. Solar radiation was not included in this model to maintain simplicity within the model inputs.

A prediction was made for the surface moisture content and plotted on Plate 13. Rainfall data are included in this plot. Some outliers appear during the latter part of August. These outliers appear to be the result of data collection errors. This conclusion is made in part because previous readings showed moisture contents below 10 percent with the outlier at 15 percent. In general, the surface data showed a good trend with the data. This prediction was based on the mean values.

Plates 14 and 15 illustrate predicted versus measured for the 3- to 6-in. layer and 9-to 12-in. layer. Variations in the prediction were within the expected range of the data. The predicted values for this layer did not vary as much as the measured data for a single time series. Errors in field measurements, differences in location of the measured values, and handling the field data may have contributed to the measured variations in data. 
Variations in the predictions were introduced in Plate 16, as defined in Table 4, to illustrate the expected prediction values given expected deviations in the initial conditions. These trends appeared to follow expected results and the measured data fell within the minimum and maximum predictions for the layers. Finally, Plate 17 illustrates the 0 - to 6 -in. accumulation of water over time. The increase in volume of water appears to correspond with the rainfall events. 


\section{Real-Time Mobility Model}

\section{Introduction}

Advanced movement algorithms and extended lookup tables are defined in this chapter as an alternative to the limited speed tables which exist in current high-resolution combat and training models. Movement algorithms in the various training models such as SAF (and the high-resolution analytical models) typically have a fixed set of speed lookups that are related to predefined conditions on the battlefield. These conditions cannot be varied without considerable cost in time and effort. However, real-world battlefield conditions that affect vehicle movement are often changing drastically based on changes in weather. The suggested replacement tables for the older version of the JointSAF vehicle files are based on field tests and high-resolution mobility model runs. Field tests have indicated that traction of the vehicle will change based on varying surface and subsurface changes in soil strength. This study discusses the issues of replacing the speed in lookup tables specific to JointSAF with movement algorithms and traction data tables that represent high-resolution model results and field tests. The product of this research was a vehicle model derived from NRMM, which changed vehicle performance as a function of continuous variations of soil strength.

The Defense Mapping and Simulation Office initiated a study (Cornish and Li 1998), which included an investigation of modeling traction and plowing forces of an Army engineer mine-plow vehicle known as the Grizzly. This study included the integration of soil strength and weather effects on terrain (Mason 2000). A subset of the NATO Reference Mobility Model, Version II (NRMM II), was selected as providing appropriate sensitivity and accuracy for the given simulation. An Application Programmer's Interface (API) was designed to facilitate the inclusion of the required functionality without the need to incorporate the entire $\mathrm{NRMM}^{1}$ model code. Additionally, a principal consideration in the design of the target simulation was to include the effects of weather on mobility performance.

A major factor in mobility performance is the state of the soil surface. In order to incorporate soil strength, or changes thereof, in the SAF environment, a model and an appropriate API called SOFT were developed to predict the moisture condition and subsequent soil strength from rainfall time histories

\footnotetext{
${ }^{1}$ For the remainder of this document, NRMM is considered synonymous with NRMM II.
} 
(Mason 2000). The SOFT model is essentially a subset of the Soil MoistureStrength Prediction, Version II (SMSP II) model recast to allow shorter or variable time increments in lieu of the fixed 24-hour period assumed for SMSP II. The SOFT was coupled with a mobility model through an appropriate Federated Object Module (FOM) (Janett et al. 2000). The mobility model currently exists within the JointSAF core libraries. This mobility model takes as input soil type, soil strength, slope, and certain vehicle characteristics to provide a prediction of maximum vehicle speed.

NRMM (Ahlvin and Haley 1992) is a force balance model. The tractionspeed relation for the vehicle is determined from the vehicle's power train and traction element characteristics and the current soil type, strength, and surface condition. Various vehicle mobility impediments in the form of resistances are determined. The sum of all impeding resistances is compared with the tractionspeed relation. If the traction exceeds the resistance force sum, excess vehicle traction is available and a suitable running speed is determined. Otherwise, if resisting forces are greater than available traction, a vehicle immobilization (NOGO) condition results. Because of limitations in the terrain information available in the target simulation database and vehicle operating mission considerations, several potential mobility impediments including the effects of vegetation, obstacles, ride dynamics, and certain driver reactions normally considered in NRMM were not considered and are not included in the mobility API.

\section{The Traction Model}

NRMM incorporates a representation of a vehicle's power train to estimate the vehicle's theoretical power in the form of a maximum available traction versus drive element speed relation. This model requires performance and configuration characteristics of the power train including the engine output torque versus speed (rpm) relation curve, torque converter characteristics (if applicable), transmission gear ratios and efficiencies, and final drive information. Optionally, the theoretical traction-speed relation can be determined through physical testing and provided as an input to NRMM.

The traction-slip relation and soil motion resistance is derived for the given soil type, soil strength, and surface condition. NRMM uses this information to produce a traction-speed relation for the specific vehicle/terrain combination. The fundamental soil relations in NRMM use an empirical system developed at ERDC, which relates vehicle performance to soil strength in terms of RCI for cohesive soils (clays, silts, and wet sands). The semiempirical numeric system relating performance to soil cone index (CI) is used for noncohesive soils (dry sands.)

To reduce the complexity and data volume for the API, a rectangular hyperbola (Equation 16) is fitted to the traction-speed relation using a modified leastsquares curve-fit algorithm. 


$$
s=\frac{a}{t / w+c}+b
$$

where

$$
\begin{aligned}
& s=\operatorname{speed}(\mathrm{mph}) \\
& t=\operatorname{tractive-force}(\mathrm{lb}) \\
& w=\text { vehicle weight }(\mathrm{lb}) \\
& a, b, \& c \text { are the curve fit coefficients (dimensionless) }
\end{aligned}
$$

(The minimum and maximum values of traction from the original relation are also retained.)

An additional power reduction factor may be included to account for the engine accessory loads such as those caused by automatic blade plow depth actuating equipment or breaching equipment. The details (such as duty cycle, etc.) of this load are not modeled; it is known to be substantial (up to 20 percent of engine power). For this implementation, the power reduction is included if plowing is in effect (plowing depth greater than zero.)

A traction reduction factor is also included to simulate the effect of the vehicle running over a disturbed (plowed) surface. The terrain description information (strength information derived from the SOFT model) is valid for in situ soils. It is believed (but unconfirmed by testing) that plowed surfaces should provide less traction than the virgin terrain. Expert opinion is that traction reduction should be at least 10 percent. Similar to the power reduction coefficient, this factor is in effect only during plowing. A comparison of a typical traction-speed relation to the curve fit relation is given in Plate 18.

Plate 19 illustrates the traction relationships of a vehicle as a function of soil strength and vehicle speed. The traction coefficient can relate directly to the vehicle's ability to climb slopes, override vegetation, and negotiate obstacles.

\section{The Resistance Model}

\section{External resistance}

The resistances considered for the API model are soil motion resistance, resistance resulting from the influence of slope, and resistance derived from the plowing action of a mine plow (or similar) blade operating at a prescribed depth. Resistance resulting from overriding vegetation or obstacles is not considered. 


\section{Slope resistance}

The effect of slope introduces additional resistance (if traveling up-slope) or additional effective traction (if traveling down-slope.) (In coefficient form, the slope resistance is simply the tangent of the slope.) This value is added to the other resisting quantities.

\section{Plow resistance}

The plow resistance coefficient is interpolated from a table of plowing force as a function of plowing depth and soil strength for several USCS soil types. This table may be populated with field test results or information from other simulation models. For this example, the theoretical plowing force model included in NRMM (Farr et al. 1991) was used to populate the data table. Plate 20 depicts this example data.

Plates 21 and 22 illustrate the SAF output as depicted by a "stealth" monitor. The vehicles are placed at the end of a virtual ramp and ordered to the top of the ramp.

\section{The Application Programmers' Interface}

The application programmers' interface consists of three primary routines:

Routine
Veh_plow_init
Veh_maximum_speed
echo_veh_data

Description

Initialize system and read in performance prediction tables

Produce a performance prediction

Echo input data to system output

The following is a detailed description of the API routines.

INTEGER FUNCTION VEH_PLOW_INIT( FPATH )

This routine initializes the system and populates the vehicle plow model internal tables from information contained in an external data file.

Input:

FPATH Path name to Vehicle plow performance information data

Outputs:

VEH_PLOW_INIT Initialization status:

$0=$ Okay

Pos $=I / O$ error; system specific $\mathrm{I} / \mathrm{O}$ status returned

$-1=$ Premature E.O.F. reading input data

$-2=$ No logical unit available for file $\mathrm{I} / \mathrm{O}$

$-3=$ NSTREN out of range [2..MSTREN] 
$-4=$ NPDEPTH out of range [0..MPDEPTH]

$-5=$ NPSTREN) out of range [2..MPSTREN]

$-6=$ Unexpected soil type code reading vehicle data

$-7=$ Soil strength mismatch reading vehicle data

$-8=$ Unexpected soil type code reading plow data

$-9=$ Soil strength mismatch reading plow data

Main API call:

\section{SUBROUTINE VEHICLE_PLOWING_SPEED(null, Yin, Plowspeed)}

This routine is the primary prediction model. The vehicle maximum speed as a function of the input terrain description is returned.

General note: No data type for Yin was stated in the original API specification. Several of the values are categorical (i.e. Yin(1), Yin(2) and Yin(3)) while the others are analog. Since there are some analog values present, Yin was assumed to be type REAL.

\begin{tabular}{|c|c|c|}
\hline \multicolumn{3}{|l|}{ Inputs: } \\
\hline \multicolumn{3}{|c|}{ Yin $(0)=$ Blade depth [in] (Note 1.) } \\
\hline \multicolumn{3}{|c|}{ Yin $(1)=$ ITD soil type code: (Note 2.$)$} \\
\hline $0=$ Unknown & $7=\mathrm{SM}$ & $14=\mathrm{OH}$ \\
\hline $1=\mathrm{GW}$ & $8=\mathrm{SC}$ & $15=\mathrm{PT}$ \\
\hline $2=\mathrm{GP}$ & $9=\mathrm{ML}$ & $16=$ Not Used \\
\hline $3=\mathrm{GM}$ & $10=\mathrm{CL}$ & $17=$ Not Used \\
\hline $4=\mathrm{GC}$ & $11=\mathrm{OL}$ & $18=$ Not Used \\
\hline $5=\mathrm{SW}$ & $12=\mathrm{CH}$ & \\
\hline $6=\mathrm{SP}$ & $13=\mathrm{MH}$ & \\
\hline
\end{tabular}

Note: and value out of range [1..14] will be assigned 0 (unknown) Yin $(2)=$ Vegetation cover code:

$$
\begin{aligned}
& 0=\text { Bare } \\
& 1=\text { Grass } \\
& 2=\text { Forest }
\end{aligned}
$$

Yin (3) = CCTT Slope class code:

$\begin{array}{llc}\text { Code } & \text { Range } & \text { Value used } \\ 1 & <=-60 & 60 \\ 2 & -40 \text { to }<-60 & -50 \\ 3 & -20 \text { to }<-40 & -30 \\ 4 & -5 \text { to }<-20 & -13 \\ 5 & >0 \text { to }<-5 & -3 \\ 6 & =0 & 0 \\ 7 & 0 \text { to }<5 & 3 \\ 8 & 5 \text { to }<20 & 13 \\ 9 & 20 \text { to }<40 & 30 \\ 10 & 40 \text { to }<60 & 50 \\ 11 & >=60 & 60\end{array}$


Note: Any codes outside the range [1..11] will be assigned 6 (slope $=0$ )

Yin(4) = Moisture content of surface layer (from SMSP/SOFT) [\% by weight]

Yin $(5)=$ Moisture content of soil layer (from SMSP/SOFT) [\% by weight]

Yin $(6)=$ Soil strength of surface (from SMSP/SOFT) $[\mathrm{CI} \mid \mathrm{RCI}]$

Yin $(7)=$ Soil strength of soil (from SMSP/SOFT) $[\mathrm{CI} \mid \mathrm{RCI}]$

Output:

Plowspeed $=$ vehicle plowing speed, meters/s (Note 3.)

Notes:

(1) Origin of measurement is not stated. The assumption is made that depth refers to the position (positive down) of the lower-most extremity of the plow unit (i.e., tine tips if plow has tines, etc.) below a flat level ground surface. Negative or zero depth means no portion of the plow blade enters the ground. (2) No table of values for the codes was given. The specification stated "ITD soil codes." The specification for the ITD encoding scheme (MIL-I-89014) shows 16 items for Soil Type Category (STC) values 0 through 15. The assumption is made here that this is the encoding scheme used.

(3) If any input data are unknown, unassigned, or out of range, the plow speed will be set to zero. Codes are produced internally which are related to various types of problems that can occur. However, no mechanism is stated to retrieve and examine these codes externally.

This system is comprised of three sections of vehicle performance information, which is read in from an external data file. (It would be possible to 'hard code' the data tables but that would limit the usefulness of this system.) The prediction is made by interpolating the appropriate information from these tables performing a few computations to provide the needed result.

The first section contains information about vehicle basic performance, which is the tractive force versus speed relation (including all soil influences) and the sum of all vehicle motion resistances for operation on level surfaces (excluding any plowing resistance.) The actual relation is given as the coefficients of a curve-fit hyperbola to the source data. The source data are derived from the NRMM.

The second section is a matrix of plow performance information comprised of resulting plowing forces as a function of soil type, soil strengths, and plowing depths. These data are derived from a combination of field test results and the plowing submodel in NRMM.

The following section describes the format and content of the external data set (data file) read in by the program.

The input data set has three sections of records. Section 1 is basic description information and the arrays of values of the independent variables for the various input tables. This is in FORTRAN NAMELIST format. Section 2 consists of records of vehicle performance information in FORTRAN free-field readable format. The third section, also in FORTRAN free-field readable format, contains 
records of information used to populate the internal tables of plow performance information.

\section{VEHDATA}

The following are records in FORTRAN NAMELIST format ordered as follows:

\begin{tabular}{|l|l|}
\hline Variable & Description \\
\hline GCW & Vehicle gross combined weight [lb] \\
\hline HPCOEF & $\begin{array}{l}\text { Power-train power reduction coefficient penalty for using plow } \\
(1.0=\text { no reduction, } 0.0=100 \% \text { reduction) }\end{array}$ \\
\hline NPDEPTH & Number of plow data plowing depths given \\
\hline NPSTREN & Number of soil strengths, plow performance data \\
\hline NSTREN & Number of soil strengths, vehicle performance data \\
\hline PDEPTHS(NPDEPTH & Values of plowing depths [in.] \\
\hline PSTREN(NPSTREN) & Soil strength values for plowing data [Cl/RCl] \\
\hline STCOEF & $\begin{array}{l}\text { Surface traction reduction coefficient penalty for operating on } \\
\text { plowed surface (1.0=no reduction, } 0.0=\text { full reduction) }\end{array}$ \\
\hline STREN(NSTREN) & Soil strength values (vehicle data) [Cl/RCl] \\
\hline
\end{tabular}

\section{Section 1. Vehicle Traction \& Resistance Performance information}

The following are records in FORTRAN free-field format ordered as follows:

\begin{tabular}{||l|l|l|l||}
\hline Record Number & Surface & Soil-type & Soil-strength \\
\hline Rec-1 & 0 (normal) & 1 (group1) & STREN(1) \\
\hline Rec-2 & 0 (normal) & 1 (group1) & STREN(2) \\
\hline$\ldots$ & $\ldots \ldots$ & $\ldots \ldots$ & $\ldots$ \\
\hline Rec-NSTREN & 0 (normal) & 1 (group1) & STREN(NSTREN) \\
\hline Rec-NSTREN+1 & 0 (normal) & 2 (group2) & STREN(1) \\
\hline Rec-NSTREN+2 & 0 (normal) & 2 (group2) & STREN(2) \\
\hline$\ldots$ & $\ldots \ldots$ & $\ldots \ldots$ & $\ldots$ \\
\hline Rec-2*NSTREN & 0 (normal) & 2 (group2) & STREN(NSTREN) \\
\hline$\ldots$ & $\ldots \ldots$ & $\ldots \ldots$ & $\ldots$ \\
\hline$\ldots$ & $\ldots \ldots$ & $\ldots \ldots$ & $\ldots$ \\
\hline Rec-6*NSTREN & 0 (normal) & 6 (group6) & STREN(NSTREN) \\
\hline Rec-6*NSTREN+1 & 1 (slippery) & 1 (group1) & STREN(1) \\
\hline$\ldots$ & $\ldots \ldots$ & $\ldots \ldots$ & $\ldots$ \\
\hline$\ldots$ & $\ldots \ldots$ & $\ldots \ldots$ & $\ldots$ \\
\hline Rec-2*6*NSTREN & 1 (slippery) & 6 (group6) & STREN(NSTREN) \\
\hline
\end{tabular}

Each record is comprised of the following information:

\begin{tabular}{|l|l|l|}
\hline Item\# & Fortran Variable & Description \\
\hline 1 & IST & Soil strength values (vehicle data) [Cl/RCl] \\
\hline 2 & CIRCI & Soil strength (checked against values given in STREN) \\
\hline 3 & RESCOEF & Vehicle total motion resistance coefficient \\
\hline 4 & TFOWMN & $\begin{array}{l}\text { Tractive force coefficient value at maximum speed point (i.e., } \\
\text { minimum traction) }\end{array}$ \\
\hline 5 & TFOWMX & $\begin{array}{l}\text { Tractive force coefficient value at minimum speed point (i.e., } \\
\text { maximum traction) }\end{array}$ \\
\hline 6,7, & B(i) & $\begin{array}{l}\text { Coefficients for curve fit hyperbola of the form: } \\
\text { TFcoef }=\frac{B_{1}}{\text { Speed }+B_{3}}+B_{2}\end{array}$ \\
\hline
\end{tabular}




\section{Section 2. Plow performance (resistance) information}

The following are records in Fortran free-field format ordered as follows:

\begin{tabular}{|l|l|l|}
\hline Record Number & Soil-type & Soil-strength \\
\hline Rec-1 & 1 (group1) & PSTREN(1) \\
\hline Rec-2 & 1 (group1) & PSTREN(2) \\
\hline$\ldots$ & $\ldots \ldots$ & $\ldots$ \\
\hline Rec-NSTREN & 1 (group1) & PSTREN(NPSTREN) \\
\hline Rec-NSTREN+1 & 2 (group2) & PSTREN(1) \\
\hline Rec-NSTREN+2 & 2 (group2) & PSTREN(2) \\
\hline$\ldots$ & $\ldots \ldots$ & $\ldots$ \\
\hline Rec-2*NSTREN & 2 (group2) & PSTREN(NPSTREN) \\
\hline$\ldots$ & $\ldots \ldots$ & $\ldots$ \\
\hline$\ldots$ & $\ldots \ldots$ & $\ldots$ \\
\hline Rec-6*NSTREN & 6 (group6) & PSTREN(NPSTREN) \\
\hline
\end{tabular}

\section{Section 3. Variable description}

Each record is comprised of the following information:

\begin{tabular}{|l|l|l|}
\hline Item\# & Fortran Variable Name & Description \\
\hline 1 & IST & Soil group code \\
\hline 2 & CIRCI & Soil strength (checked against values in PSTREN) \\
\hline 3 & PFORCES $(1,)$. & Plowing force [lb] for depth PDEPTHS(1) \\
\hline 4 & PFORCES $(2,)$. & Plowing force $[\mathrm{lb}]$ for depth PDEPTHS(2) \\
\hline. & $\ldots \ldots$ & $\ldots \ldots \ldots \ldots \ldots \ldots$ \\
\hline $2+$ NPDEPTH & PFORCES(NPDEPTH,..) & Plowing force [lb] for depth PDEPTHS(NPDEPTH) \\
\hline
\end{tabular}




\section{References}

Ahlvin, R. B., and Haley, P. W. (1992). "NATO reference mobility model, edition II, NRMM II user's guide,” Technical Report GL-92-19, U.S. Army Engineer Waterways Experiment Station, Vicksburg, MS, and Department of the Army, Tank-Automotive Command, Warren, MI.

Bekker, M. G. (1969). "Introduction to terrain-vehicle systems," The University of Michigan Press, MI.

Caron, B. D. K., and Kachanoski, R. G. (1992). "Modeling temporal changes in structural stability of a clay loam soil," Soil Science 56, 1597-1604.

Clapp, R. B., and Hornberger, G. M. (1978). "Empirical equations for some soil hydraulic properties," Water Resource Research 14, 601-604.

Cornish, C., and Li, X. (1998). "Hydrosim: Hydrologic modeling in the synthetic natural environment." Proceedings of the 1998 spring simulation interoperability workshop, Paper 98S-SIW-146.

Farr, J. V., Rabalais, C. P., Underwood, R. B. III, and Ahlvin, R. B. (1991). "Mobility and plowing capabilities of the combat mobility vehicle," Technical Report GL-91-6, U.S. Army Engineer Waterways Experiment Station, Vicksburg, MS.

Haley, P. W., Jurkat, M. P., and Brady, P. M., Jr. (1979). "NATO reference mobility model, edition I, user's guide, volume i, operational modules," Technical Report 12503, U.S. Army Tank-Automotive Research and Development Command, Warren, MI.

Headquarters, Department of the Army. (1989). "Weather support for Army tactical operations," FM 34-81/AFM 105-4, Washington, DC.

Janett A. C., Adelson, J. S., Miller, D. D., and Reynolds, R. A. (2000). "The FOM for atmosphere, ocean, space, and dynamic terrain - Environment federation," 2000 Fall Simulation Interoperability Workshop, Paper 00F-SIW092.

Kennedy, J. G., Rush, E. S., Turnage, G. W., and Morris, P. A. (1988). "Updated soil moisture-strength prediction (SMSP) methodology," Technical Report 
GL-88-13, U.S. Army Engineer Waterways Experiment Station, Vicksburg, MS.

Lins, W. F. (1972). "Human vibration response measurement," Technical Report 1151, U.S. Army Tank-Automotive Command, Warren, MI.

Mason, G. L. (2000). "Short-term operational forecasts of trafficability (SOFT)," 2000 Spring Simulation Interoperability Workshop, Paper 00S-SIW-066.

McWilliams, G. B. (1999). "Providing physically consistent environmental data in support of simulation based acquisition." Proceedings of the 1999 Spring Simulation Interoperability Workshop. Paper 99S-SIW-120.

Meyer, M. P., Ehrlich, I. R., Sloss, D., Murphy, N. R., Jr., Wismer, R. D., and Czako, T. (1977). "International society for terrain-vehicle systems standards," Journal of Terramechanics 14 (3), 153-182.

Morris, P. A. (1994). "Development of climatological data for prediction of soil strength," Technical Report GL-94-27, U.S. Army Engineer Waterways Experiment Station, Vicksburg, MS.

Murphy, N. R. (1981). "Armored combat vehicle technology (ACTV) program," Technical Report GL-81-13, U. S. Army Engineer Waterways Experiment Station, Vicksburg, MS.

Nuttall, C. J., Jr., and Randolph, D. D. (1976). "Mobility analysis of standardand high-mobility tactical support vehicles (HIMO study)," Technical Report M-76-3, U.S. Army Engineer Waterways Experiment Station, Vicksburg, MS.

Penman H. L. (1948). "Natural evaporation from open water, bare soil and grass." Proceedings of the Royal Society, A. Vol 193, 121-125.

Pradko, F., Lee, R., and Kaluza, V. (1966). "Theory of human vibration response," Winter Annual Meeting and Energy Systems Exposition, The American Society of Mechanical Engineers, New York.

Rada, G. R., Schwarz, C. W., and Witczak, W. M. (1989). "Prediction of damage to secondary roads," Journal of Transportation Engineering 115 (4).

Schwab, G. O., Frevert, R. K., Edminster, T. W., and Barnes, K. K. (1971). Soil and water conversation engineering. Wiley, New York.

Sellers, P. J., Sud, Y. A., and Dalcher A. (1986). “A simple biosphere model (SIB) for use within general circulation models," Journal Atmospheric Sciences 43, 505-531.

Singh, P. V. (1988). Hydrologic systems rainfall-runoff modeling. Vol 1, Prentice-Hall, Englewood Cliffs, NJ.

Spangler, M. G., and Handy R. L. (1984). Soil Engineering. 4th ed., Harper Collins Publishers, New York. 


\begin{tabular}{|c|c|c|c|c|c|c|c|c|}
\hline \multicolumn{9}{|c|}{$\begin{array}{l}\text { Table } 1 \\
\text { Static Soil Coefficients (after Rada, Schwarz, and Witczak 1989) }\end{array}$} \\
\hline $\begin{array}{l}\text { USCS } \\
\text { Soil } \\
\text { Type } \\
\end{array}$ & $\psi_{\mathrm{s}}$ & $k_{s}$ & $\beta$ & $\begin{array}{l}\text { Residual } \\
\text { Moisture }\end{array}$ & $\begin{array}{l}\text { Saturated } \\
\text { Moisture } \\
\mathrm{S} \\
\end{array}$ & $\begin{array}{l}\text { Density } \\
\left(\mathrm{lb} / \mathrm{ft}^{3}\right) \\
\gamma_{\mathrm{d}} \\
\end{array}$ & $\begin{array}{l}\text { Soil } \\
\text { Strength } \\
\text { a }\end{array}$ & $\begin{array}{l}\text { Soil } \\
\text { Strength } \\
\text { b }\end{array}$ \\
\hline sw & 16.6 & .07620 & 1.852 & 1.60 & 34.70 & 93.6 & 3.987 & 0.8150 \\
\hline $\mathrm{SP}$ & 16.6 & .07620 & 1.852 & 1.60 & 24.70 & 93.6 & 3.987 & 0.8150 \\
\hline SM & 14.1 & .00861 & 2.375 & 2.60 & 40.80 & 93.7 & 12.542 & -2.9550 \\
\hline SC & 18.4 & .00384 & 2.667 & 5.60 & 41.90 & 97.4 & 12.542 & -2.9550 \\
\hline SM-SC & 17.2 & .00484 & 2.597 & 4.80 & 41.80 & 100.5 & 12.542 & -2.9550 \\
\hline $\mathrm{CL}$ & 33.5 & .00060 & 4.505 & 3.60 & 46.90 & 86.8 & 15.506 & -3.5300 \\
\hline $\mathrm{ML}$ & 33.9 & .00079 & 4.202 & 2.60 & 53.70 & 73.7 & 11.936 & -2.4070 \\
\hline CL-ML & 32.9 & .00008 & 4.292 & 2.60 & 46.80 & 83.7 & 14.236 & -3.1370 \\
\hline $\mathrm{CH}$ & 32.9 & .00038 & 5.208 & 7.10 & 47.50 & 85.5 & 13.686 & -2.7050 \\
\hline $\mathrm{MH}$ & 39.0 & .00004 & 4.878 & 3.80 & 54.70 & 66.2 & 23.641 & -5.1910 \\
\hline $\mathrm{OL}$ & 28.6 & .00122 & 3.876 & 3.00 & 62.70 & 77.4 & 17.399 & -3.5840 \\
\hline $\mathrm{OH}$ & 29.3 & .00088 & 4.237 & 4.10 & 89.20 & 52.5 & 12.189 & -1.9420 \\
\hline GM & 12.7 & .09980 & 3.247 & 4.10 & 43.80 & & & \\
\hline GC & 23.2 & .00174 & 4.065 & 3.40 & 45.20 & & & \\
\hline
\end{tabular}

\begin{tabular}{|c|c|c|c|}
\hline \multicolumn{4}{|c|}{$\begin{array}{l}\text { Table } 2 \\
\text { Runoff Coefficients (after Singh 1983) }\end{array}$} \\
\hline Vegetation & $\begin{array}{l}\text { Open Sandy Loam } \\
\text { Soil Class }(0-6)\end{array}$ & $\begin{array}{l}\text { Clay and Loam } \\
\text { Soil Class(7-9) }\end{array}$ & $\begin{array}{l}\text { Tight Clay } \\
\text { Soil Class (10-15) }\end{array}$ \\
\hline \multicolumn{4}{|c|}{ Woodland (Class 2) ${ }^{++}$} \\
\hline$(0-1)^{+}$ & 0.10 & 0.30 & 0.40 \\
\hline Rolling & 0.25 & 0.35 & 0.50 \\
\hline Hilly & 0.30 & 0.50 & 0.60 \\
\hline \multicolumn{4}{|l|}{ Cultivated (Class 1) } \\
\hline$(0-1)$ & 0.30 & 0.50 & 0.60 \\
\hline Rolling & 0.40 & 0.60 & 0.70 \\
\hline Hilly & 0.52 & 0.72 & 0.82 \\
\hline \multicolumn{4}{|l|}{ Pasture (Class 0) } \\
\hline$(0-1)$ & 0.10 & 0.30 & 0.40 \\
\hline Rolling & 0.16 & 0.36 & 0.55 \\
\hline Hilly $\quad$ (3) & 0.22 & 0.42 & 0.60 \\
\hline
\end{tabular}




\begin{tabular}{|c|c|c|c|c|c|c|c|c|c|c|c|c|c|c|}
\hline \multicolumn{15}{|c|}{$\begin{array}{l}\text { Table } 3 \\
\text { Initial Conditions }\end{array}$} \\
\hline & \multicolumn{14}{|c|}{ Depth in Inches } \\
\hline & 0 & 1 & 2 & 3 & 4 & 5 & 6 & 7 & 8 & 9 & 10 & 11 & 12 & 18 \\
\hline & \multicolumn{14}{|c|}{ Measured Cone Index Values } \\
\hline High Cl & 600 & 750 & 700 & 600 & 600 & 600 & 525 & 625 & 650 & 625 & 625 & 530 & 550 & 600 \\
\hline Low Cl & 300 & 600 & 610 & 550 & 525 & 475 & 475 & 450 & 475 & 500 & 500 & 500 & 525 & 500 \\
\hline $1 \mathrm{std} \mathrm{Cl}$ & 528 & 762.8 & 678 & 610 & 586 & 566 & 525 & 590 & 611 & 592 & 588 & 532 & 546 & 573.4 \\
\hline $1 \mathrm{std} \mathrm{Cl}$ & 352 & 643.2 & 616 & 570 & 536 & 482 & 485 & 462 & 477 & 490 & 484 & 508 & 524 & 496.6 \\
\hline \multirow[t]{2}{*}{$\begin{array}{l}\text { Average } \\
\mathrm{Cl}\end{array}$} & 440 & 703 & 647 & 590 & 561 & 524 & 505 & 526 & 544 & 541 & 536 & 520 & 535 & 535 \\
\hline & \multicolumn{14}{|c|}{ Predicted Cone Index Values } \\
\hline $\begin{array}{l}\text { Initial } \\
\text { Pred Cl }\end{array}$ & 437 & 695 & 665 & 587 & 507 & 495 & 502 & 556 & 507 & 507 & 507 & 507 & 507 & 507 \\
\hline
\end{tabular}

\begin{tabular}{|c|c|c|c|c|}
\hline \multicolumn{5}{|c|}{$\begin{array}{l}\text { Table } 4 \\
\text { Model Input Parameters for Site } 1\end{array}$} \\
\hline Soil Type ML & Nominal Value & Mean Value & High & Low \\
\hline Saturated Permeability & 2.27E-04 & 9.00E-05 & 5.00E-04 & 9.00E-05 \\
\hline Bubbling Pressure & $2797 \%$ & 33.9 & 35 & 15 \\
\hline Saturation Moisture Content & $45 \%$ & $45 \%$ & $50 \%$ & $40 \%$ \\
\hline Residual Moisture Content & $3 \%$ & $3 \%$ & $5 \%$ & $2 \%$ \\
\hline $\begin{array}{l}\text { BETA Relationship factor for } \\
\text { Pressure versus Permeability }\end{array}$ & 4.735 & 4.205 & 6 & 4 \\
\hline $\begin{array}{l}\text { ALPHA Relationship Factor for Cl } \\
\text { versus w }\end{array}$ & 13.267 & 13.300 & 13.400 & 13.100 \\
\hline $\begin{array}{l}\text { GAMMA Relation Factor for } \mathrm{Cl} \\
\text { versus w }\end{array}$ & -2.407 & -2.402 & -2.400 & -2.420 \\
\hline Dry Density of Soil & 75.0 & 75 & 80 & 70 \\
\hline Density w & 69.4 & 69.4 & & \\
\hline Time (sec) & 60.00 & 60.00 & & \\
\hline Slope & 0.00 & 0.00 & & \\
\hline Specific Grav & 2.71 & 2.71 & & \\
\hline
\end{tabular}

\begin{tabular}{|c|c|c|c|c|}
\hline \multicolumn{5}{|c|}{$\begin{array}{l}\text { Table } 5 \\
\text { Model Input Parameters for Site } 2\end{array}$} \\
\hline Soil Type CL & Nominal Value & Mean Value & High & Low \\
\hline S Saturated Permeability & 3.7E-06 & 1.00E-06 & 1.00E-05 & 1.00E-07 \\
\hline Bubbling Pressure & 14.0 & 15 & 20 & 7 \\
\hline Saturation Moisture Content & $40.0 \%$ & $40.0 \%$ & $45.0 \%$ & $35.0 \%$ \\
\hline Residual Moisture Content & $2.5 \%$ & $2.0 \%$ & $4.0 \%$ & $1.5 \%$ \\
\hline $\begin{array}{l}\text { BETA Coefficient for Pressure } \\
\text { versus Permeability }\end{array}$ & 4.50 & 4.51 & 4.80 & 4.20 \\
\hline $\begin{array}{l}\text { ALPHA Factor for } \mathrm{Cl} \text { versus } \\
\text { moisture content }\end{array}$ & 15.502 & 15.506 & 16.000 & 15.000 \\
\hline $\begin{array}{l}\text { GAMMA Relation Factor for } \mathrm{Cl} \\
\text { versus Moisture Content }\end{array}$ & -3.633 & -3.600 & -3.300 & -4.000 \\
\hline Dry Density of Soil & 81.7 & 85.0 & 90.0 & 70.0 \\
\hline
\end{tabular}




\begin{tabular}{|c|c|c|c|c|c|c|c|c|c|c|c|c|c|c|c|}
\hline \multicolumn{16}{|c|}{$\begin{array}{l}\text { Table } 6 \\
\text { Initial Conditions for Site 1, Poor House Property }\end{array}$} \\
\hline Depth & 0.00 & 1.00 & 2.00 & 3.00 & 4.00 & 5.00 & 6.00 & 7.00 & 8.00 & 9.00 & 10.00 & 11.00 & 12.00 & 18.00 & $\begin{array}{l}\text { Relative } \\
\text { Depth to } \\
\text { Surface } \\
\end{array}$ \\
\hline $\begin{array}{l}\text { Delta } \\
\text { Depth }\end{array}$ & 2.54 & 2.54 & 2.54 & 2.54 & 2.54 & 2.54 & 2.54 & 2.54 & 2.54 & 2.54 & 2.54 & 2.54 & 2.54 & 10.00 & $\begin{array}{l}\text { Depth of } \\
\text { Layer in } \\
\mathrm{cm}\end{array}$ \\
\hline $\begin{array}{l}\text { Field } \\
\text { Min }\end{array}$ & 0.09 & 0.09 & 0.09 & 0.09 & 0.09 & 0.09 & 0.09 & 0.09 & 0.09 & 0.09 & 0.09 & 0.09 & 0.09 & 0.36 & $\begin{array}{l}\text { Volume of } \\
\text { Water in } \\
\mathrm{cm}\end{array}$ \\
\hline $\begin{array}{l}\text { Field } \\
\text { Max }\end{array}$ & 1.24 & 1.24 & 1.24 & 1.24 & 1.24 & 1.24 & 1.24 & 1.24 & 1.24 & 1.24 & 1.24 & 1.24 & 1.24 & 4.86 & $\begin{array}{l}\text { Volume of } \\
\text { Water in } \\
\mathrm{cm}\end{array}$ \\
\hline Density & 75.00 & 75.08 & 75.15 & 75.23 & 75.30 & 75.38 & 75.45 & 75.53 & 75.60 & 75.68 & 75.75 & 75.83 & 75.90 & 75.98 & $\begin{array}{l}\text { Initial } \\
\text { Densities }\end{array}$ \\
\hline Init $\mathrm{RCl}$ & 426 & 677 & 649 & 572 & 495 & 482 & 490 & 542 & 495 & 495 & 495 & 495 & 495 & 495 & \begin{tabular}{|l|} 
Initial \\
Cone \\
Index \\
profile \\
\end{tabular} \\
\hline
\end{tabular}

\begin{tabular}{|c|c|c|c|c|c|c|c|c|c|c|c|c|c|c|}
\hline $\begin{array}{l}\text { Cone } \\
\text { Index }\end{array}$ & 0 & 1 & 2 & 3 & 4 & 5 & 6 & 7 & 8 & 9 & 10 & 11 & 12 & 18 \\
\hline High Cl & 150 & 480 & 620 & 600 & 500 & 510 & "550 & 2550 & "650 & 600 & "650 & 650 & "650 & 750 \\
\hline Low & 70 & 170 & 220 & 320 & 450 & 430 & 450 & 450 & 500 & 500 & 475 & 550 & 550 & 750 \\
\hline 1std & 138 & 410.6 & 523 & 560 & 487 & 513 & 556 & 537 & 626 & 600 & 631 & 647 & 647 & 750 \\
\hline 1std & 82 & 181.4 & 225 & 368 & 445 & 455 & 484 & 463 & 526 & 524 & 499 & 577 & 573 & 750 \\
\hline Avg & 110 & 296 & 374 & 464 & 466 & 484 & 520 & 500 & 576 & 562 & 565 & 612 & 610 & 750 \\
\hline Predicted & 61 & 141 & 301 & 571 & 495 & 482 & 490 & 542 & 495 & 495 & 495 & 495 & 495 & 495 \\
\hline
\end{tabular}

\begin{tabular}{|c|c|c|c|c|c|c|c|c|c|c|c|c|c|c|}
\hline \multicolumn{15}{|c|}{$\begin{array}{l}\text { Table } 8 \\
\text { Data at } 24 \text { Hours }\end{array}$} \\
\hline $\begin{array}{l}\text { Cone } \\
\text { Index }\end{array}$ & 0 & 1 & 2 & 3 & 4 & 5 & 6 & 7 & 8 & 9 & 10 & 11 & 12 & 18 \\
\hline High & 0 & 70 & 260 & 350 & 270 & 250 & 220 & 250 & 260 & 260 & 290 & 300 & 350 & 530 \\
\hline Low & 0 & 10 & 80 & 10 & 120 & 140 & 130 & 130 & 140 & 160 & 130 & 170 & 160 & 250 \\
\hline 1std & 0 & 53 & 249 & 290 & 232 & 221 & 211 & 227 & 245 & 243 & 265 & 267 & 295 & 495.6 \\
\hline 1std & 0 & 13 & 128 & 103 & 132 & 151 & 153 & 163 & 159 & 175 & 175 & 189 & 201 & 324.4 \\
\hline Avg & 0 & 33 & 188 & 196 & 182 & 186 & 182 & 195 & 202 & 209 & 220 & 228 & 248 & 410 \\
\hline Predicted & 61 & 65 & 69 & 72 & 76 & 129 & 186 & 510 & 495 & 495 & 495 & 495 & 495 & 495 \\
\hline
\end{tabular}




\begin{tabular}{|c|c|c|c|c|c|c|c|c|c|c|c|c|c|c|c|}
\hline \multicolumn{16}{|c|}{$\begin{array}{l}\text { Table } 9 \\
\text { Initial Conditions for Site 2, Fort Leonard Wood }\end{array}$} \\
\hline Depth & 0.00 & 1.00 & 2.00 & 3.00 & 4.00 & 5.00 & 6.00 & 7.00 & 8.00 & 9.00 & 10.00 & 11.00 & 12.00 & 18.00 & $\begin{array}{l}\text { Relative } \\
\text { Depth to } \\
\text { Surface } \\
\end{array}$ \\
\hline \begin{tabular}{|l|} 
Delta \\
Depth \\
\end{tabular} & 2.54 & 2.54 & 2.54 & 2.54 & 2.54 & 2.54 & 2.54 & 2.54 & 2.54 & 2.54 & 2.54 & 2.54 & 2.54 & 10.00 & \begin{tabular}{|l|}
$\begin{array}{l}\text { Depth of } \\
\text { Layer in } \mathrm{cm}\end{array}$ \\
\end{tabular} \\
\hline Field Min & 0.09 & 0.09 & 0.08 & 0.08 & 0.08 & 0.08 & 0.08 & 0.08 & 0.08 & 0.08 & 0.08 & 0.08 & 0.08 & 0.33 & \begin{tabular}{|l|} 
Volume of \\
Water in $\mathrm{cm}$ \\
\end{tabular} \\
\hline Field Max & 1.33 & 1.33 & 1.33 & 1.33 & 1.33 & 1.33 & 1.33 & 1.33 & 1.33 & 1.33 & 1.33 & 1.33 & 1.33 & 5.24 & \begin{tabular}{|l|} 
Volume of \\
Water in $\mathrm{cm}$
\end{tabular} \\
\hline Density & 92 & 89 & 82 & 82 & 82 & 82 & 82 & 82 & 82 & 82 & 82 & 82 & 82 & 82 & \begin{tabular}{|l|} 
Initial \\
Densities \\
\end{tabular} \\
\hline Init $\mathrm{RCl}^{1}$ & 3000 & 750 & 750 & 150 & 150 & 130 & 130 & 140 & 100 & 100 & 90 & 100 & 250 & 250 & $\begin{array}{l}\text { Initial Cone } \\
\text { Index profile }\end{array}$ \\
\hline $\begin{array}{l}\text { Init Moist } \\
\%\end{array}$ & 7.9 & 11.5 & 11.5 & 17.9 & 17.9 & 18.7 & 18.7 & 18.3 & 20.1 & 20.1 & 20.7 & 20.1 & 15.6 & 15.6 & \begin{tabular}{|l|} 
Initial \\
Moisture \\
Content \\
\end{tabular} \\
\hline
\end{tabular}




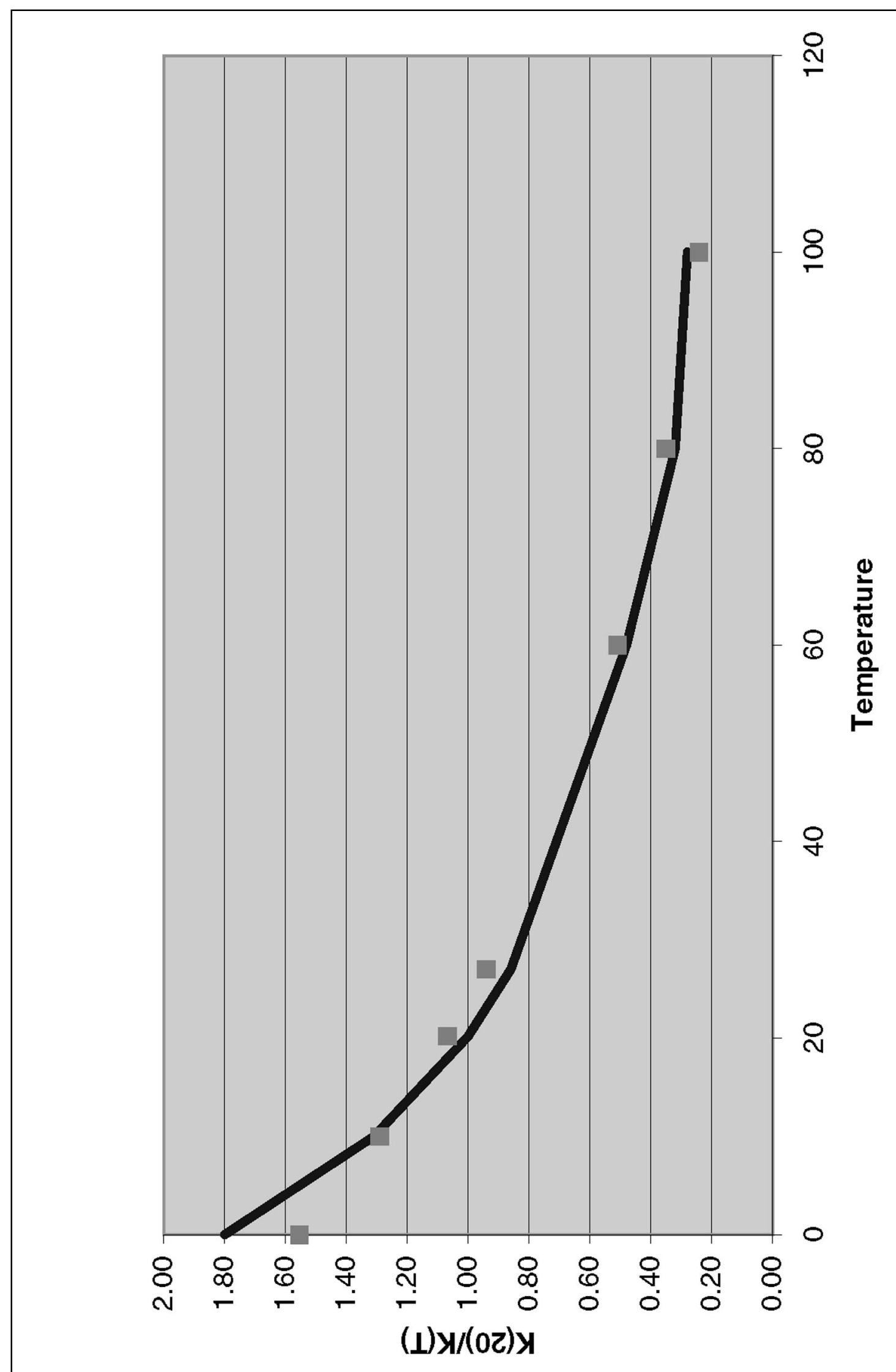

PLATE 1 


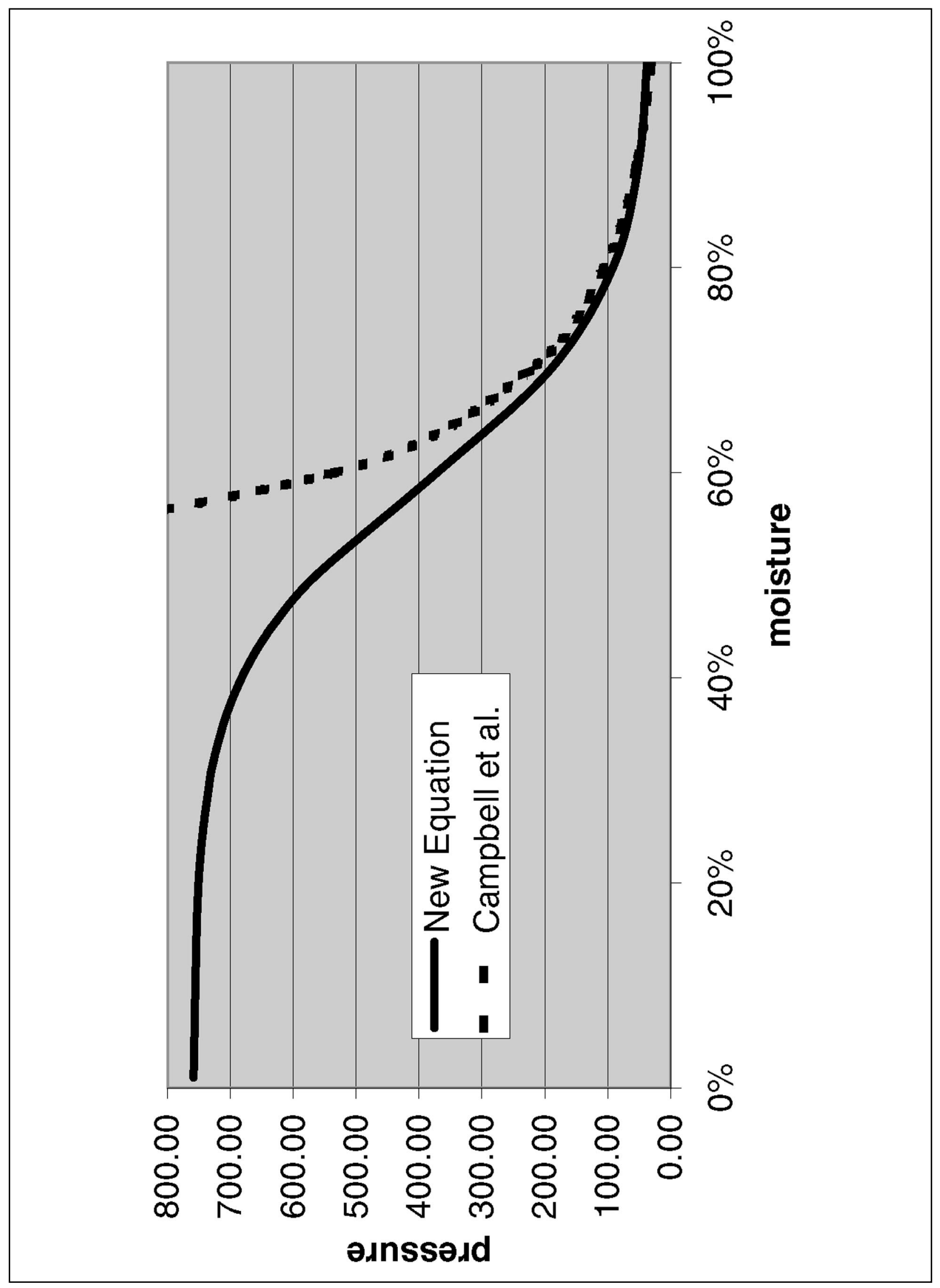

PLATE 2 


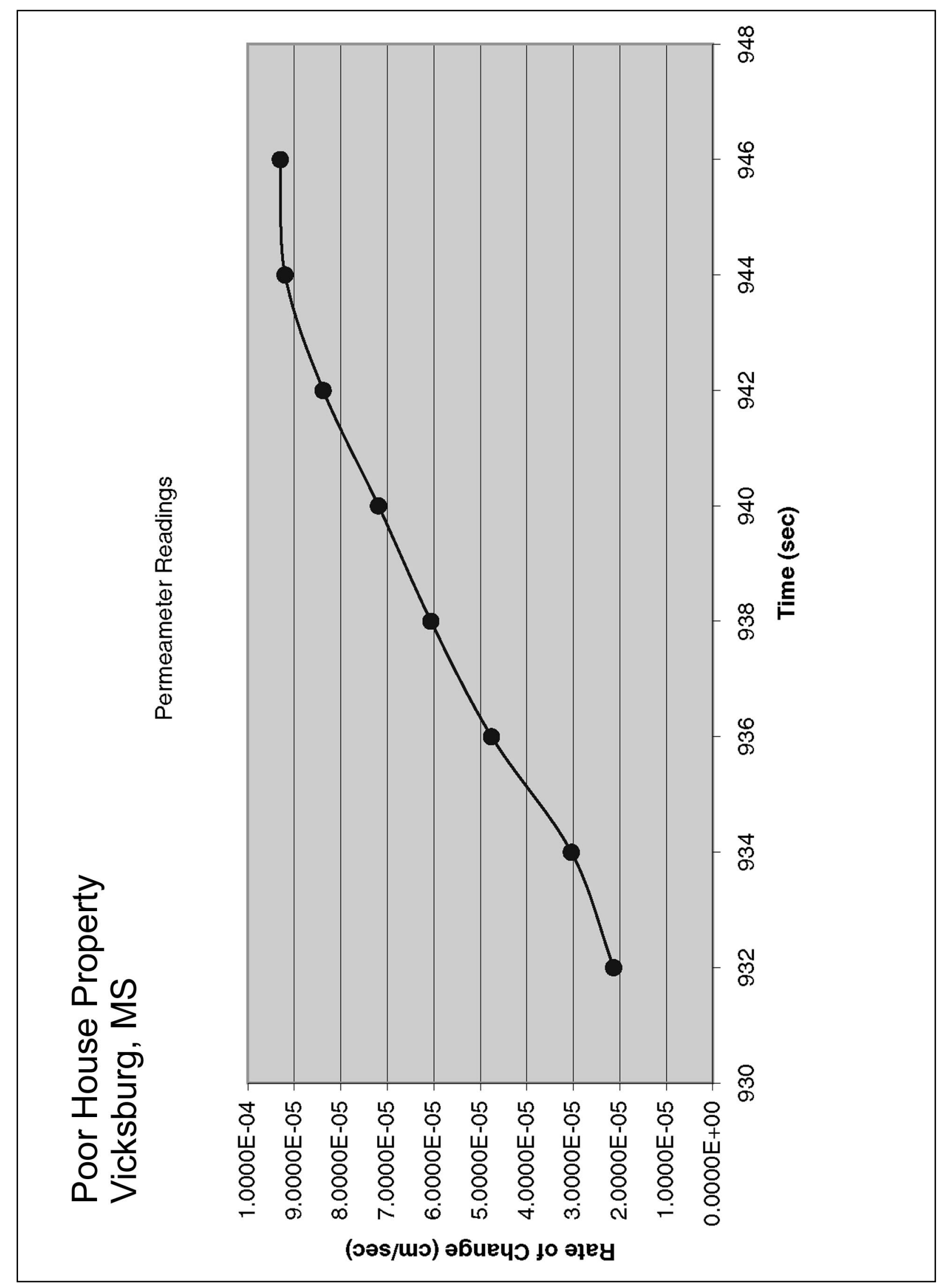

PLATE 3 


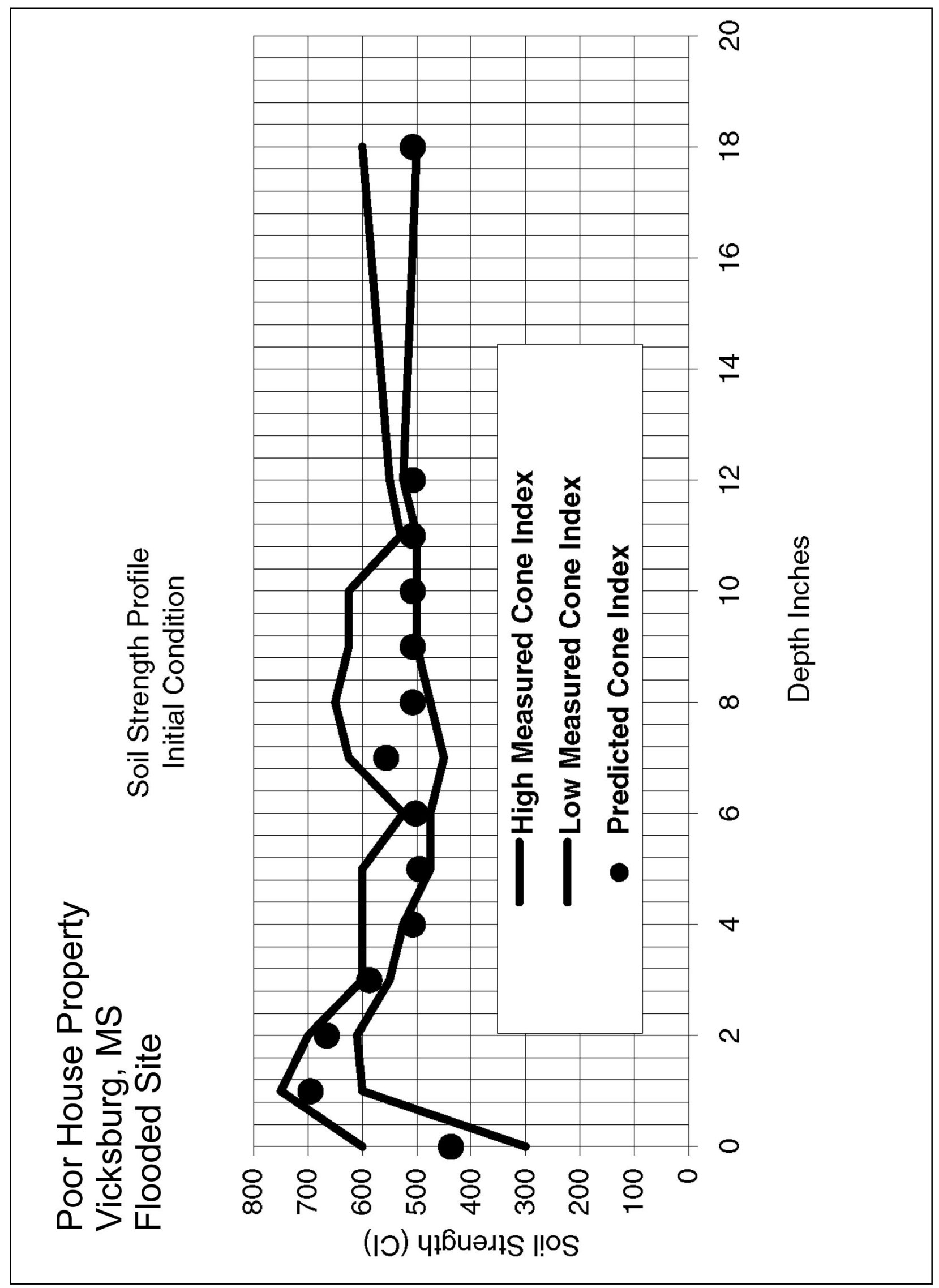

PLATE 4 


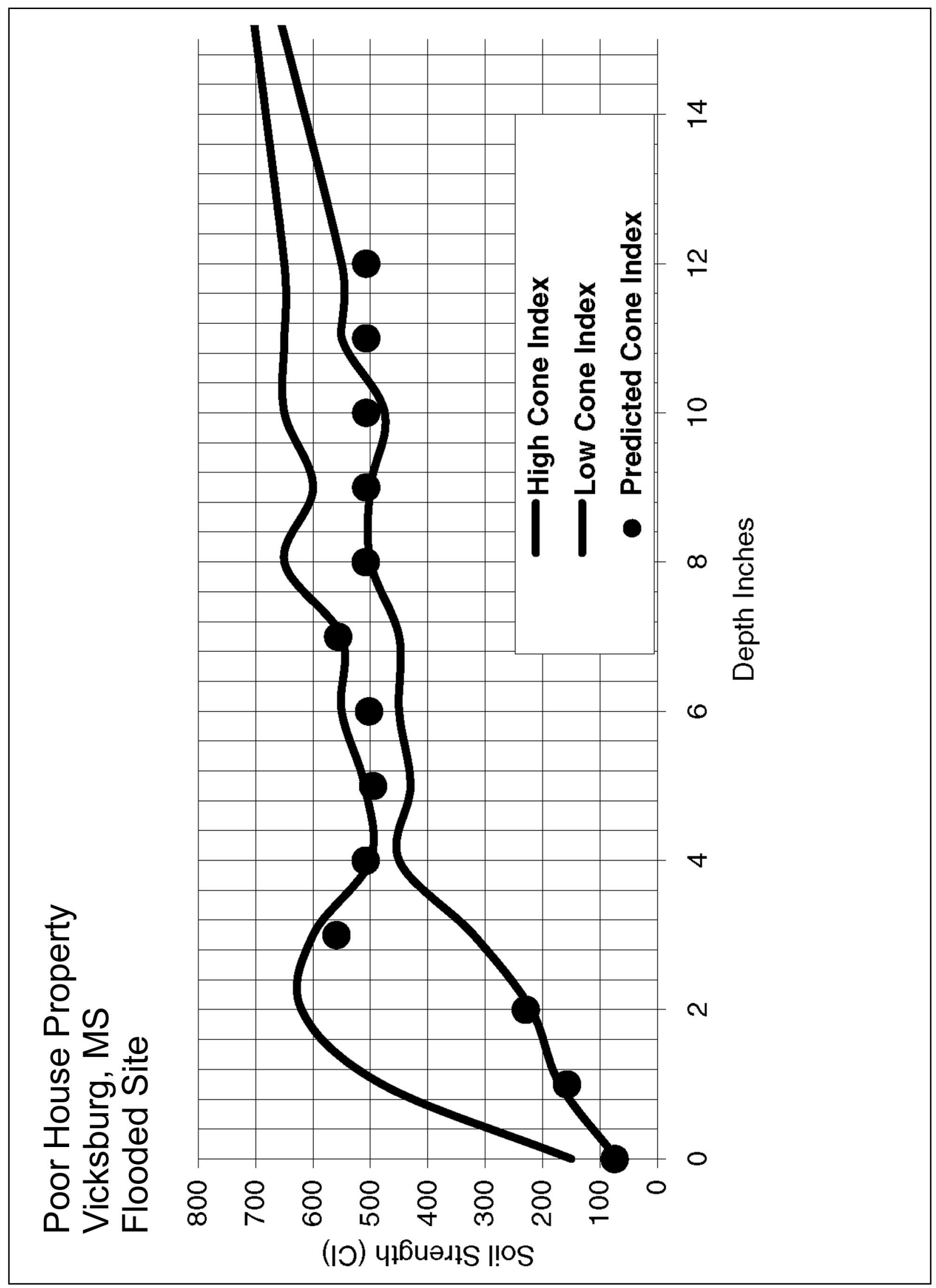




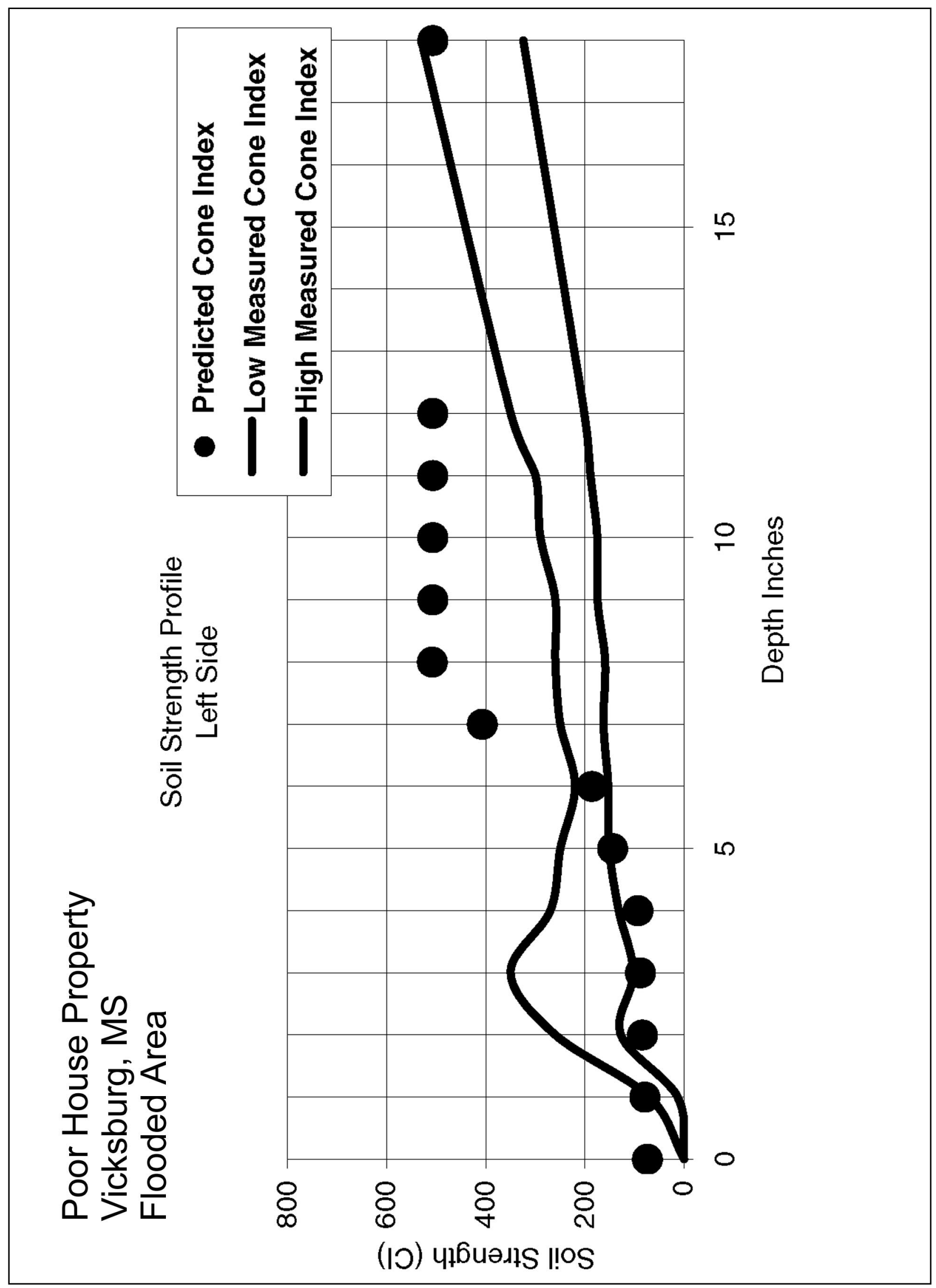

PLATE 6 


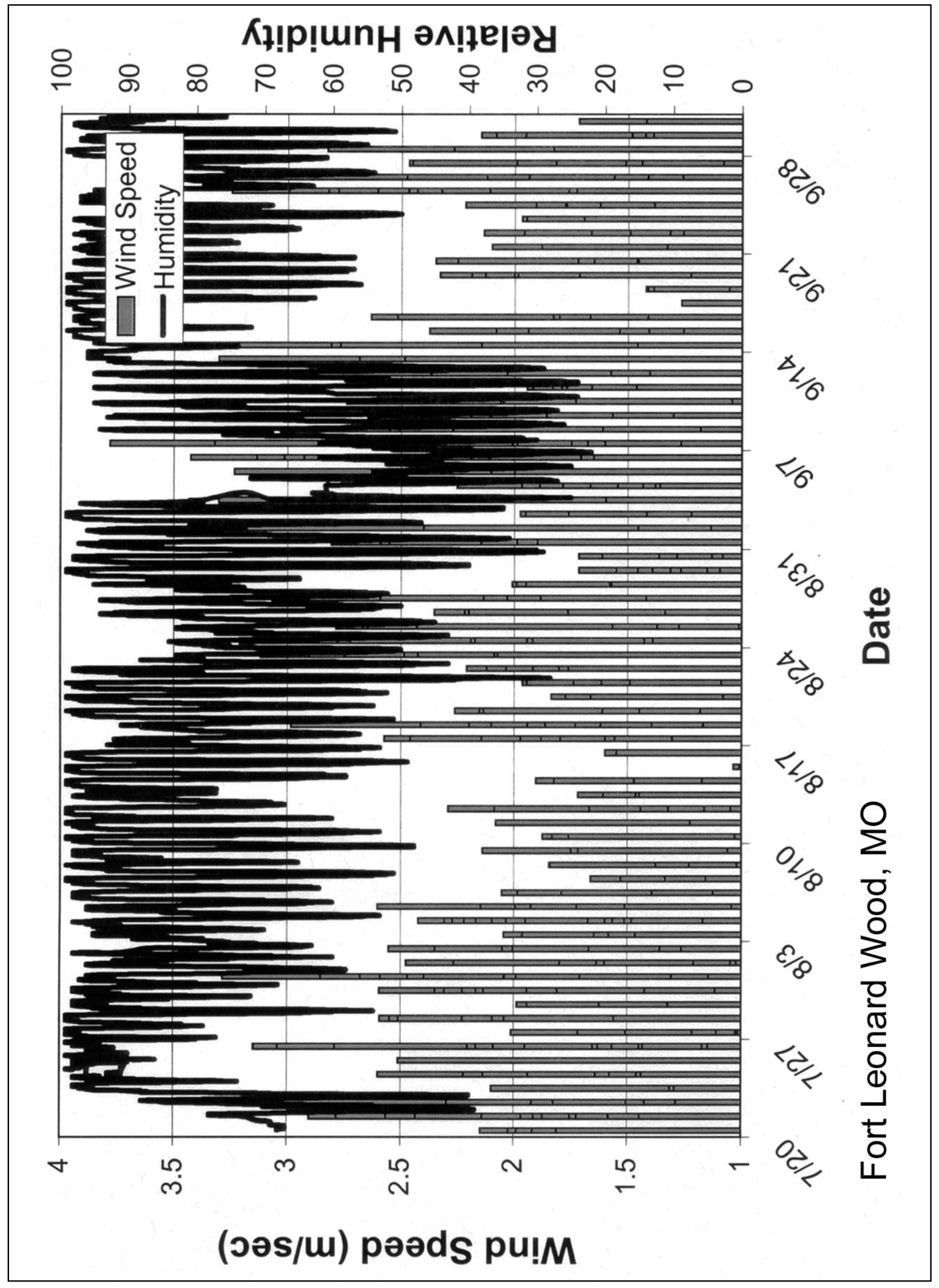

PLATE 7 


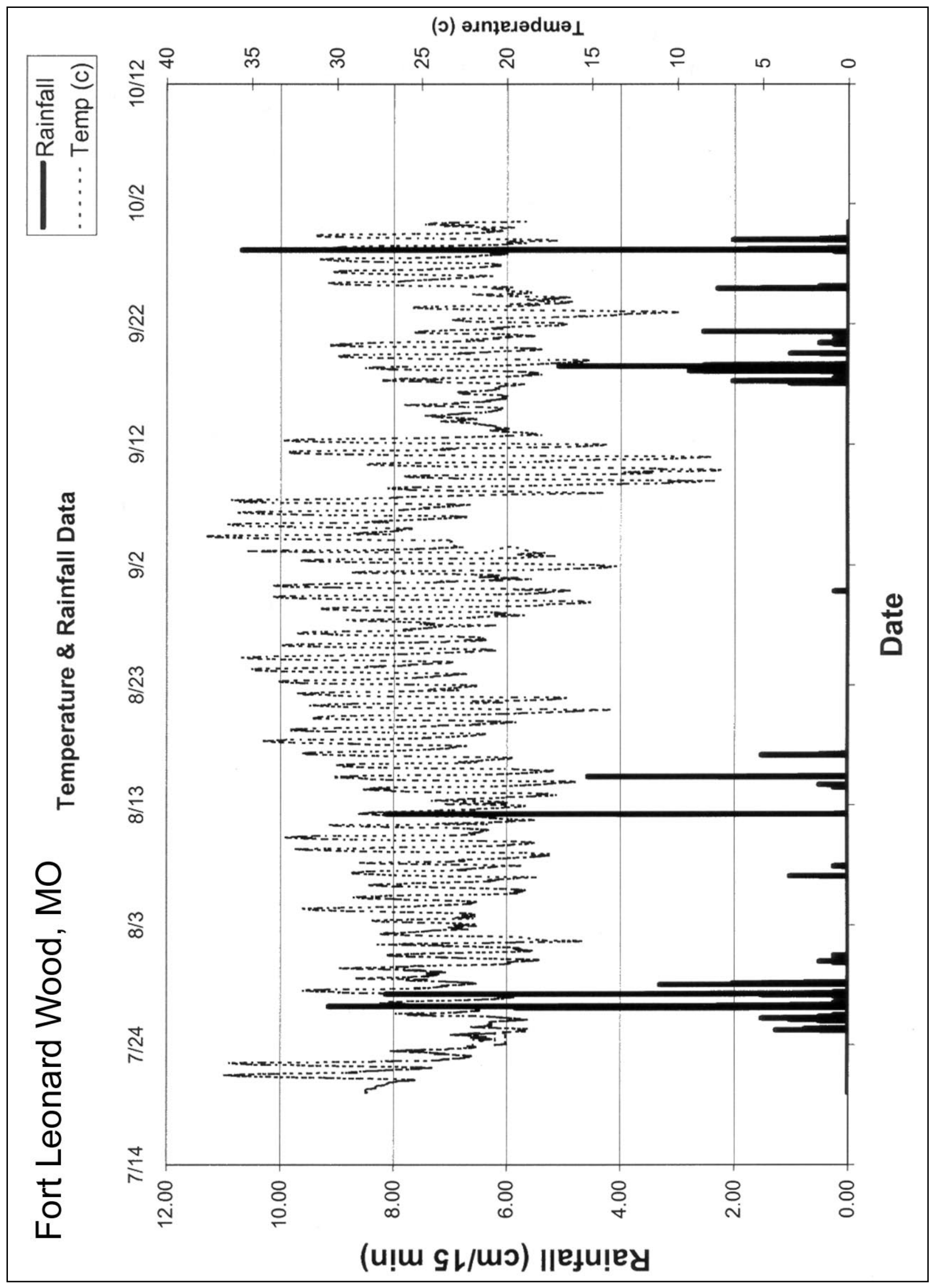

PLATE 8 


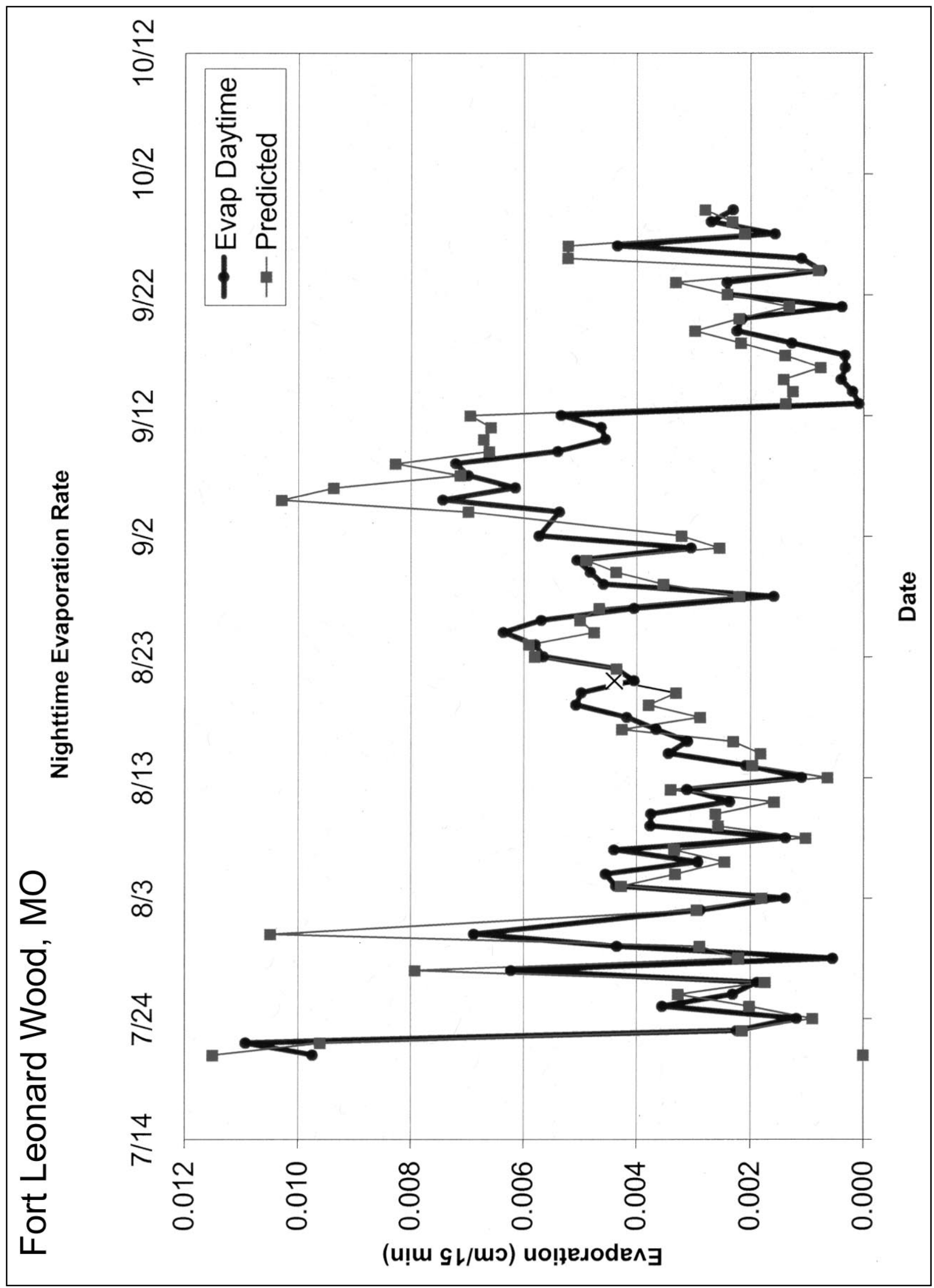

PLATE 9 


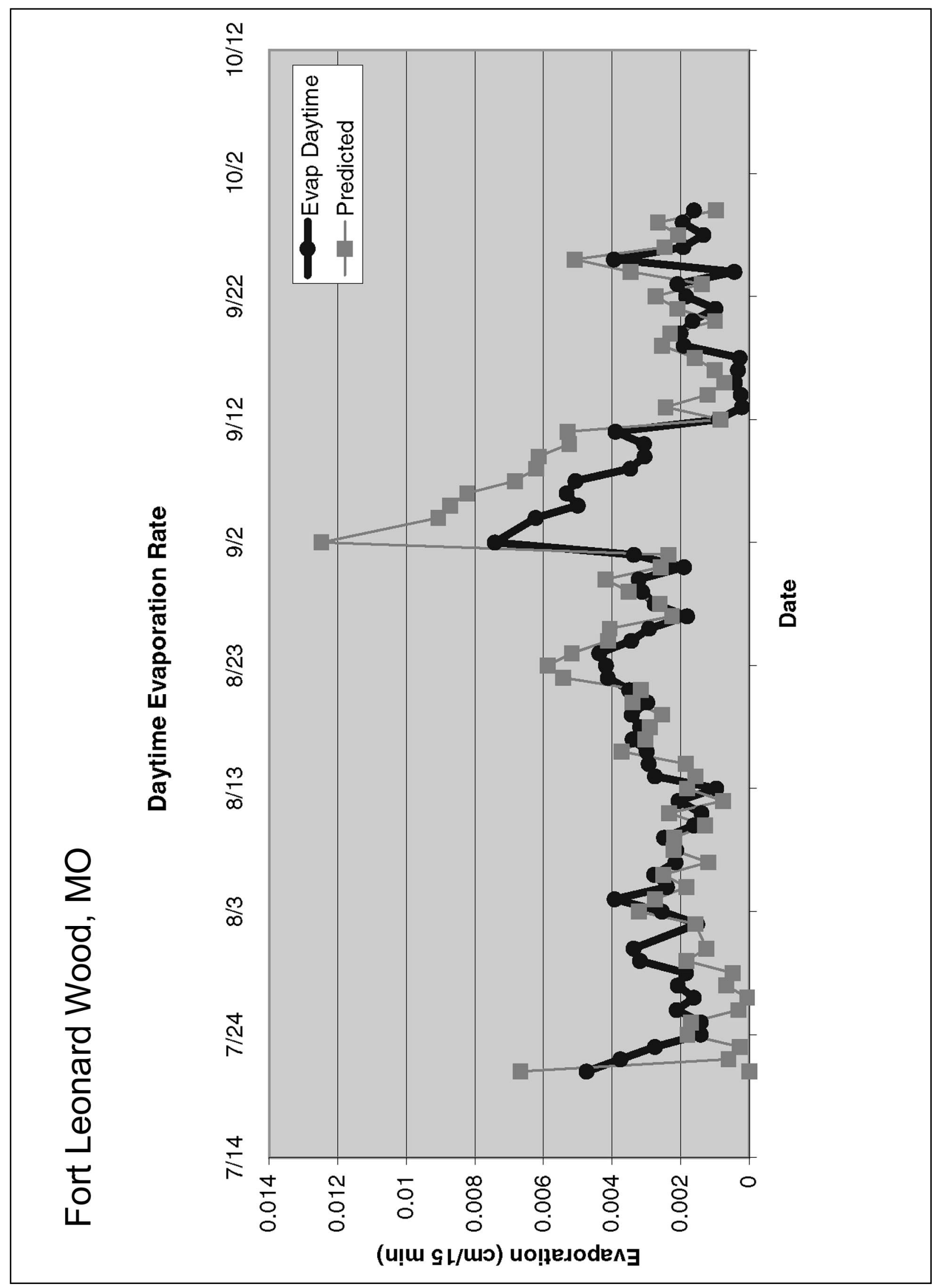

PLATE 10 


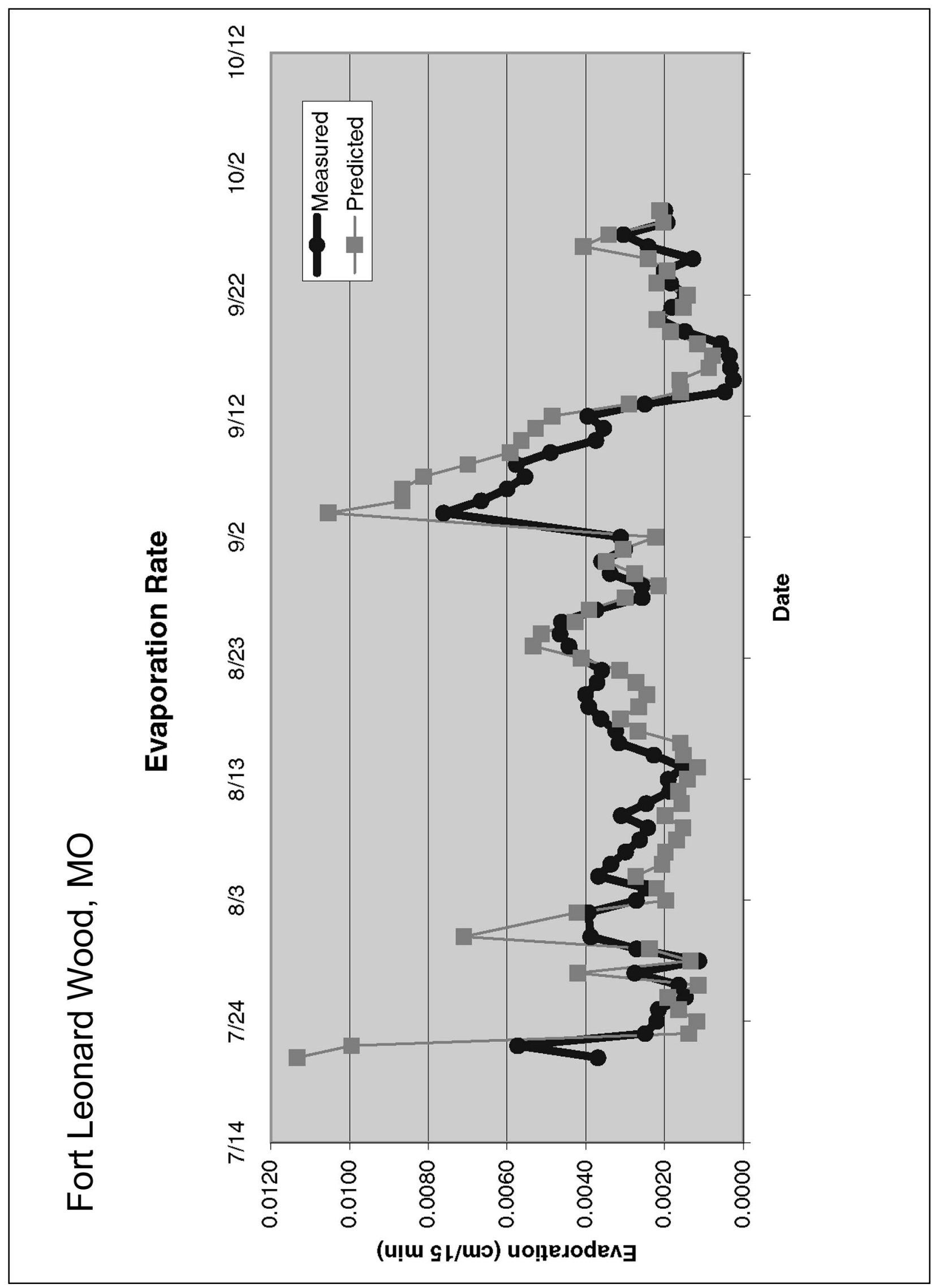




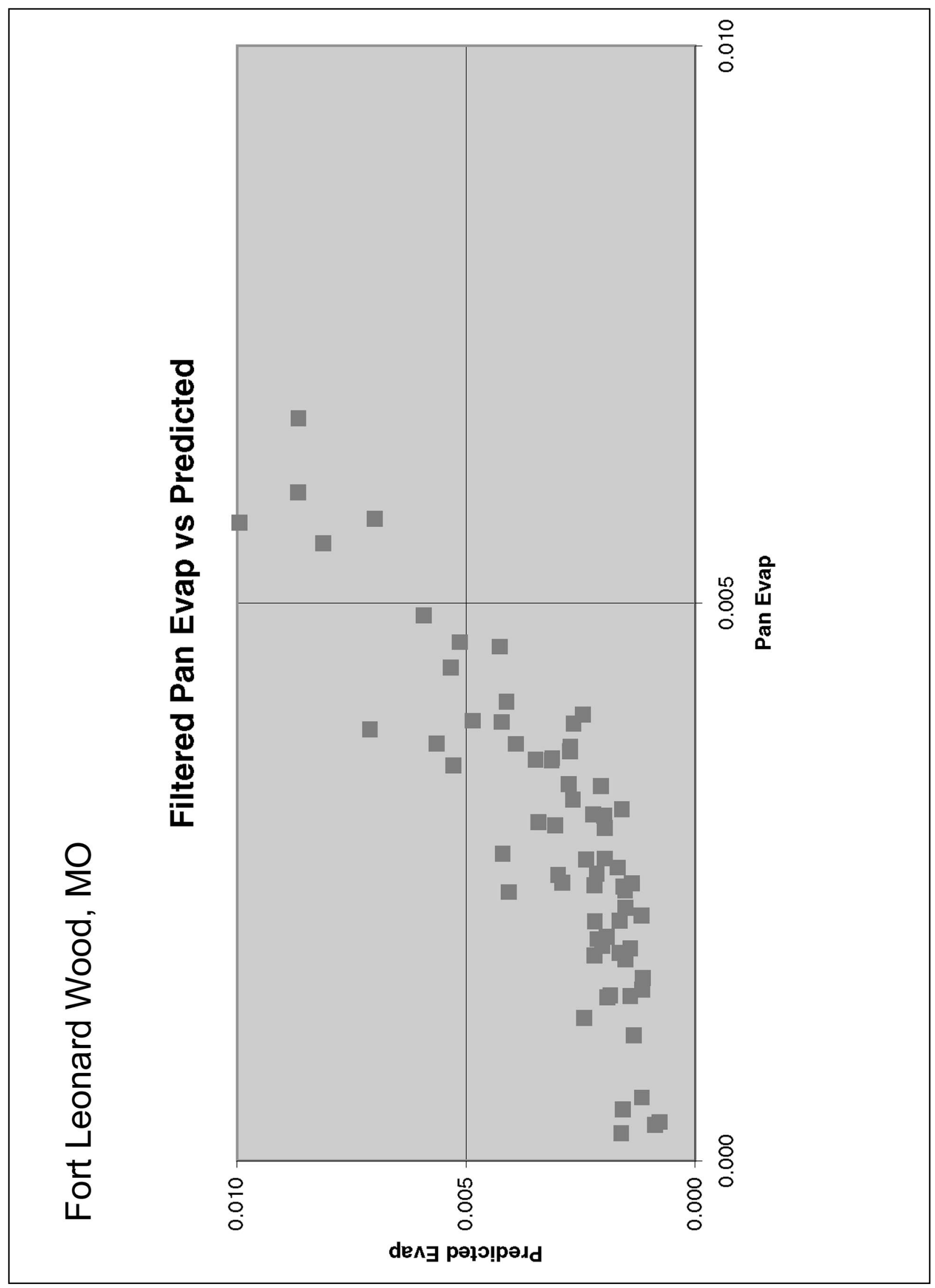

PLATE 12 


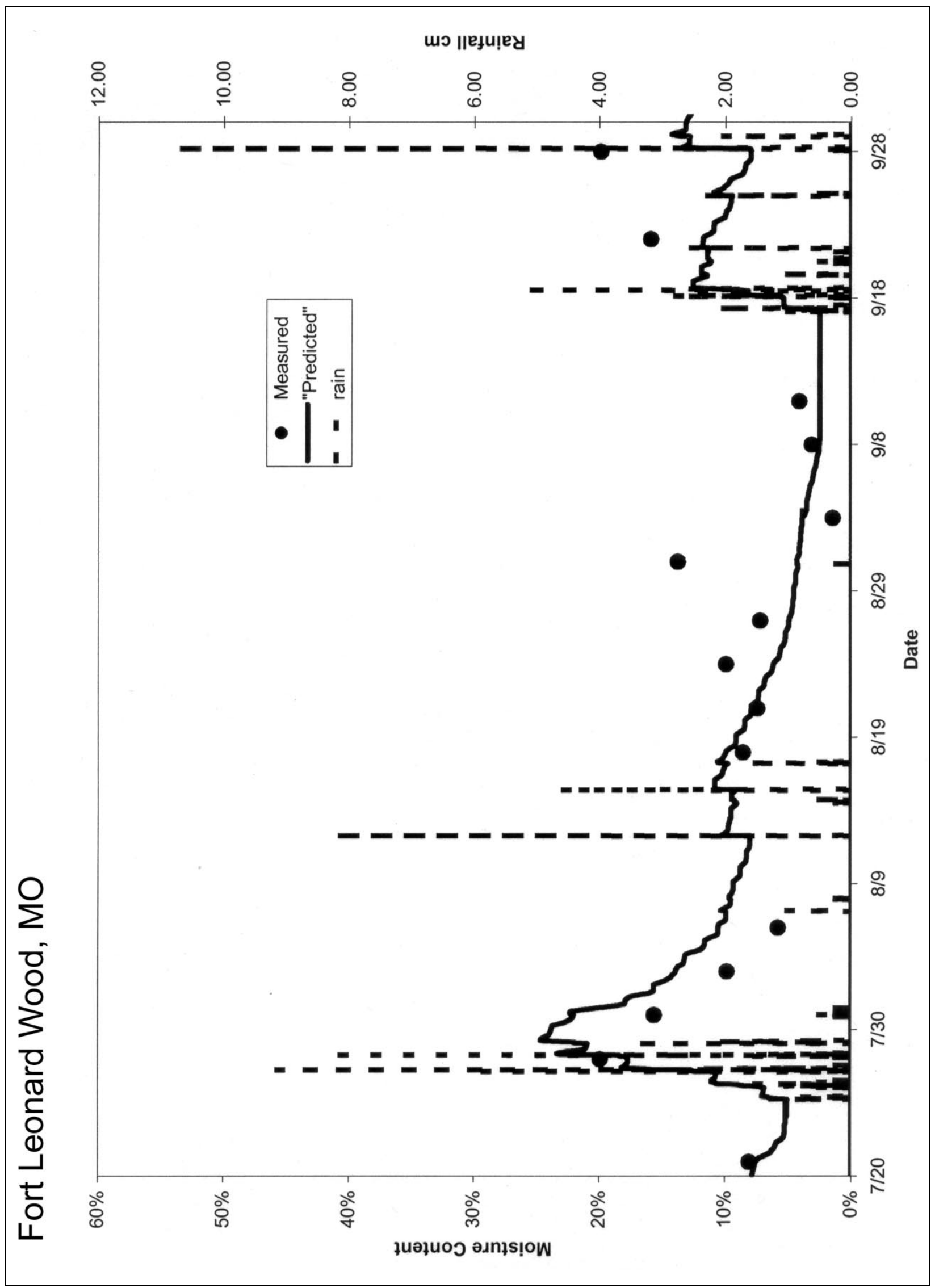

PLATE 13 


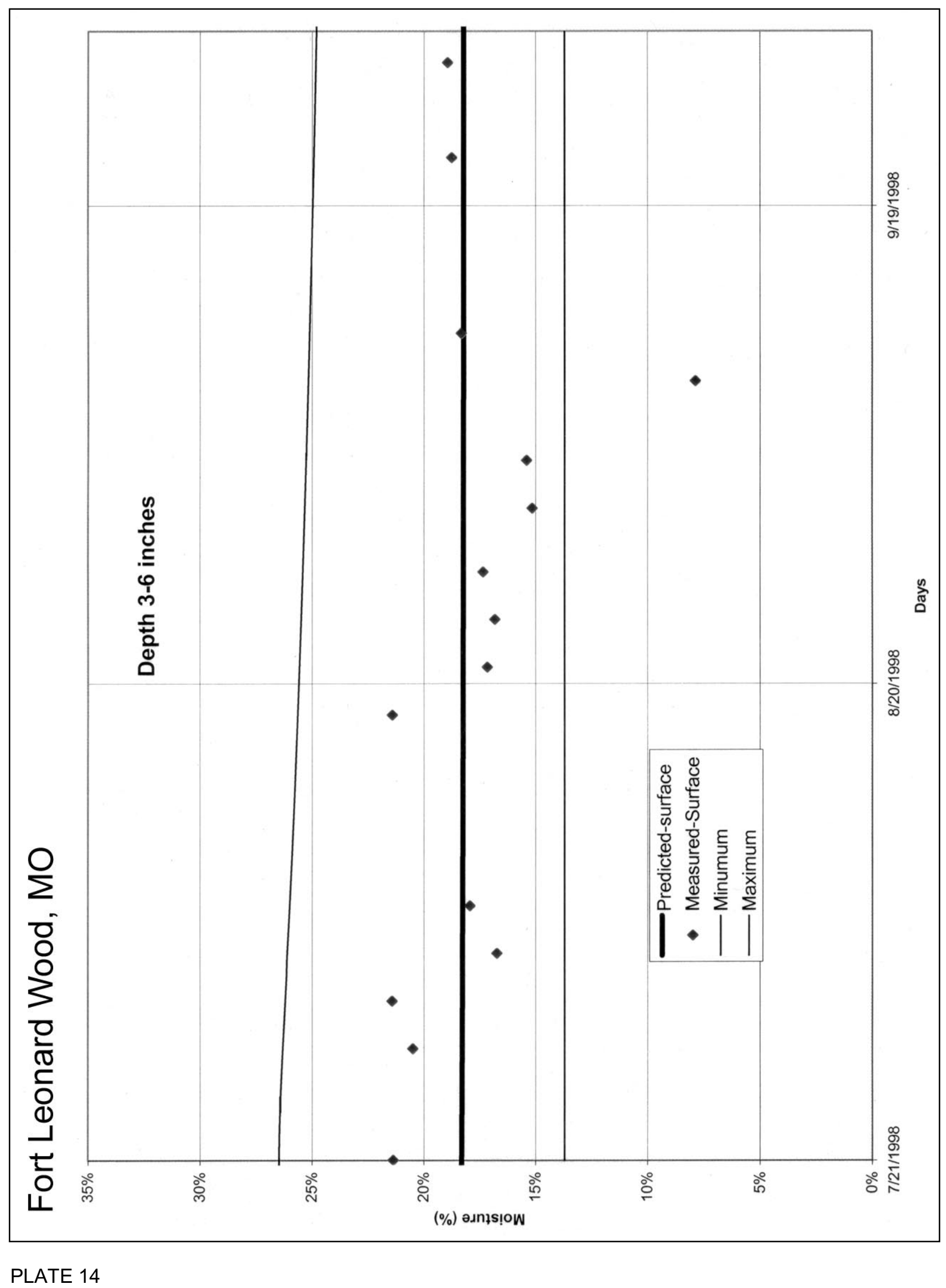




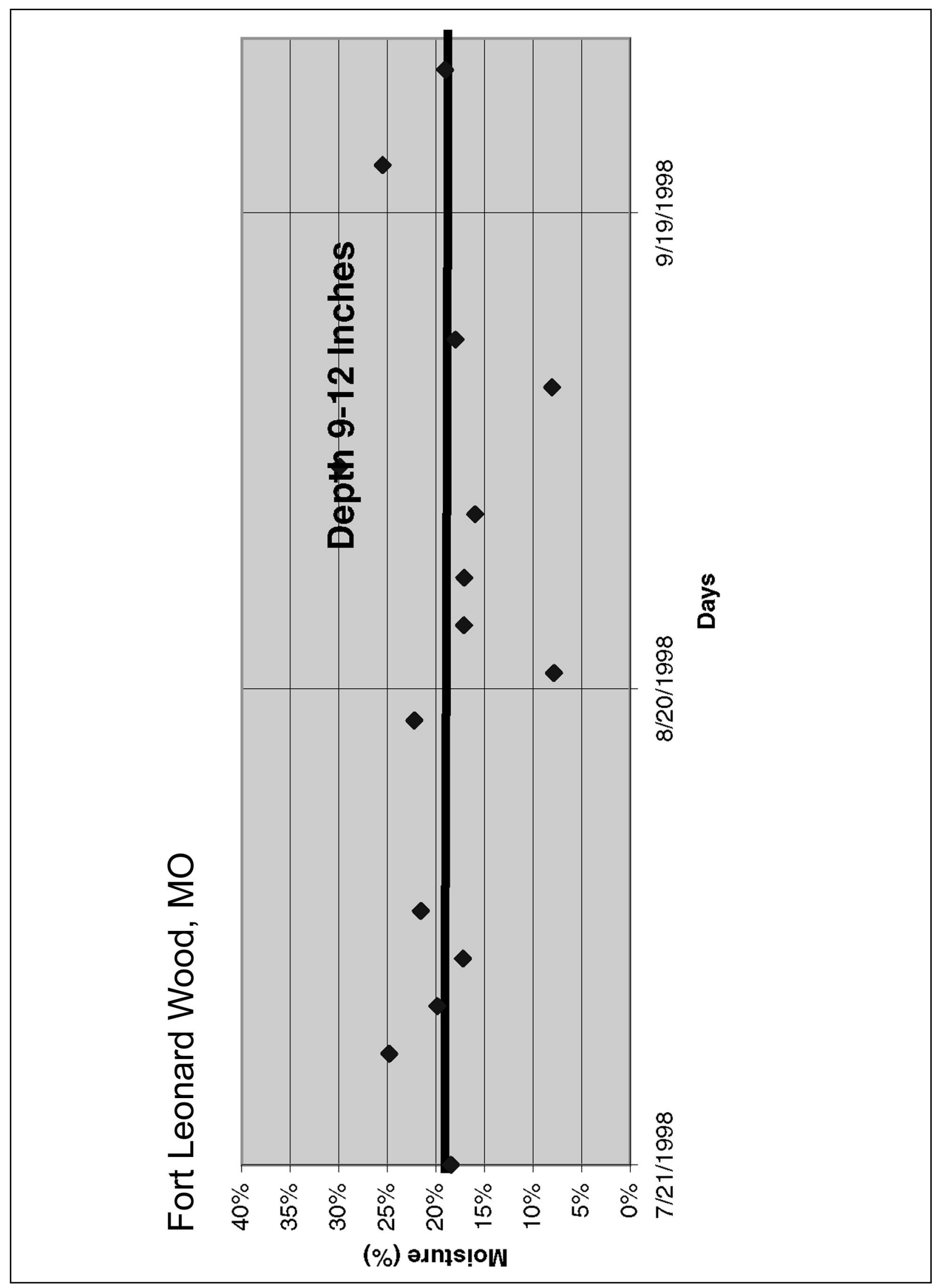

PLATE 15 


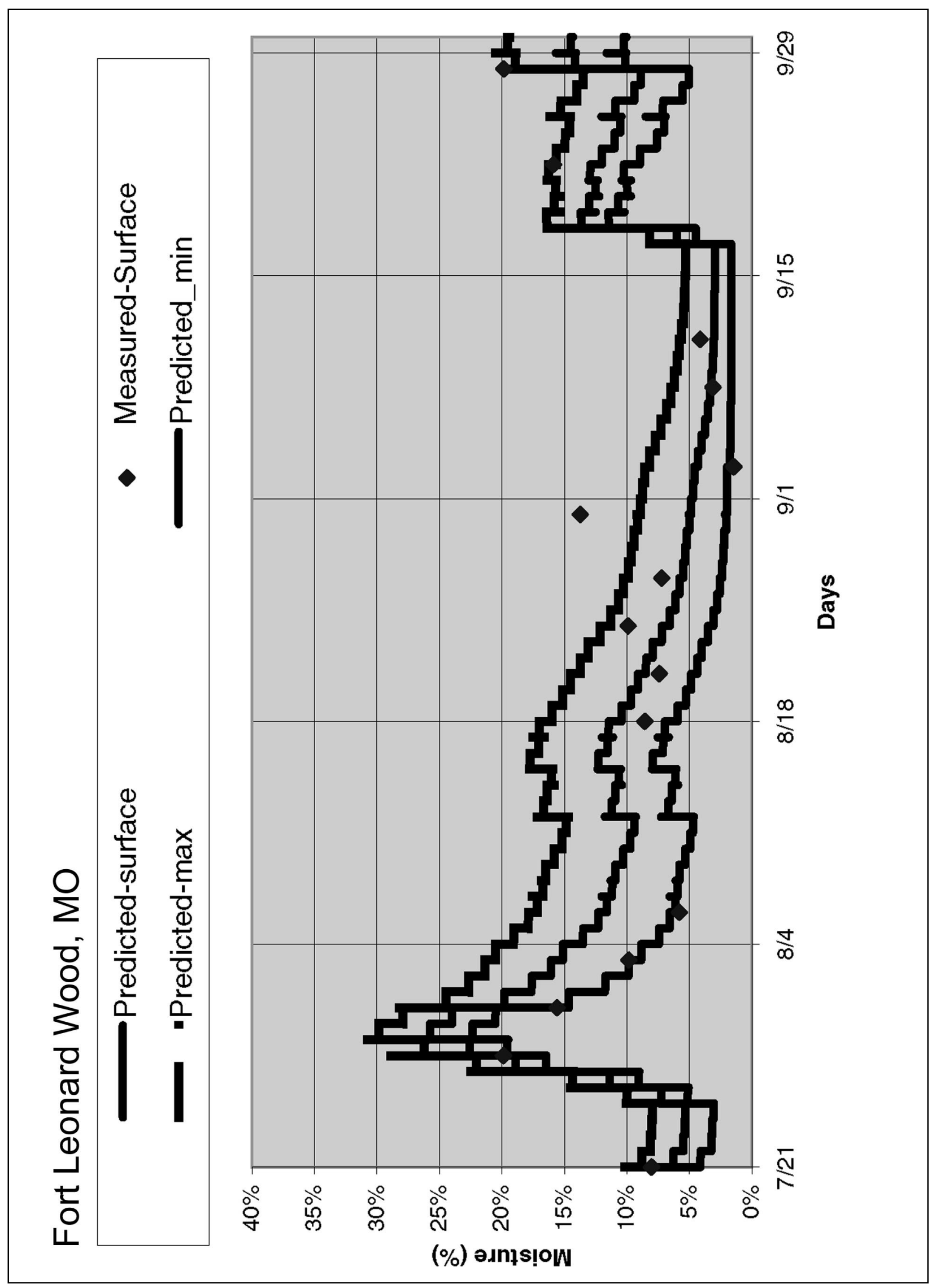

PLATE 16 


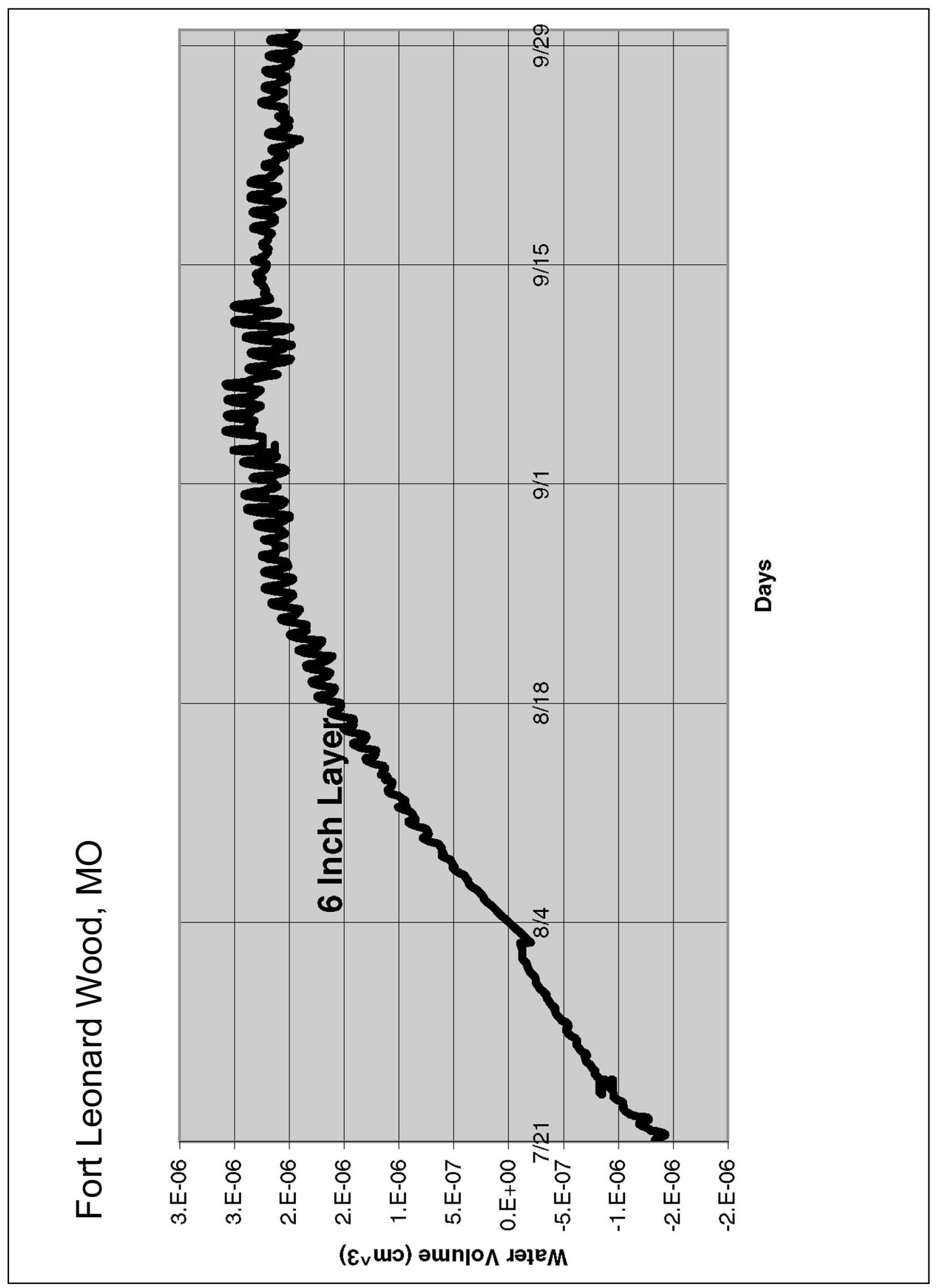

PLATE 17 


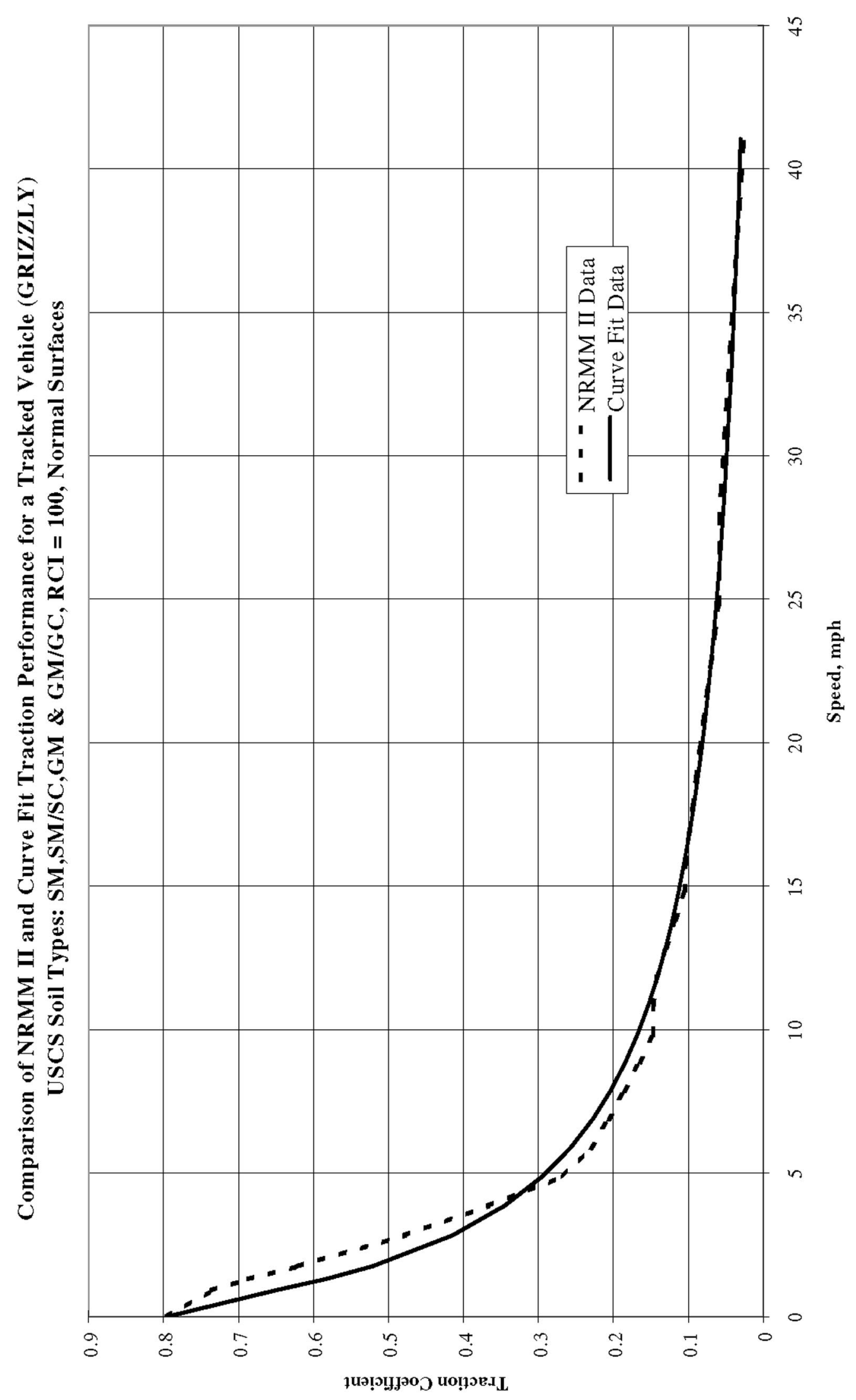

PLATE 18 


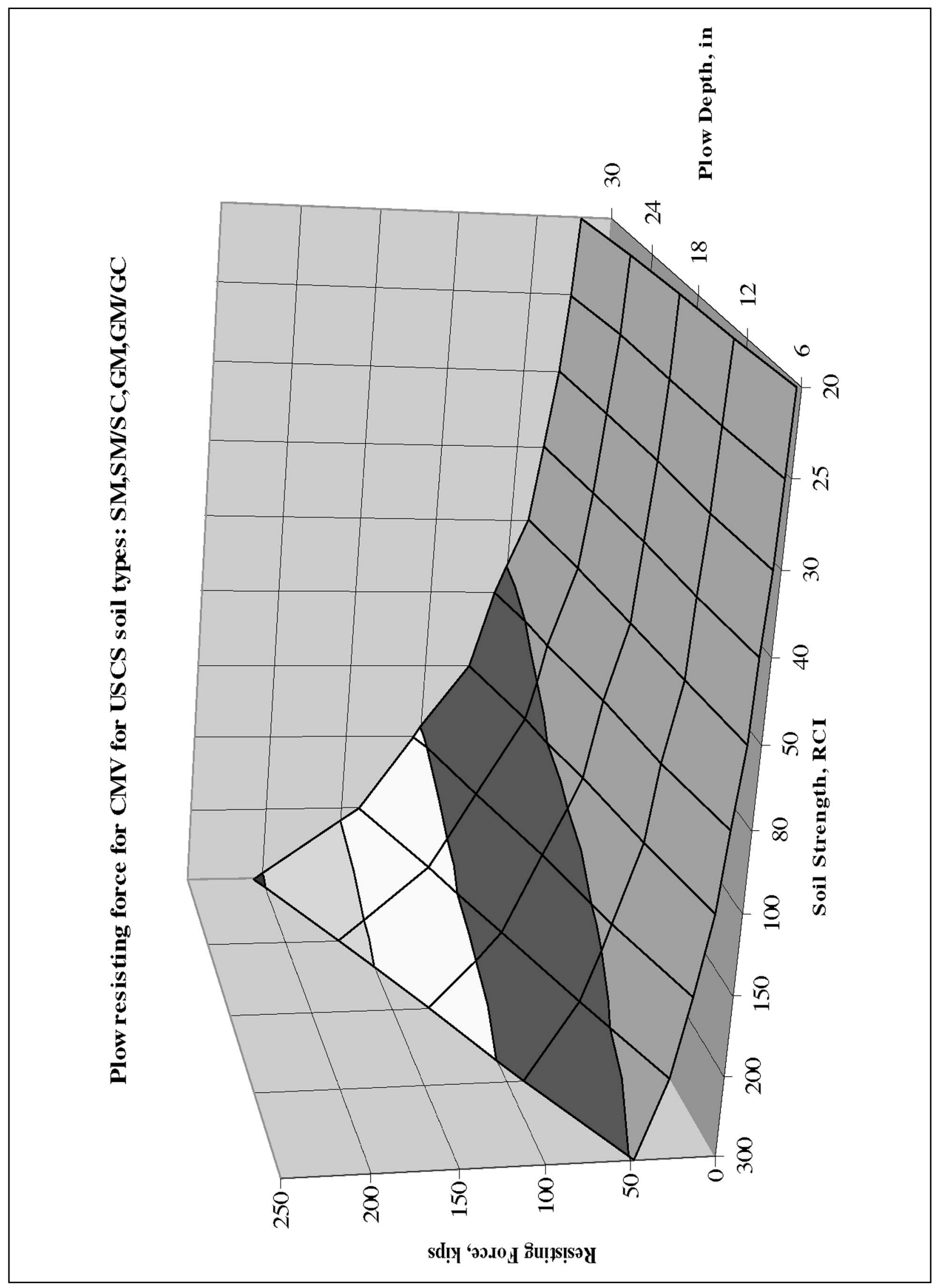

PLATE 19 


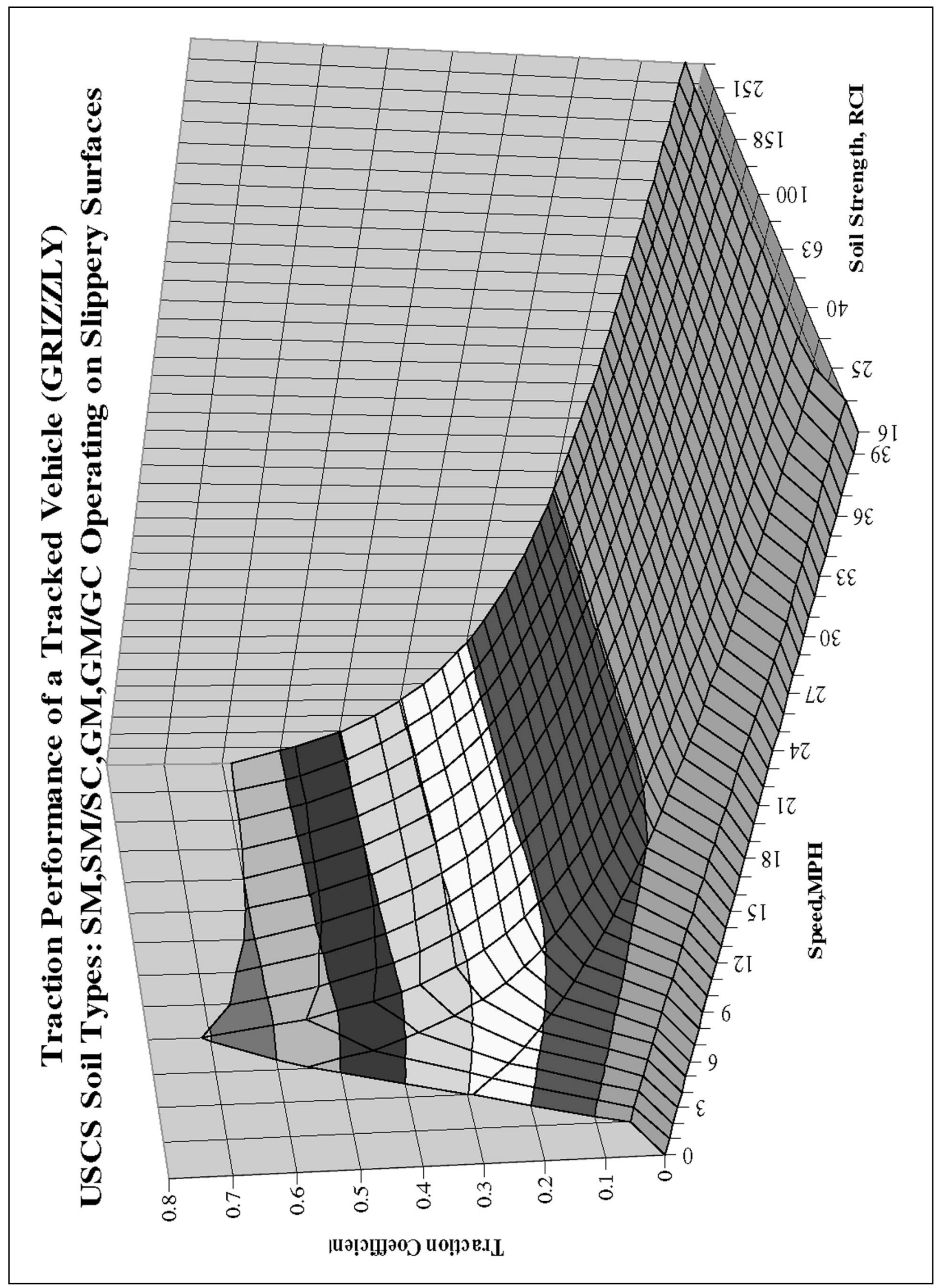

PLATE 20 


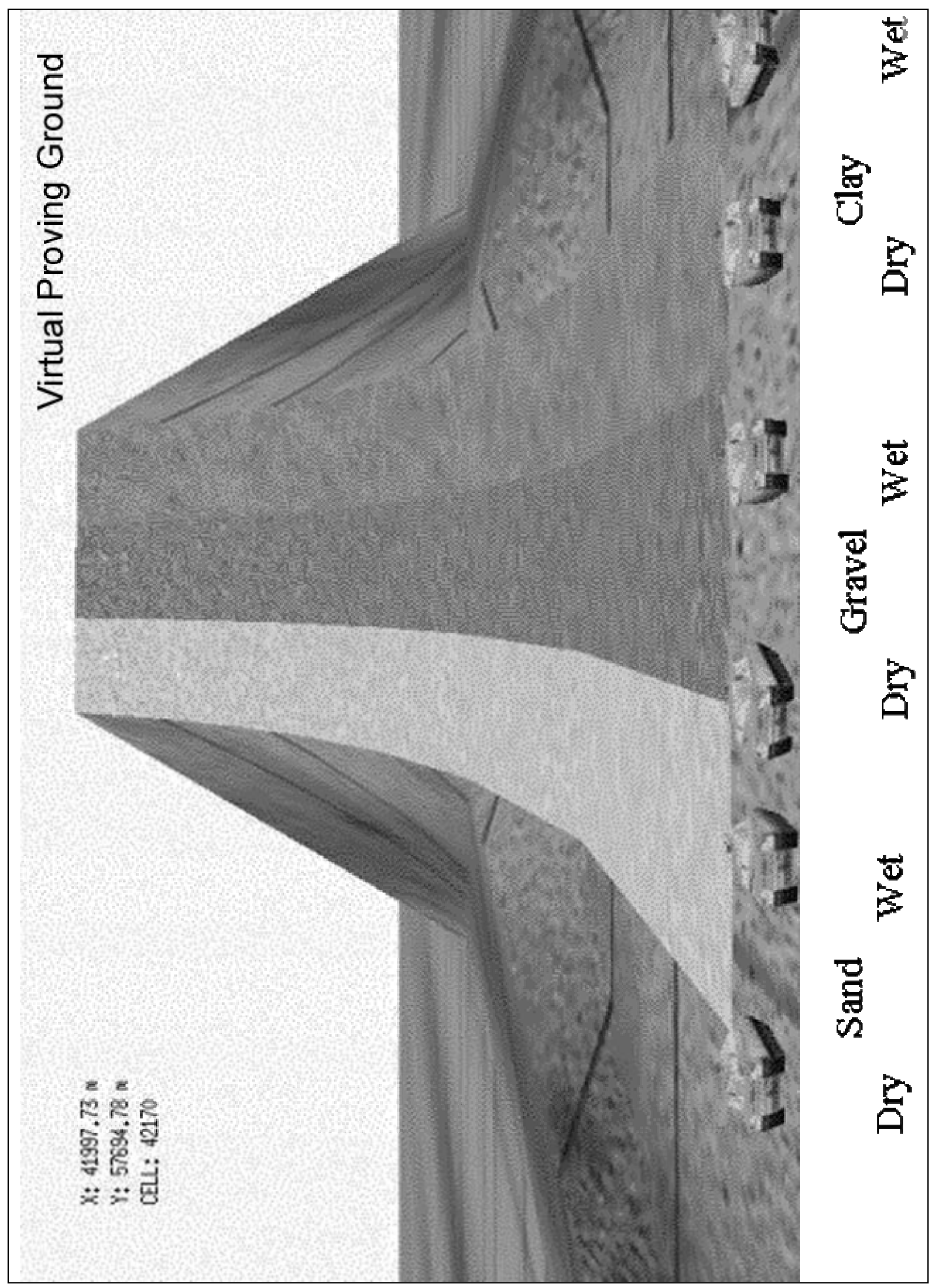

PLATE 21 


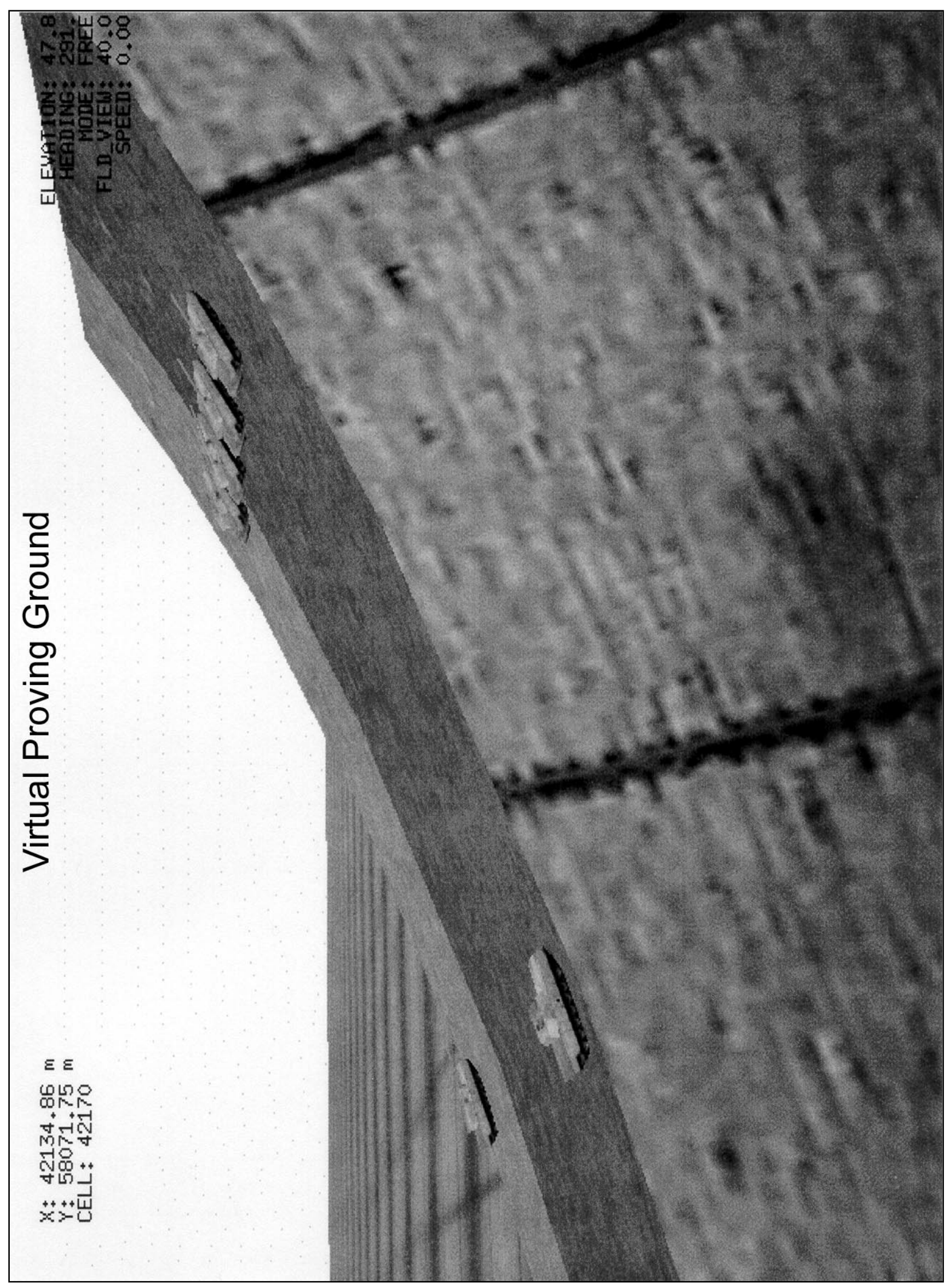

PLATE 22 


\section{Appendix A SOFT API for SAF model}

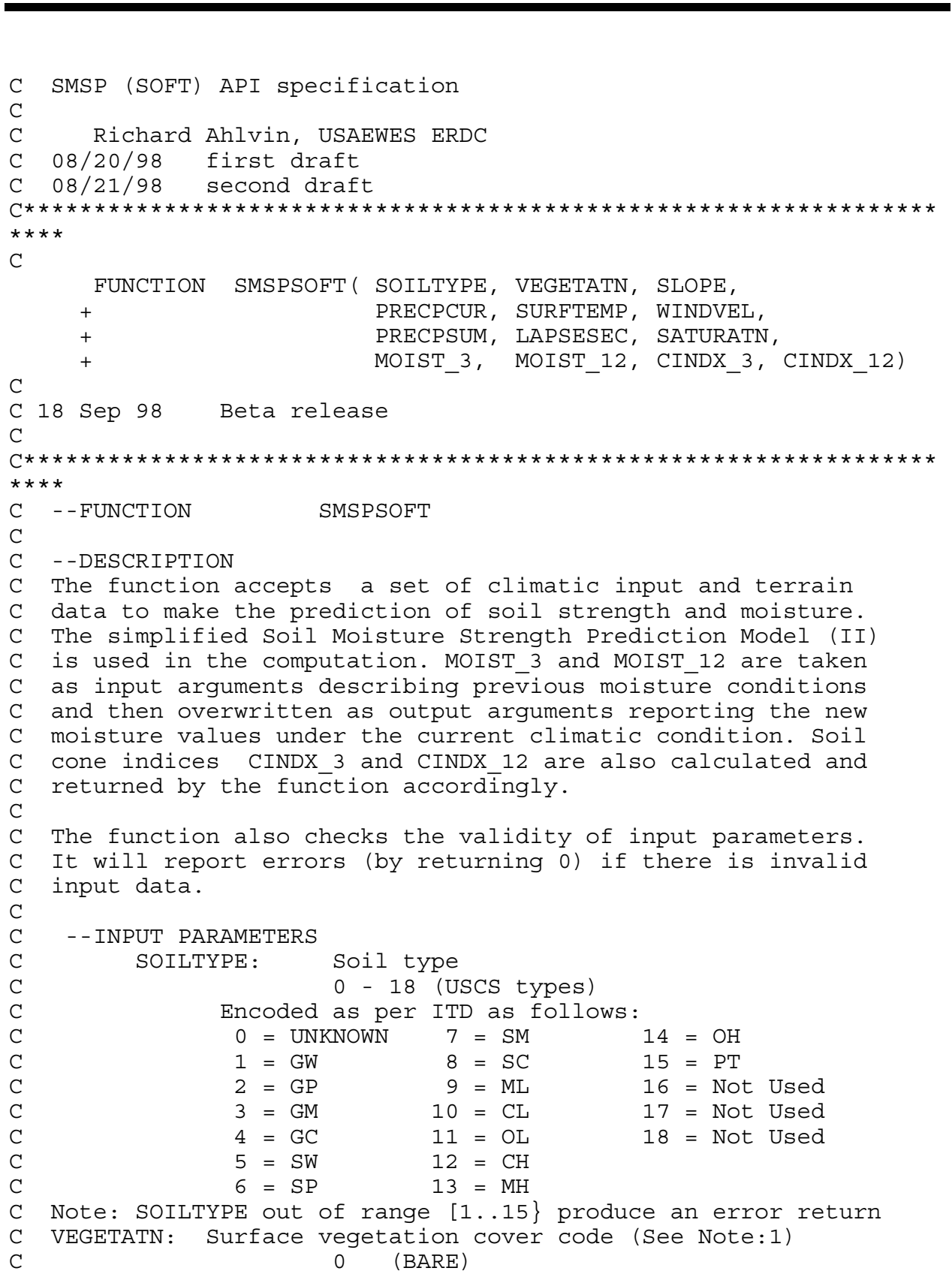




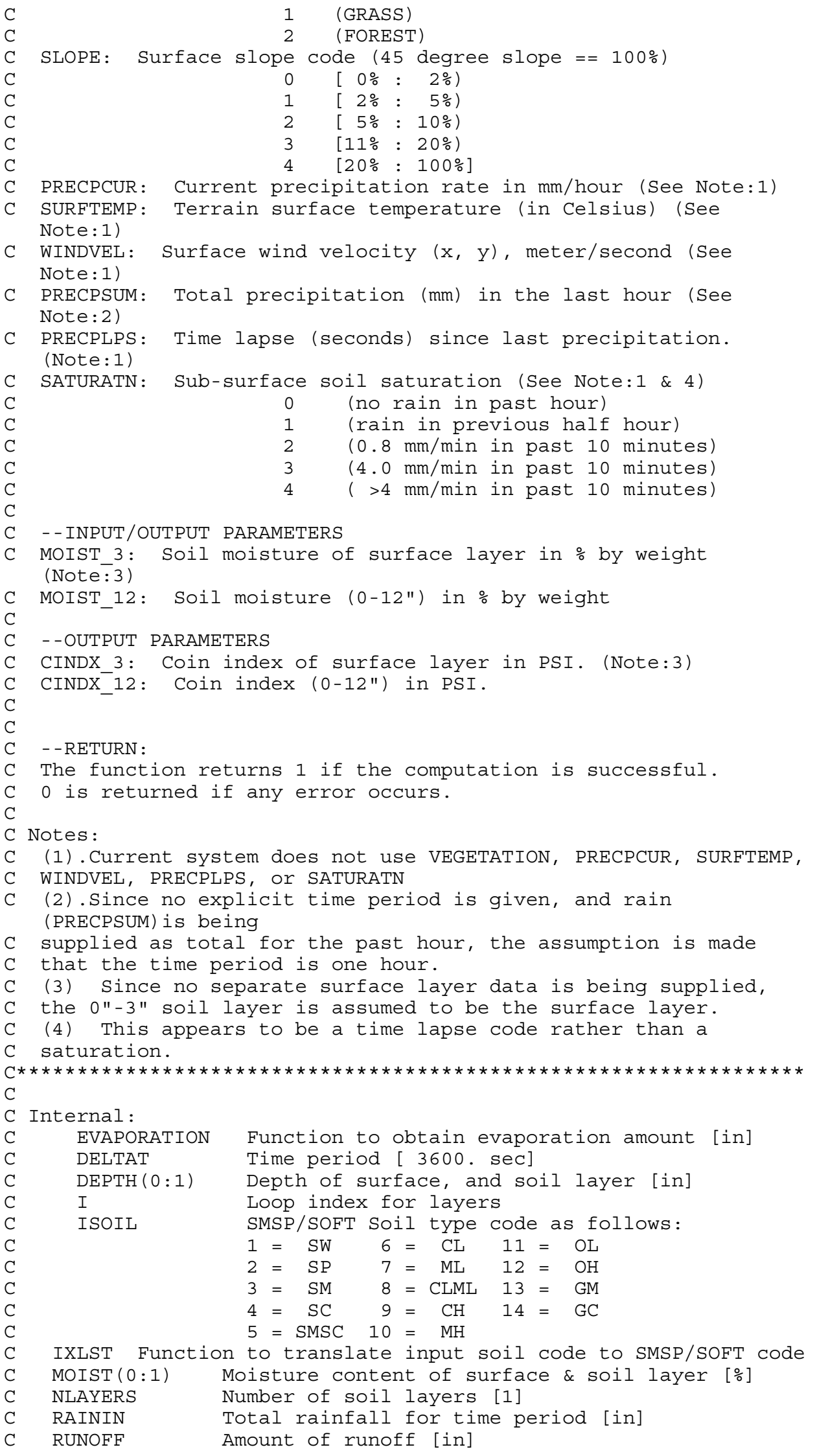




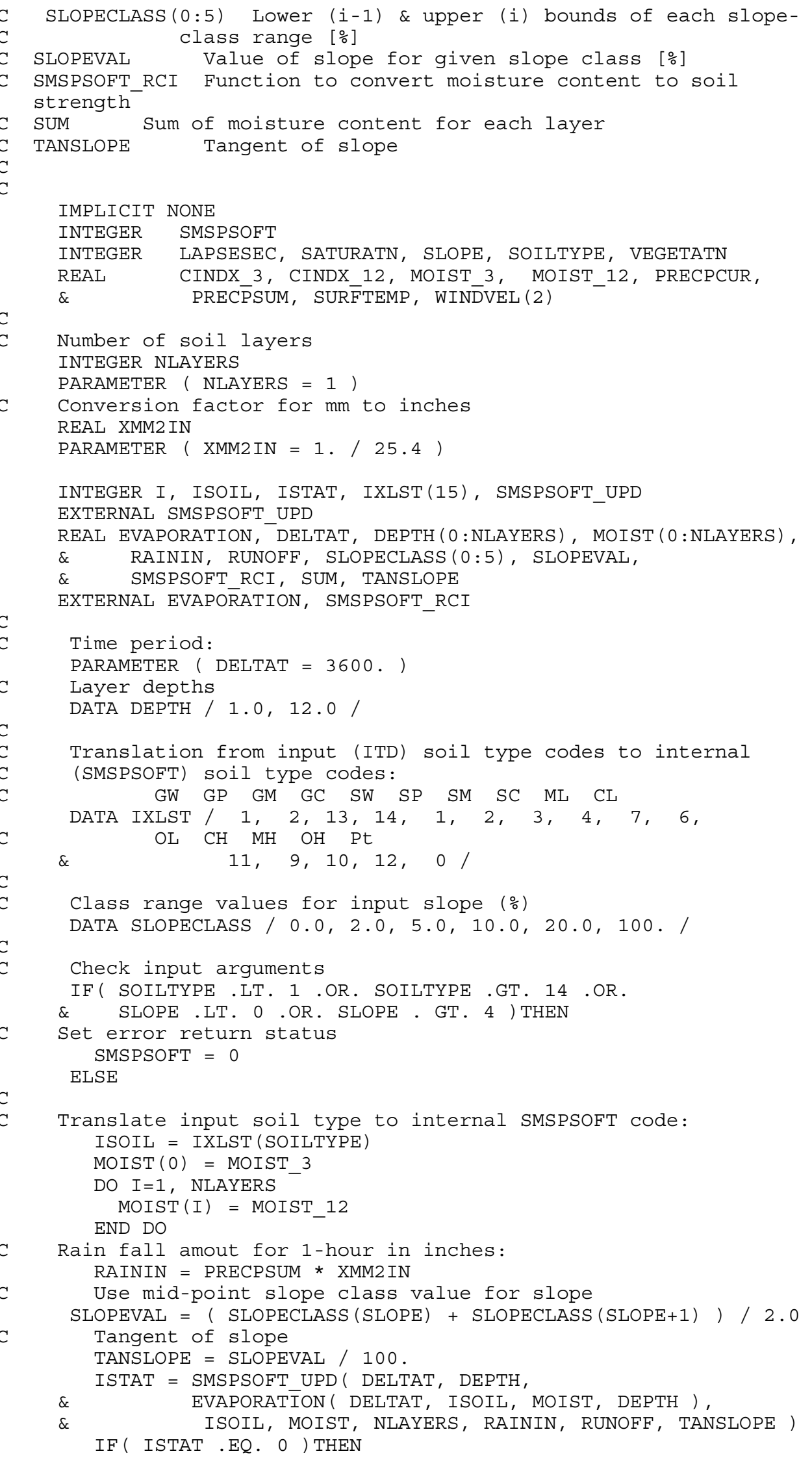




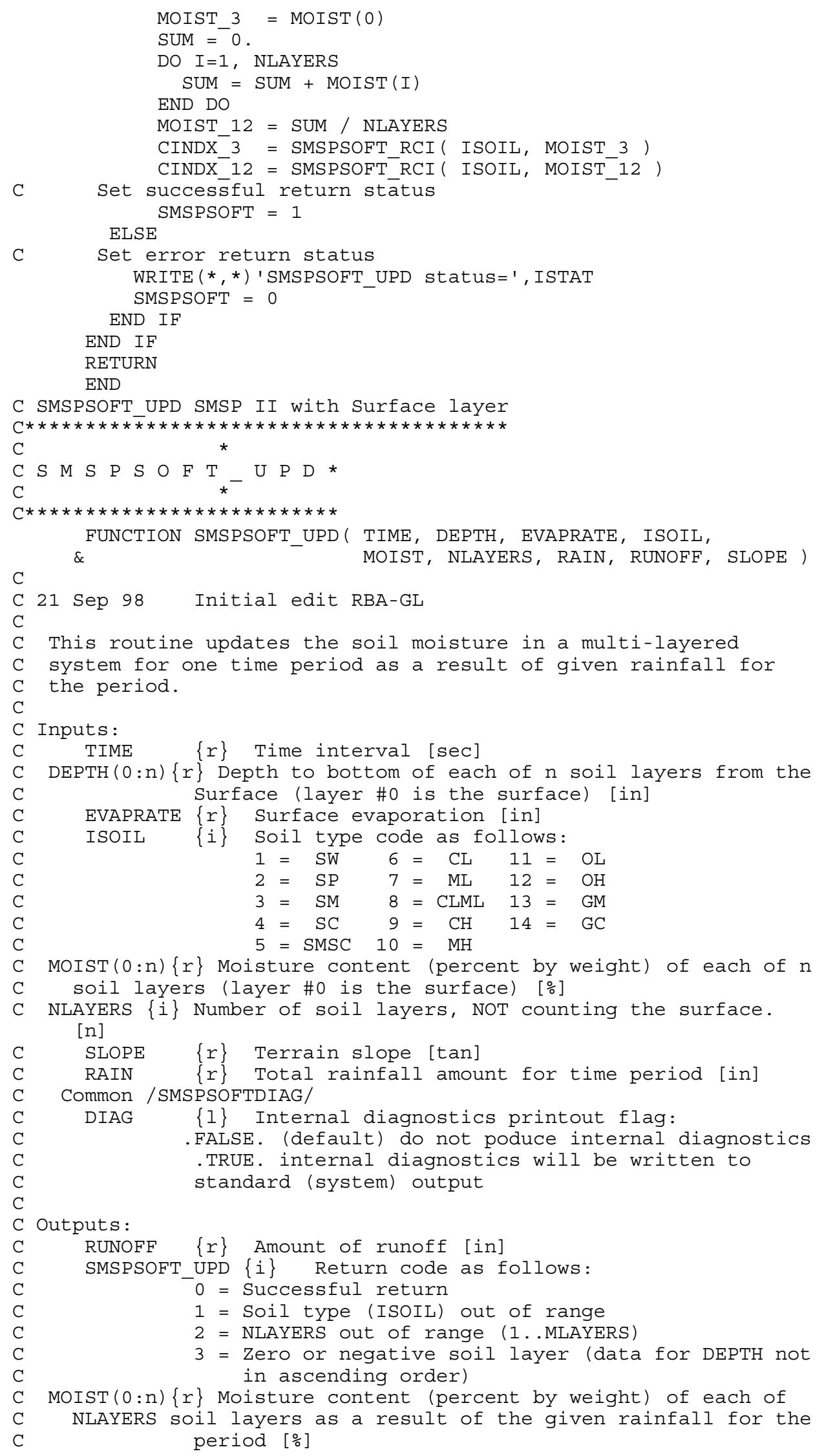




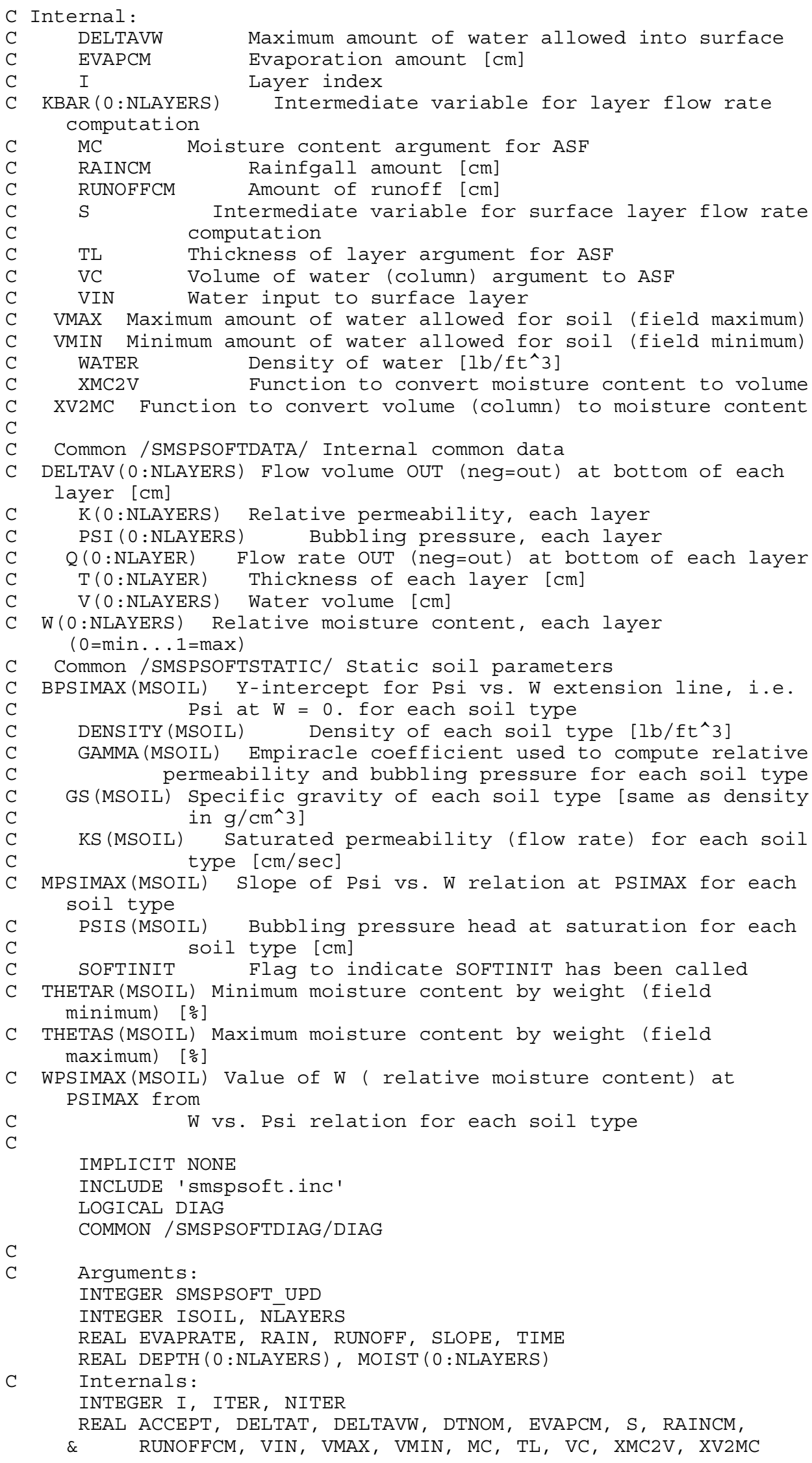




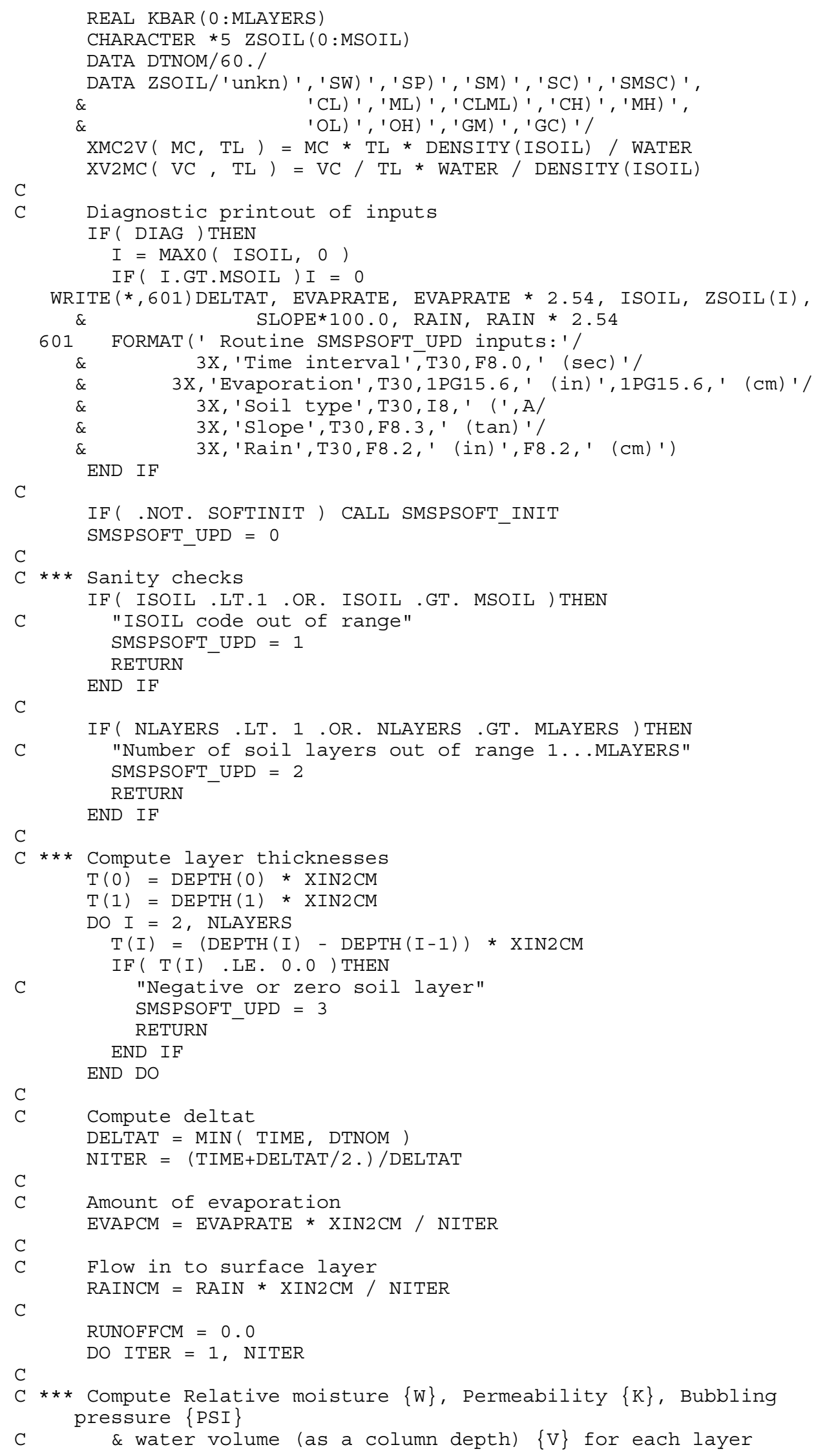




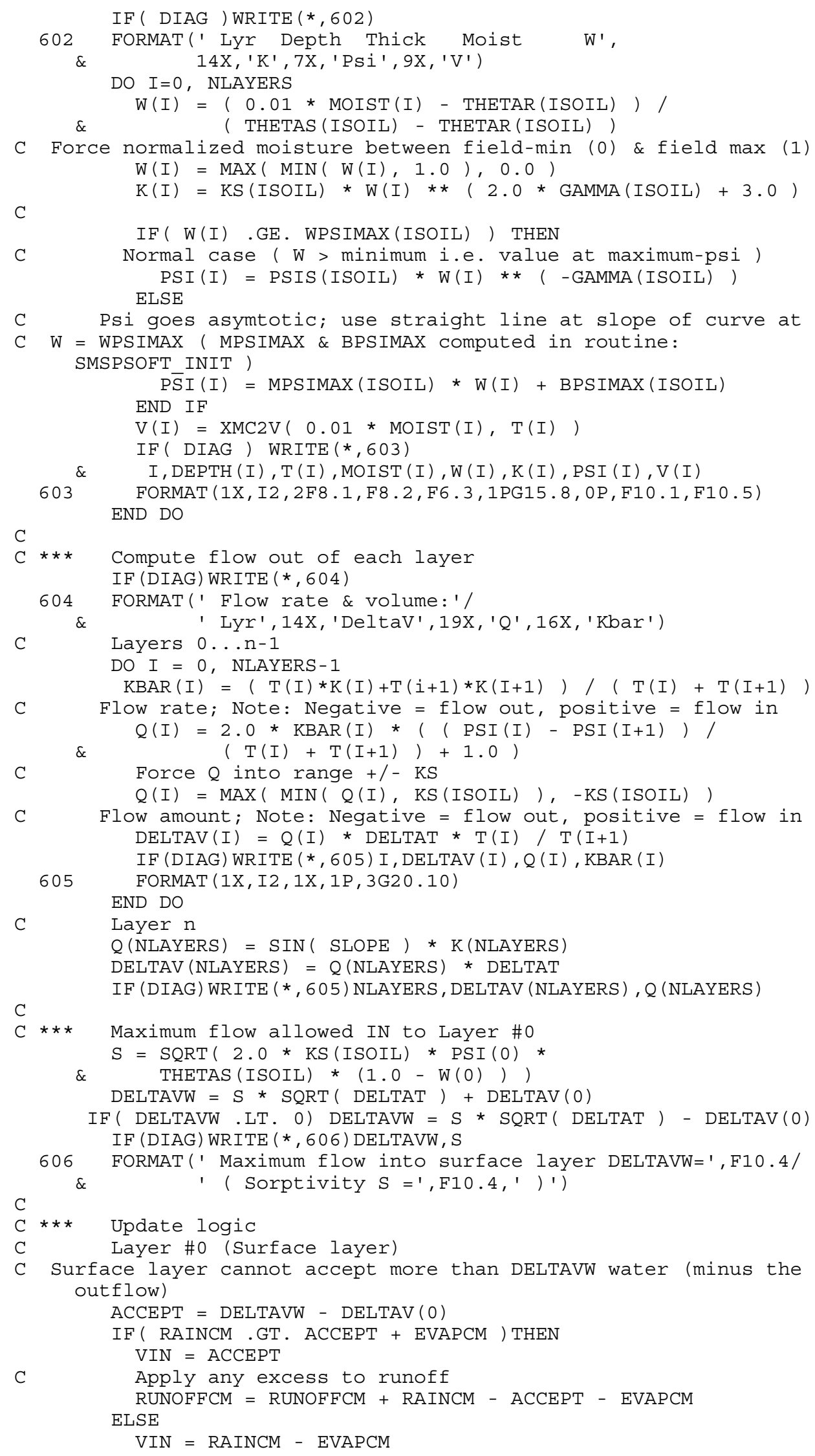




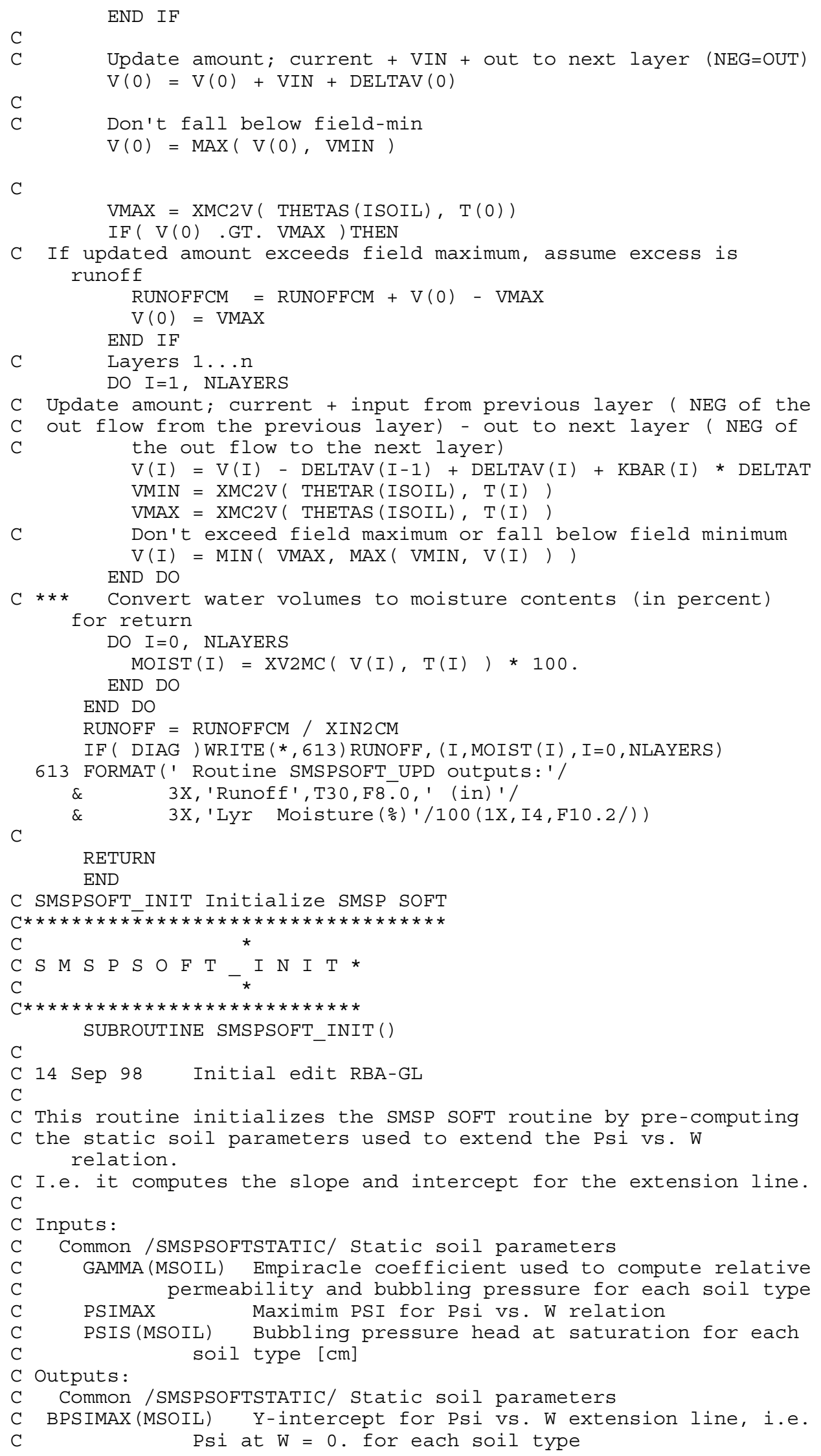




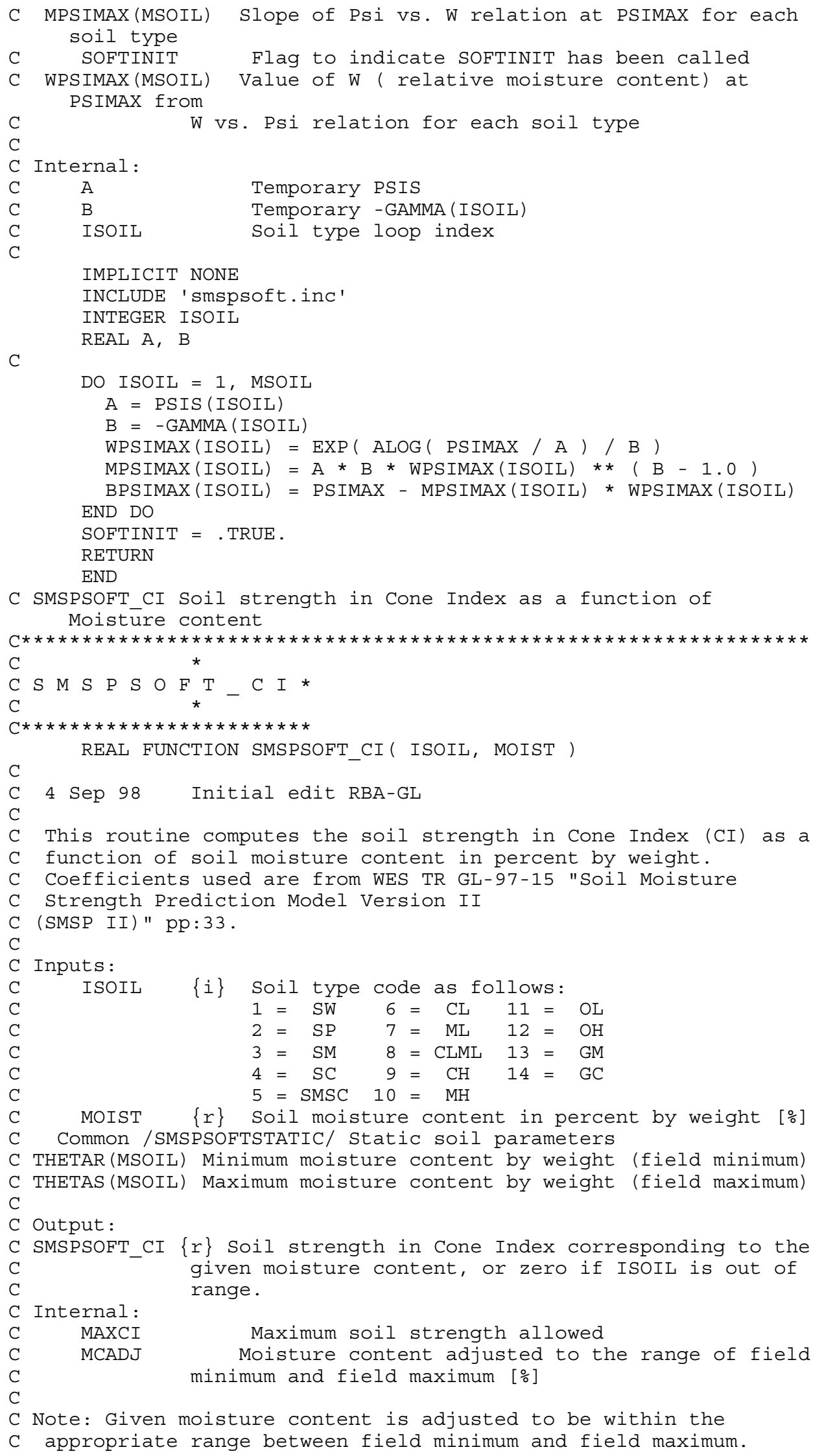


C

IMPLICIT NONE

INCLUDE 'smspsoft.inc'

INTEGER MCOEFS

PARAMETER ( MCOEFS $=12$ )

REAL COEFS (2, MCOEFS)

C Arguments:

INTEGER ISOIL

REAL MOIST

C Internal:

REAL MAXCI, MCADJ

C SW SP SM 1. 1949

C SC SMSC CL

$\begin{array}{r}\delta \\ 1.8480,\end{array} \quad 9.056,-1.3566,9.056,-1.3566,10.998,-$

$5.5830^{\&}$

C

$\&$

$\&$
$0 /$

ML CLML CH $10.225,-1.5650,9.454,-1.3850,13.816,-$

\&

C

IF ( ISOIL . LT. 1 .OR. ISOIL .GT. 14 ) THEN

SMSPSOFT CI $=0.0$

ELSE IF ( I $\bar{S} O I L$. GT. MCOEFS ) THEN

SMSPSOFT_CI $=300$.

ELSE

C Force moisture content in range from field minimum to field maximum

$\&$

MCADJ $=$ MIN $($ THETAS (ISOIL), MAX ( THETAR (ISOIL),

SMSPSOFT_CI $=$ EXP (

$\operatorname{COEFS}(1$, ISOIL $)+\operatorname{COEFS}(2$, ISOIL $) * A L O G(M C A D J)$ )

$\mathrm{C}$ Don't let soil strength exceed allowable maximum

IF（ ISOIL .LE. 2 ) THEN

C Maximum CI for Coarse-grained soils

MAXCI $=300.0$

ELSE

C Maximum CI for Finee-grained soils

MAXCI $=750.0$

END IF

SMSPSOFT CI $=$ MIN ( SMSPSOFT CI, MAXCI)

END IF

RETURN

END

C SMSPSOFT_RCI Soil strength in RCI as a function of Moisture content

$\mathrm{C} * * * * * * * * * * * * * * * * * * * * * * * * * * * * * * * * * * * * * * * * * * * * * * * * * * * * * * * * * * * * * * * * *$

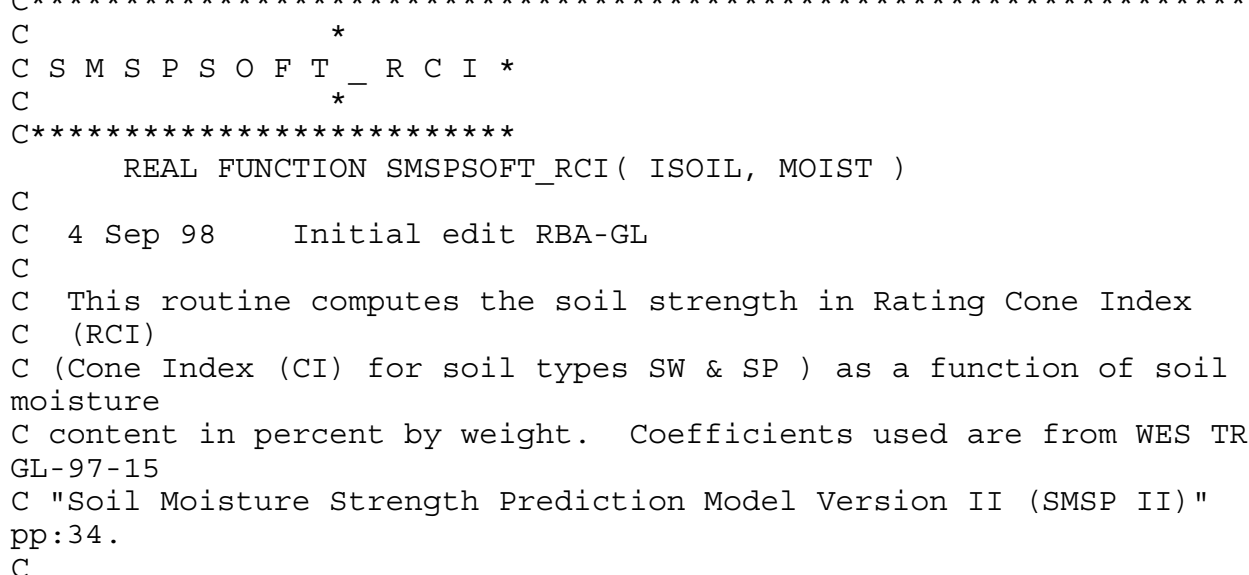
$\mathrm{pp}: 34$ 


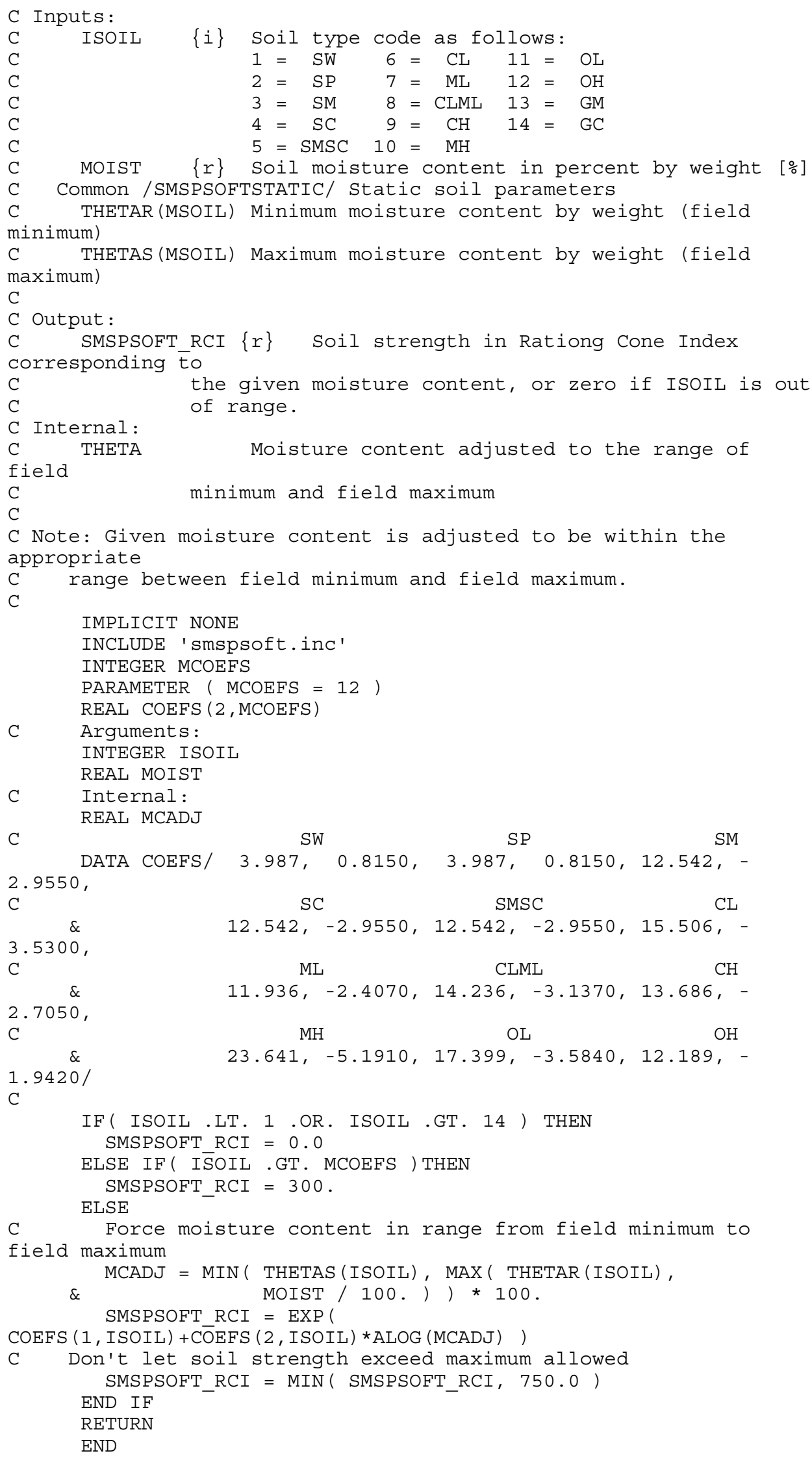




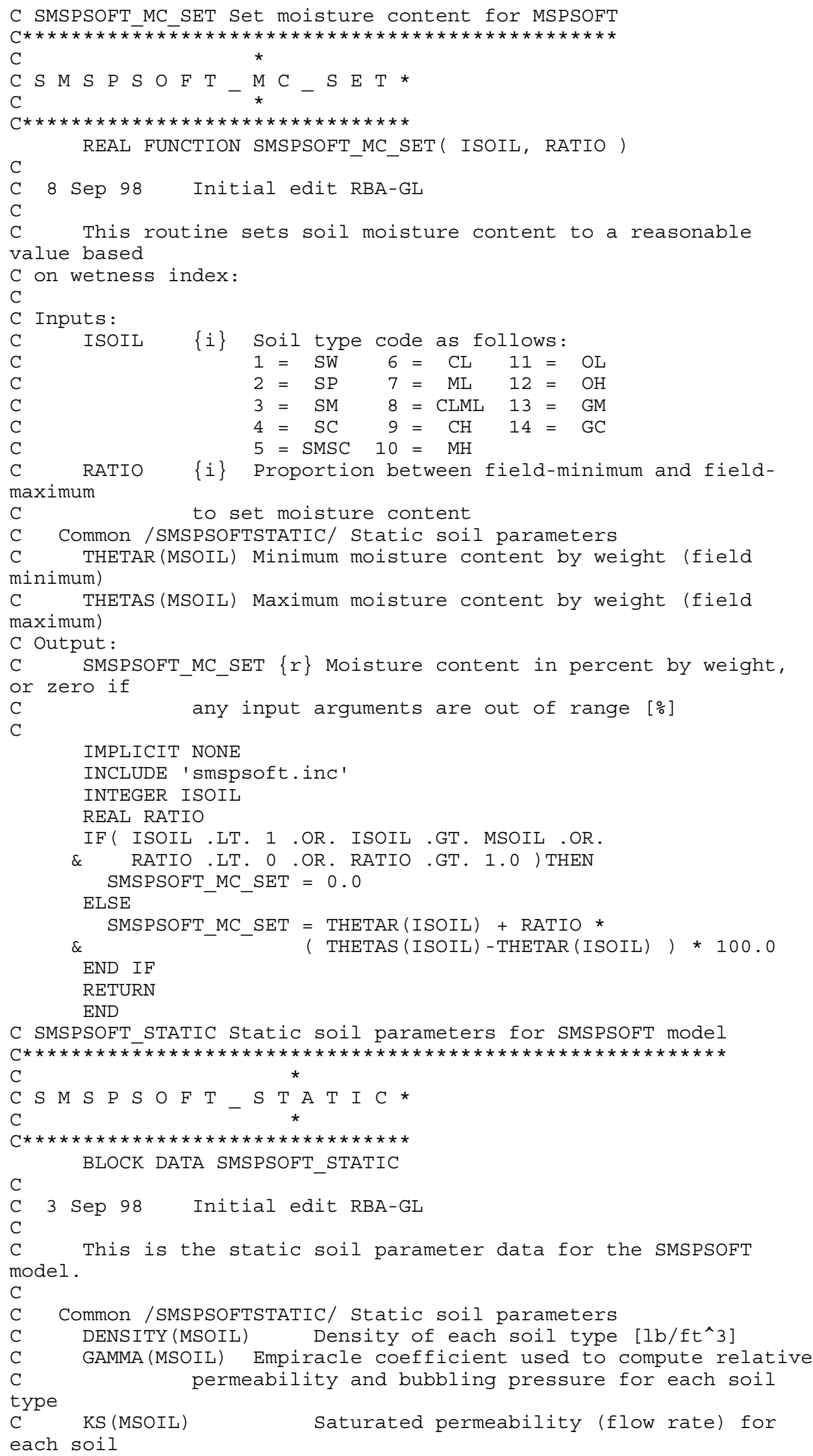




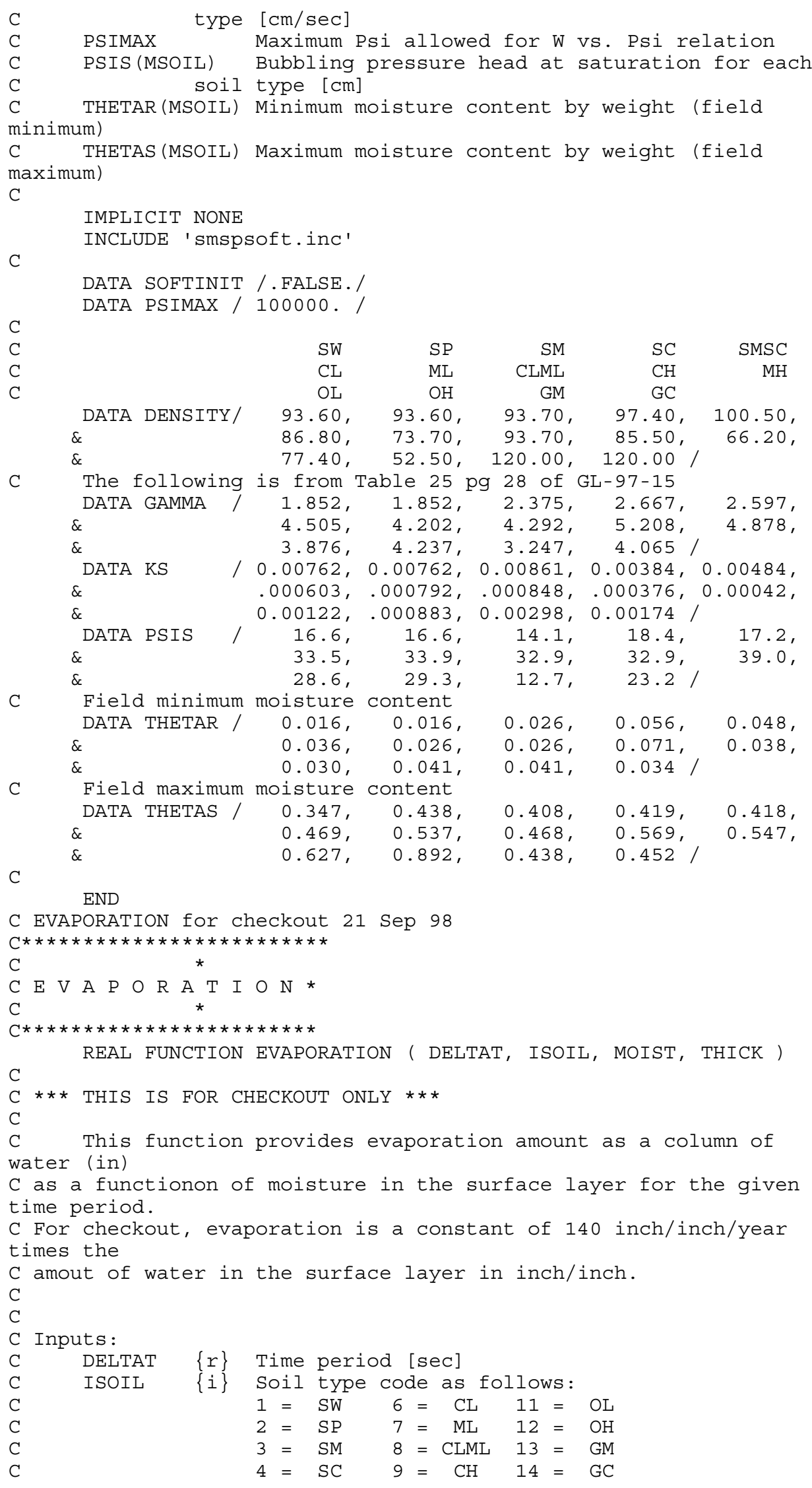




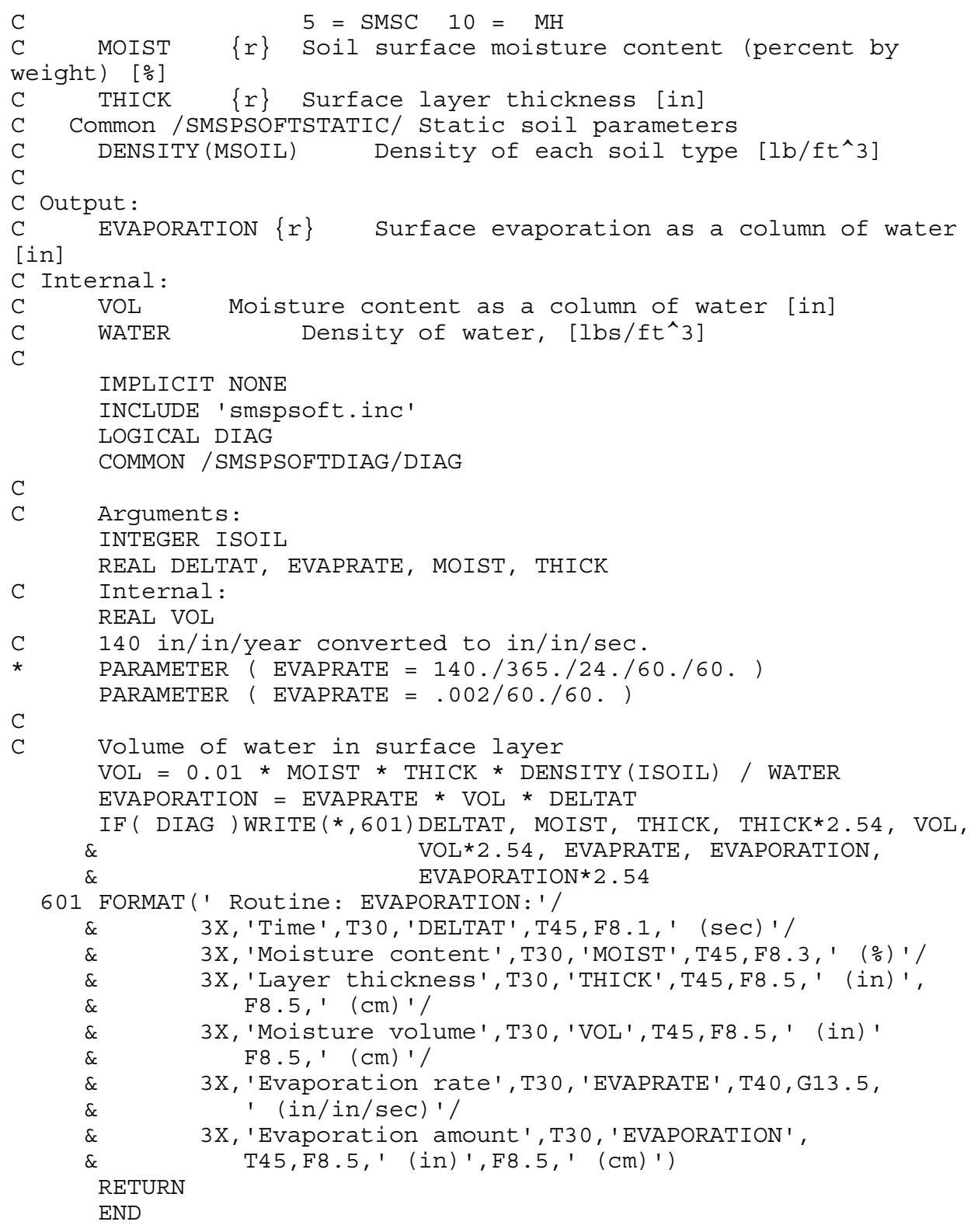




\begin{tabular}{|c|c|c|c|c|}
\hline \multicolumn{5}{|c|}{$\begin{array}{l}\text { Table A1 } \\
\text { Quantification of Wheels Study Definitions of Tactical Mobility }\end{array}$} \\
\hline \multirow[t]{2}{*}{ Mobility Level } & \multicolumn{2}{|c|}{$\begin{array}{c}\text { Operating } \\
\text { Distance, Percent }\end{array}$} & \multirow{2}{*}{$\begin{array}{l}\text { Off-Road }^{2} \\
\text { Percent of } \\
\text { Terrain } \\
\text { Challenged }\end{array}$} & \multirow{2}{*}{$\begin{array}{l}\text { On-Road } \\
\text { Percent of } \\
\text { Trails } \\
\text { Challenged }\end{array}$} \\
\hline & $\begin{array}{l}\text { Off- } \\
\text { Road } \\
\end{array}$ & $\begin{array}{l}\text { On- } \\
\text { Road }^{1} \\
\end{array}$ & & \\
\hline $\begin{array}{l}\text { High-High Mobiility = All off-road } \\
\text { operations }\end{array}$ & $\overline{c 100}$ & 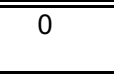 & $\overline{c 100}$ & "-- \\
\hline $\begin{array}{l}\text { Tactical High Mobility = The highest level } \\
\text { of mobility designating the requirements } \\
\text { for extensive cross-country maneuverabil- } \\
\text { ity characteristics of combat operations in } \\
\text { the ground-gaining and fire-support } \\
\text { environment. }\end{array}$ & 50 & 50 & 90 & 100 \\
\hline $\begin{array}{l}\text { Tactical Standard Mobility }=\text { The second } \\
\text { highest level of mobility designating the } \\
\text { requirement for occasional cross-country } \\
\text { movement, characteristic of combat } \\
\text { support operations. }\end{array}$ & 15 & 85 & 80 & 100 \\
\hline $\begin{array}{l}\text { Tactical Support Mobility = A level of } \\
\text { mobility designating the requirement for } \\
\text { infrequent off-road operations over } \\
\text { selected terrain with the preponderance of } \\
\text { movement on primary and secondary } \\
\text { roads, characteristic of combat service } \\
\text { support operations. }\end{array}$ & 5 & 95 & 50 & 80 \\
\hline $\begin{array}{l}\text { On-Road Mobility }{ }^{3}=\text { All on superhighways, } \\
\text { primary and secondary roads, and the } \\
\text { best tertiary roads and trails. }\end{array}$ & 0 & 100 & -- & 50 \\
\hline
\end{tabular}




\begin{tabular}{|c|c|c|c|c|c|c|c|c|}
\hline \multicolumn{9}{|c|}{$\begin{array}{l}\text { Table A2 } \\
\text { Network Composition and Severity at Tactical Mobility Levels for Study Area } \\
\text { Indicated }\end{array}$} \\
\hline \multirow[b]{2}{*}{$\begin{array}{l}\text { Mobility } \\
\text { Levels }\end{array}$} & \multicolumn{4}{|c|}{ Composition of Network in Percent } & \multicolumn{4}{|c|}{$\begin{array}{c}\text { Severity of Operation in Terms of Percent } \\
\text { of Terrain and Roads Challenged }\end{array}$} \\
\hline & $\begin{array}{l}\text { Primary } \\
\text { Roads } \\
\left(P_{\mathrm{P}}\right)\end{array}$ & $\begin{array}{l}\text { Secondary } \\
\text { Roads }\left(P_{S}\right)\end{array}$ & $\begin{array}{l}\text { Trails } \\
\left(\mathbf{P}_{\mathrm{T}}\right) \\
\end{array}$ & $\begin{array}{l}\text { Off- } \\
\text { Road } \\
\text { (P) }\end{array}$ & $\begin{array}{l}\text { Primary } \\
\text { Roads } \\
\left(\mathbf{V}_{\mathrm{PP}}\right)\end{array}$ & $\begin{array}{l}\text { Secondary } \\
\text { Roads } \\
\left(V_{\mathrm{SP}}\right)\end{array}$ & $\begin{array}{l}\text { Trails } \\
\left(V_{\mathrm{PP}}\right)\end{array}$ & $\begin{array}{l}\text { Off- } \\
\text { Road } \\
\left(V_{c}\right)\end{array}$ \\
\hline \multicolumn{9}{|c|}{ Central Europe } \\
\hline "High-High & 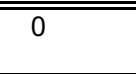 & 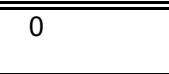 & 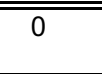 & 100 & 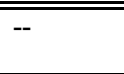 & 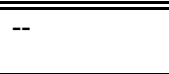 & --- & $V_{100}$ \\
\hline Tactical High & 10 & 30 & 10 & 50 & $V_{100}$ & $V_{100}$ & $\mathrm{~V}_{100}$ & $V_{90}$ \\
\hline $\begin{array}{l}\text { Tactical } \\
\text { Standard }\end{array}$ & 20 & 50 & 15 & 15 & $V_{100}$ & $V_{100}$ & $V_{100}$ & $\mathrm{~V}_{80}$ \\
\hline $\begin{array}{l}\text { Tactical } \\
\text { Support }\end{array}$ & 30 & 55 & 10 & 5 & $V_{100}$ & $V_{100}$ & $\mathrm{~V}_{80}$ & $V_{50}$ \\
\hline On-Road & 35 & 60 & 5 & 0 & $V_{100}$ & $V_{100}$ & $\mathrm{~V}_{50}$ & -- \\
\hline \multicolumn{9}{|c|}{ Far East } \\
\hline "High-High & 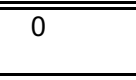 & 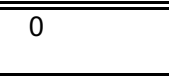 & 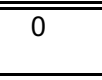 & 100 & 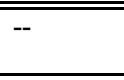 & 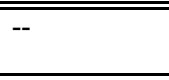 & 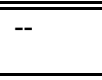 & $V_{100}$ \\
\hline Tactical High & 10 & 30 & 10 & 50 & $V_{100}$ & $V_{100}$ & $V_{100}$ & $V_{90}$ \\
\hline $\begin{array}{l}\text { Tactical } \\
\text { Standard }\end{array}$ & 20 & 50 & 15 & 15 & $V_{100}$ & $V_{100}$ & $V_{100}$ & $\mathrm{~V}_{80}$ \\
\hline $\begin{array}{l}\text { Tactical } \\
\text { Support }\end{array}$ & 30 & 55 & 10 & 5 & $V_{100}$ & $V_{100}$ & $\mathrm{~V}_{80}$ & $V_{50}$ \\
\hline On-Road & 35 & 60 & 5 & 0 & $V_{100}$ & $V_{100}$ & $\mathrm{~V}_{50}$ & -- \\
\hline \multicolumn{9}{|c|}{ Middle East } \\
\hline "High-High & 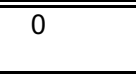 & 0 & 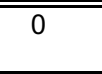 & 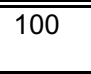 & "-- & "-- & "-- & $V_{100}$ \\
\hline Tactical High & 5 & 20 & 25 & 50 & $V_{100}$ & $V_{100}$ & $V_{100}$ & $V_{90}$ \\
\hline $\begin{array}{l}\text { Tactical } \\
\text { Standard }\end{array}$ & 15 & 35 & 35 & 15 & $V_{100}$ & $V_{100}$ & $V_{100}$ & $V_{80}$ \\
\hline $\begin{array}{l}\text { Tactical } \\
\text { Support }\end{array}$ & 20 & 40 & 35 & 5 & $V_{100}$ & $V_{100}$ & $\mathrm{~V}_{80}$ & $V_{50}$ \\
\hline On-Road & 30 & 45 & 30 & 0 & $V_{100}$ & $V_{100}$ & $\mathrm{~V}_{50}$ & -- \\
\hline
\end{tabular}




\section{Appendix B Real-Time Mobility API for SAF}

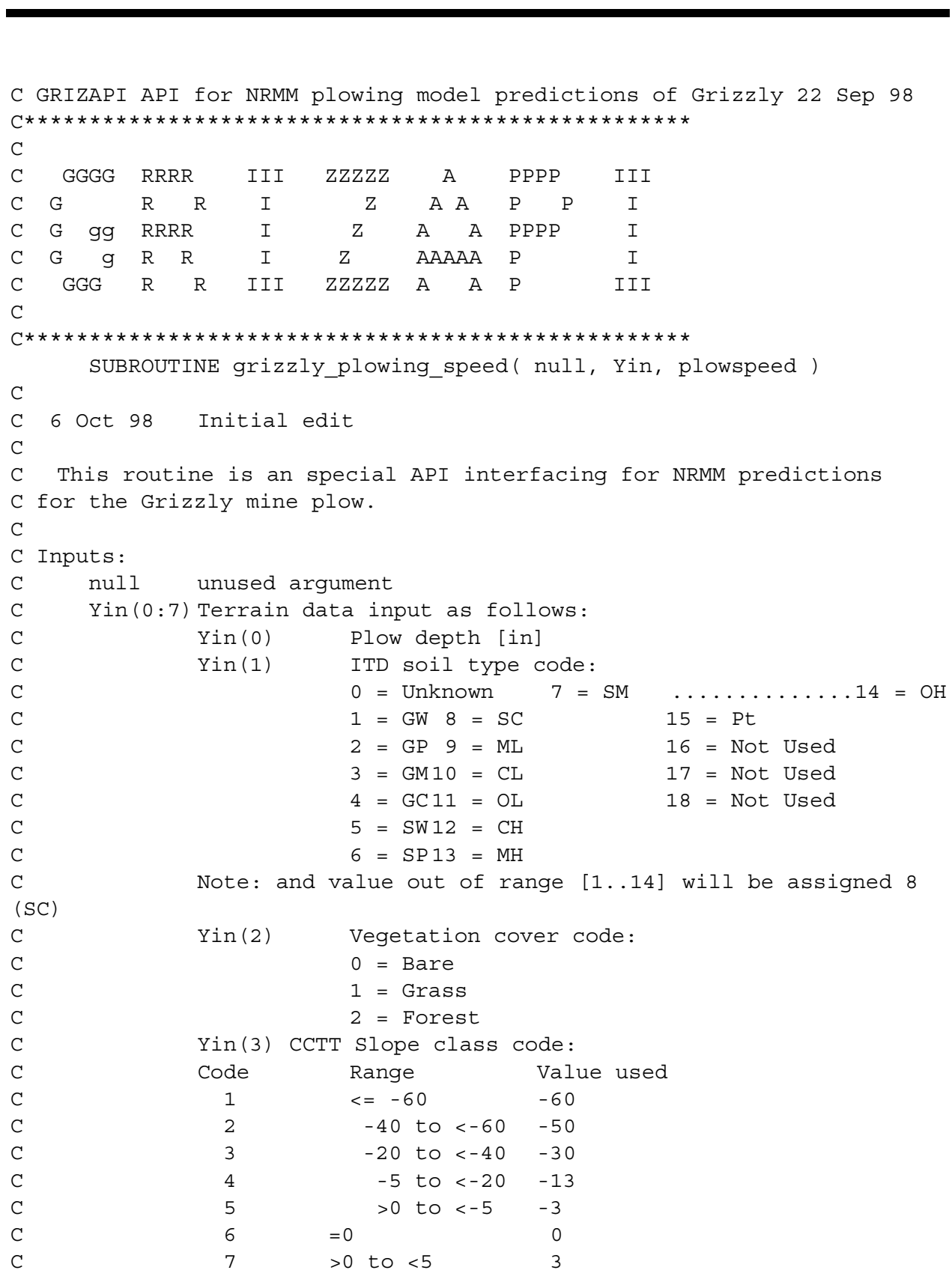




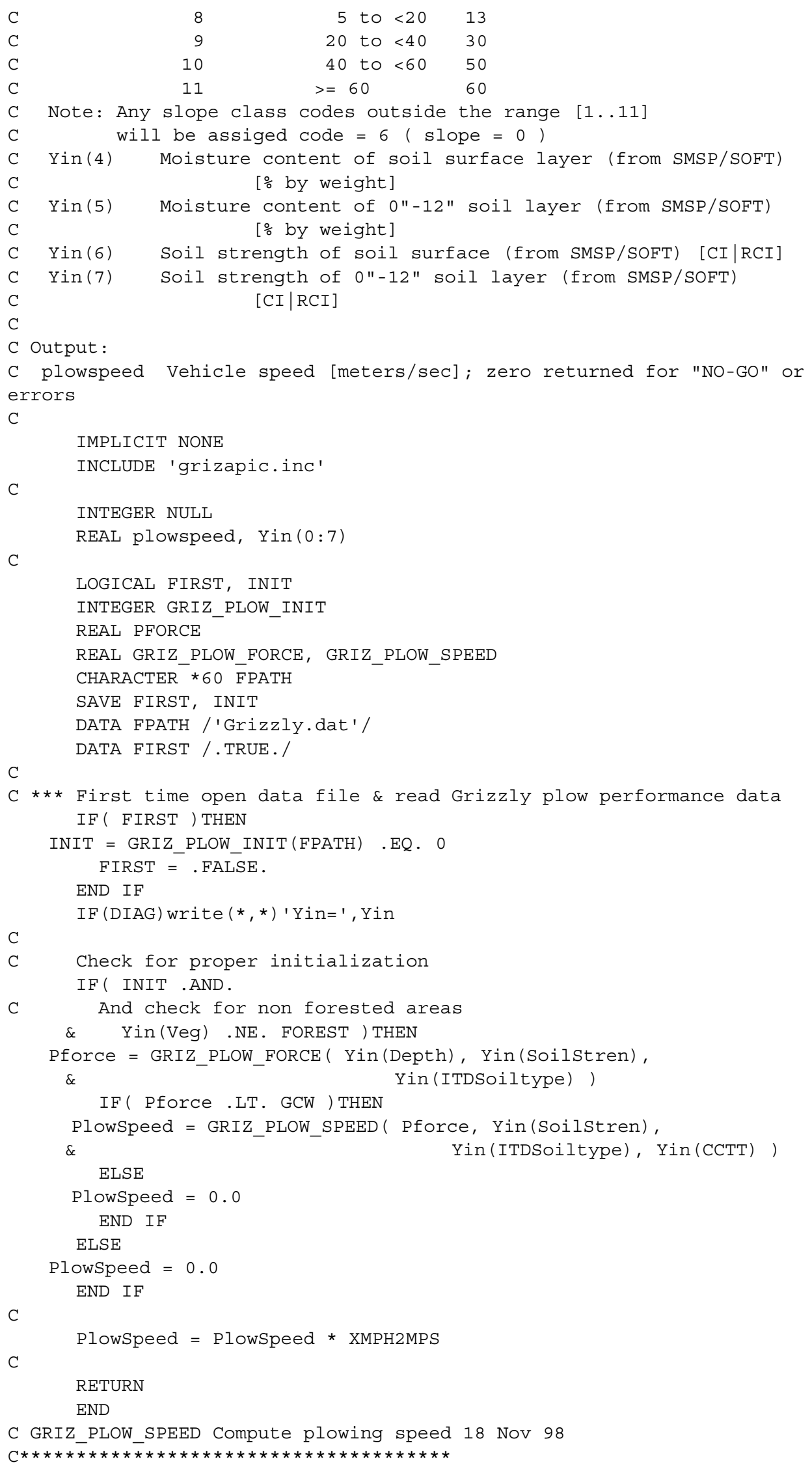




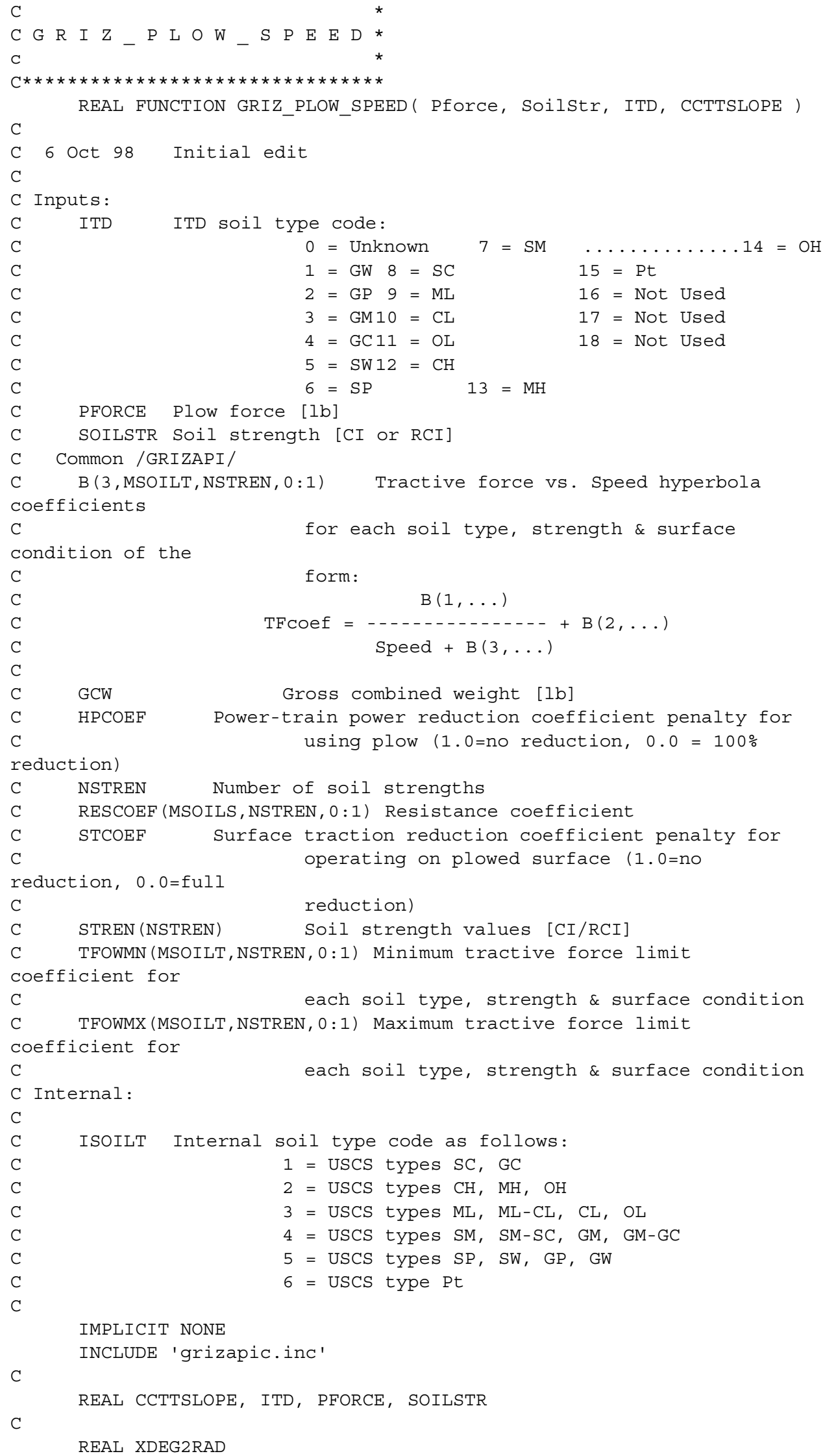

REAL XDEG2RAD 


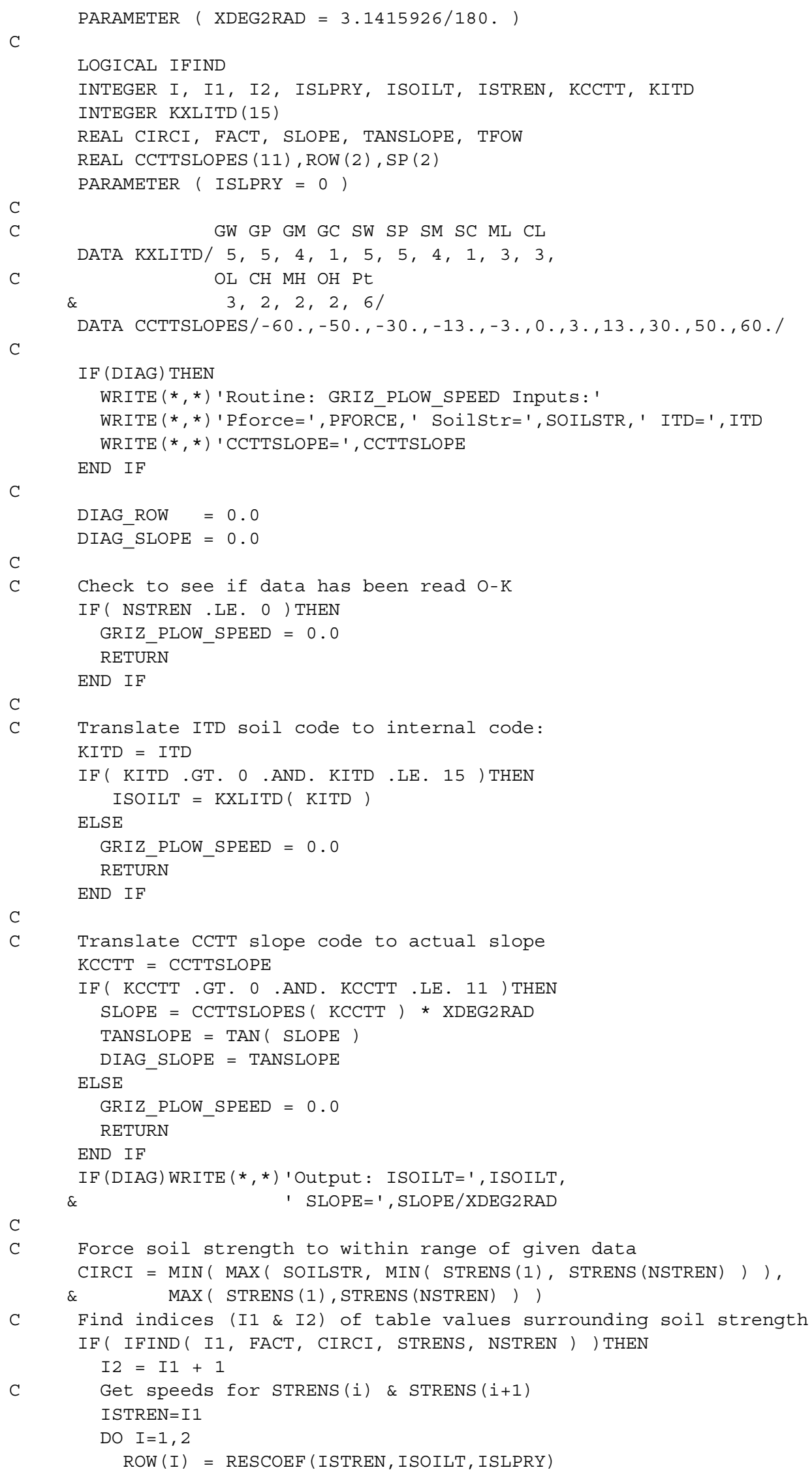


C Don't let speed be less than zero ELSE 


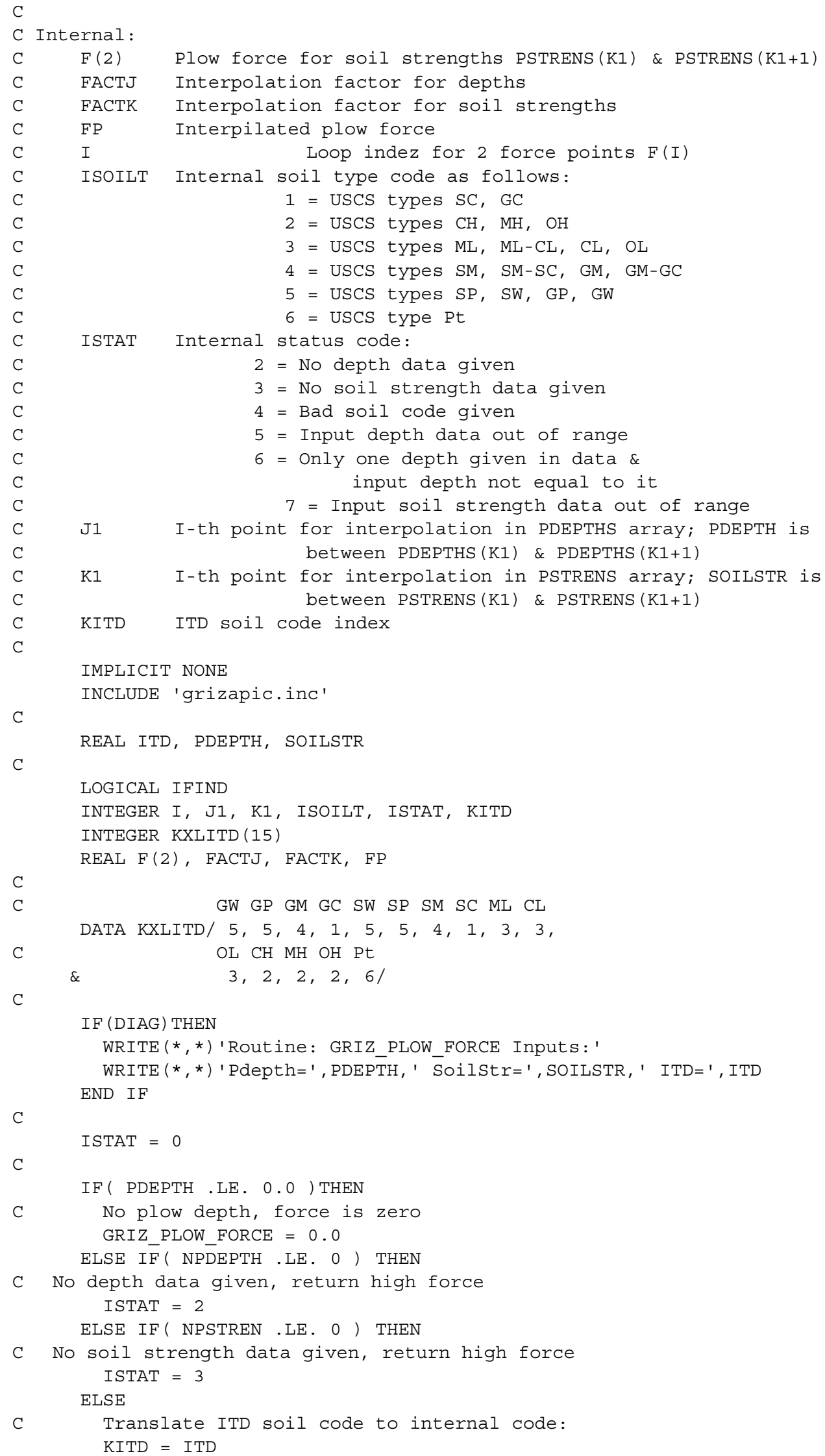




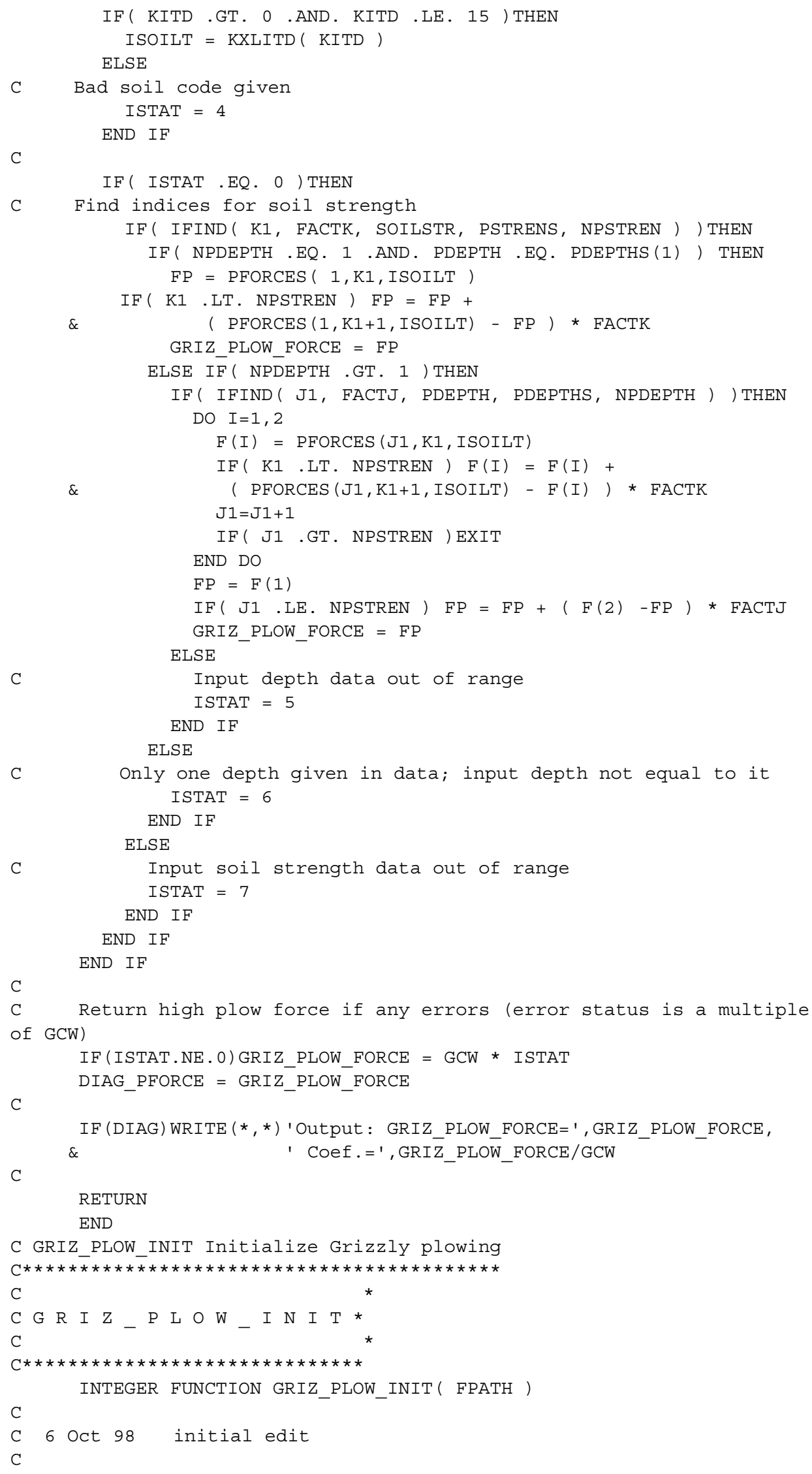




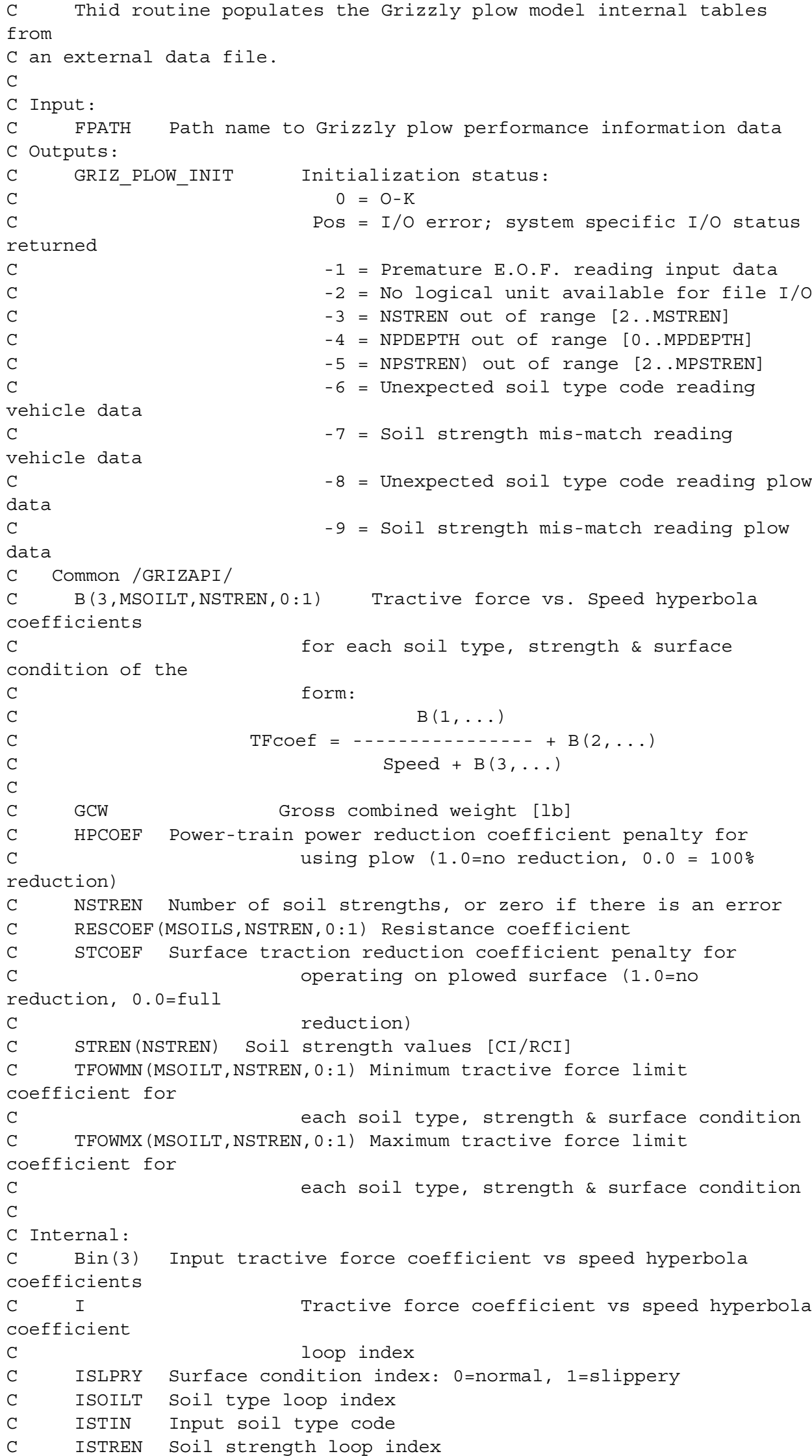


C

IMPLICIT NONE

INCLUDE 'grizapic.inc'

CHARACTER * * * FPATH

INTEGER I, IOSTAT, IPDEPTH, IPSTREN, ISLPRY, ISOILT, \& ISTREN, ISTIN, LDEV, NREC

INTEGER LDEVUNQ

REAL CIRCI

C

NAMELIST /GRIZDATA/GCW, DIAG, HPCOEF, NPDEPTH, NPSTREN, NSTREN, PDEPTHS, PSTRENS, STCOEF， STRENS

C

$\mathrm{DIAG}=. \mathrm{FALSE}$

C Get an unused logical unit number LDEV=LDEVUNQ ( ) IF (LDEV. LE . 0) THEN

C Logical unit unavailable

IOSTAT $=-2$

ELSE

OPEN ( UNIT=LDEV, FILE=FPATH, STATUS='OLD', IOSTAT=IOSTAT)

IF (DIAG. AND. IOSTAT.NE. 0) WRITE $(*, *)$

\& 'OPEN : " ' , CHARNB (FPATH), ' " IOSTAT $=$ ', IOSTAT

IF (IOSTAT . EQ . 0) READ (UNIT=LDEV, NML=GRIZDATA, IOSTAT=IOSTAT)

IF (DIAG. AND. IOSTAT.NE. 0) WRITE $(*, *)$

$\mathrm{C}$

$\& \quad$ 'READ /GRIZDATA/: IOSTAT $=$ ', IOSTAT

C Check input data so far IF (IOSTAT. EQ. O) THEN

IF（ NSTREN .LT. 2 .OR. NSTREN . GT. MSTREN ) THEN

C No. of vehicle performance soil strengths out of range [2. .MSTREN]

IOSTAT $=-3$

ELSE IF( NPDEPTH .LT. 0 .OR. NPDEPTH .GT. MPDEPTH ) THEN

C Number of plow depths out of range [0..MPDEPTH] IOSTAT $=-4$

ELSE IF( NPDEPTH .GT. 0 .AND.

\& ( NPSTREN .LT. 2 .OR. NPSTREN .GT. MPSTREN ) ) THEN C Number of plow soil strengths (NPSTREN) out of range

[2. .MPSTREN]

END IF

END IF

C

C Read vehicle performance information

IF ( IOSTAT .EQ. O ) THEN

NREC $=0$

DO ISLPRY $=0,1$

DO ISOILT $=1$, MSOILS

DO ISTREN $=1$, NSTREN

READ (LDEV, *, IOSTAT=IOSTAT)

$\& \quad$ ISTIN, CIRCI,

$\& \ldots \ldots \ldots \ldots \ldots \ldots \ldots \ldots \ldots \ldots \ldots E$ REST (ISTREN, ISOILT, ISLPRY),

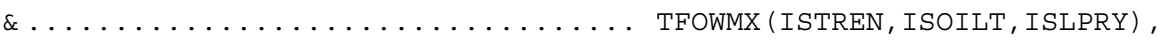

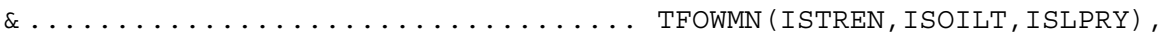

$\& \quad(B(I$, ISTREN , ISOILT, ISLPRY $), I=1,3)$

NREC $=$ NREC +1

IF ( IOSTAT.EQ. 0 ) THEN

IF（ ISTIN .NE. ISOILT ) THEN 


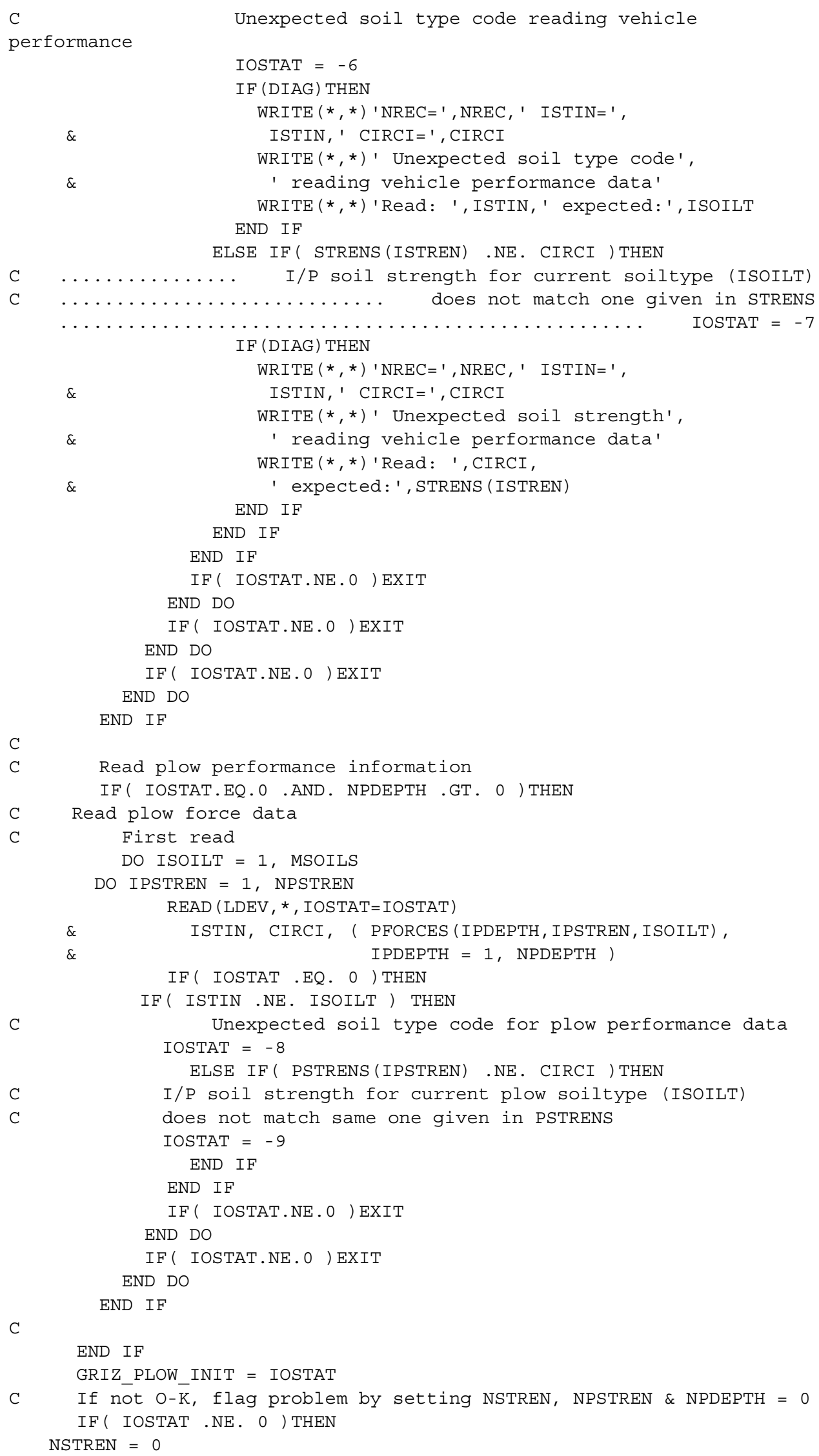




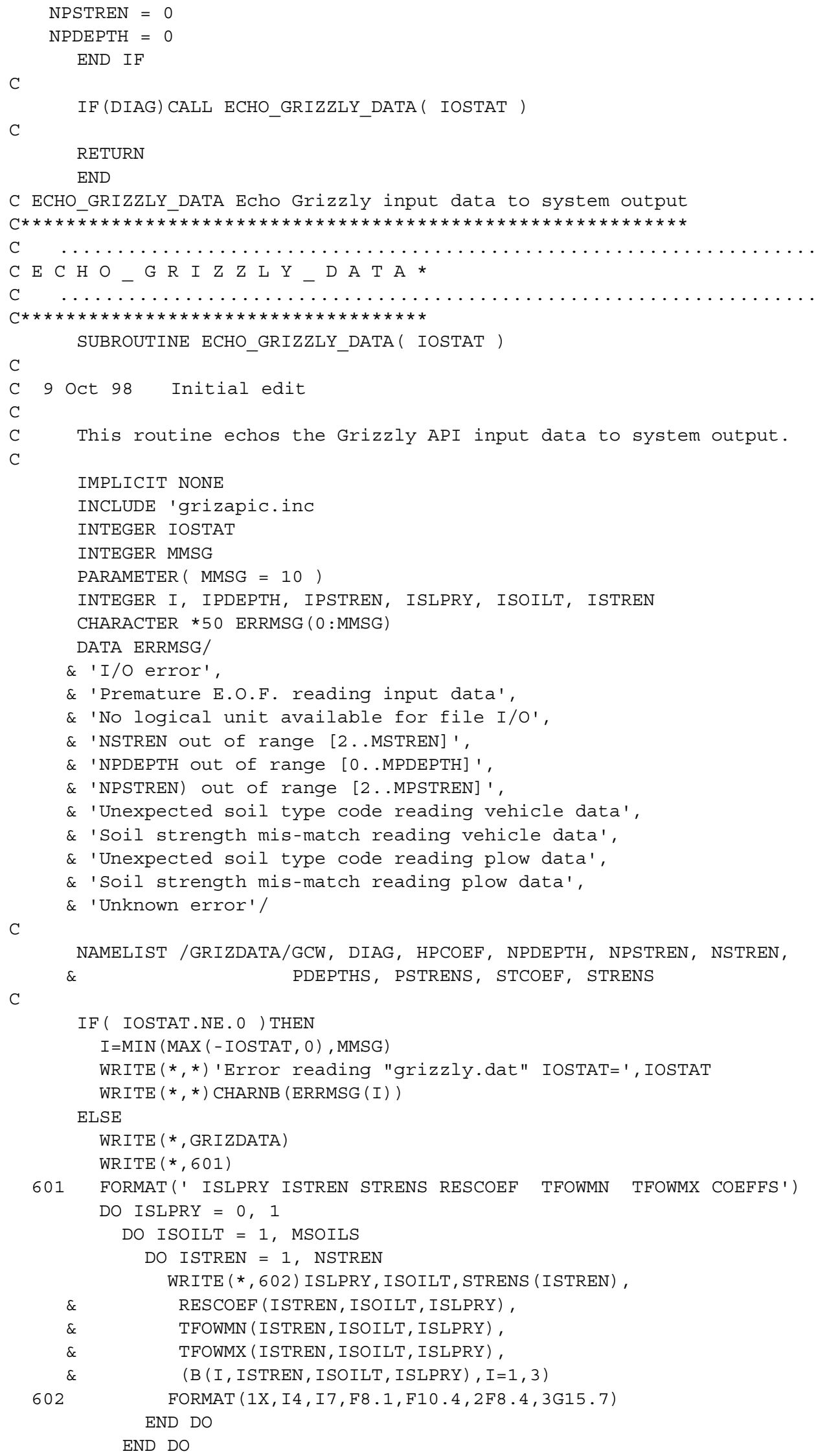


END DO

C $\operatorname{WRITE}(*, 603)$ ( PDEPTHS (IPDEPTH), IPDEPTH $=1, \operatorname{NPDEPTH})$

C

RETURN

END

C IFIND Find subscript and interpolation factor of data in table 18 Nov 98 
$\mathrm{FACT}=0$.

IFIND $=$. FALSE .

ELSE

IF ( ARRAY (NPTS) .GE. ARRAY (1) ) THEN

C Ascending order

$I 1=1$

$\mathrm{I} 2=\mathrm{NPTS}$

ELSE

C

$I 1=N P T S$

$\mathrm{I} 2=1$

END IF

DO WHILE ( ABS(I2-I1) .GT. 1 )

$I=(I 1+I 2) / 2$

IF ( DATA .LT. ARRAY (I) ) THEN

$I 2=I$

ELSE IF( DATA . GT. ARRAY(I) ) THEN

$I 1=I$

ELSE

C Exactly equal ARRAY(I)

$\mathrm{I} 1=\mathrm{I}$

IF（ II.LT.NPTS ) THEN

$I 2=I+1$

ELSE

$I 2=I-1$

END IF

EXIT

END IF

END DO

C Data is between ARRAY(I1) and ARRAY(I2)

$I=\operatorname{MINO}(I 1, I 2)$

$I 2=\operatorname{MAX} 0(I 1, I 2)$

FACT $=$ ARRAY $(I 2)-A R R A Y(I)$

IF ( FACT .NE. 0.0 ) FACT = (DATA-ARRAY(I) ) / FACT

IFIND $=$. TRUE .

END IF

RETURN

END

C LDEVUNQ Obtain a unique logical unit number

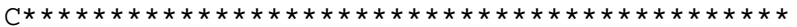

$\mathrm{C} *$

C L D E V U N Q *

C *

$\mathrm{C} * * * * * * * * * * * * * * * *$

INTEGER FUNCTION LDEVUNQ()

$\mathrm{C}$

C 7 Oct 98 initial edit

C

C This routine obtains an unused logical unit number for

C fortran I/O

$\mathrm{C}$

C Output:

C LDEVUNQ Unused logical unit number or zero if none is available

C

IMPLICIT NONE

LOGICAL OPENED

INTEGER L

DO $L=1,1024$

INQUIRE（ UNIT=L， OPENED=OPENED )

IF ( . NOT. OPENED ) THEN

LDEVUNQ $=\mathrm{L}$

RETURN 
END IF

END DO

LDEVUNQ $=0$

RETURN

END 


\section{Appendix B}

\section{GRIZZLY API Checkout Performance Data}

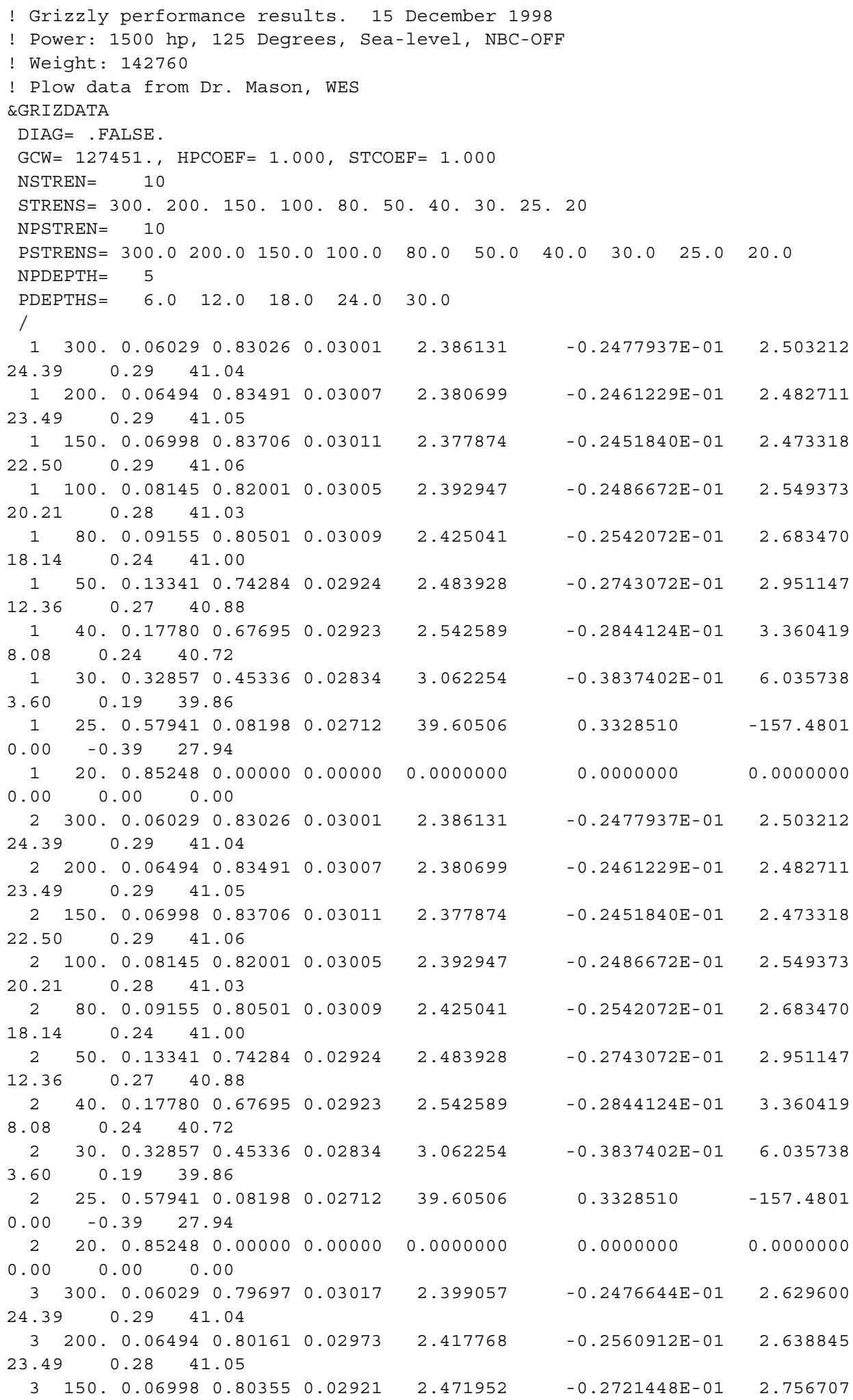




\begin{tabular}{|c|c|c|c|c|c|c|c|}
\hline 22.50 & & 0.22 & 41.06 & & & & \\
\hline 3 & 100 & .0 .08145 & 50.78498 & 0.02922 & 2.449261 & $-0.2677252 \mathrm{E}-01$ & 2.721935 \\
\hline 20.19 & & 0.30 & 41.02 & & & & \\
\hline 3 & 80 & .0 .09155 & 50.76898 & 0.02994 & 2.421088 & $-0.2543395 \mathrm{E}-01$ & 2.741838 \\
\hline 18.12 & & 0.31 & 40.98 & & & & \\
\hline 3 & 50 & .0 .13341 & 10.70576 & 0.02945 & 2.488902 & $-0.2718630 \mathrm{E}-01$ & 3.117707 \\
\hline 12.32 & & 0.28 & 40.83 & & & & \\
\hline 3 & 40 & .0 .17780 & 0.64398 & 0.02934 & 2.556455 & $-0.2848813 E-01$ & 3.550984 \\
\hline 8.05 & & 0.25 & 0.65 & & & & \\
\hline 3 & 30 & .0 .32857 & 70.46965 & 0.02932 & 2.905509 & $-0.3455392 \mathrm{E}-01$ & 5.585680 \\
\hline 3.65 & & 0.18 & 9.90 & & & & \\
\hline 3 & 25 & .0 .57941 & 10.25243 & 0.02778 & 4.740184 & $-0.6354313 E-01$ & 14.37724 \\
\hline 0.00 & & 0.62 & 7.53 & & & & \\
\hline 3 & 20 & . 0.85248 & 30.02218 & 0.00000 & 0.0000000 & 0.0000000 & 0.0000000 \\
\hline 0.00 & & 0.00 & 0.00 & & & & \\
\hline 4 & 300 & .0 .07029 & 90.80697 & 0.03101 & 2.372528 & $-0.2331115 \mathrm{E}-01$ & 2.612162 \\
\hline 22.44 & & 0.25 & 41.06 & & & & \\
\hline 4 & 200 & . 0.07494 & 40.81161 & 0.02929 & 2.440238 & $-0.2652041 E-01$ & 2.654501 \\
\hline 21.52 & & 0.26 & 41.07 & & & & \\
\hline 4 & 150 & .0 .07998 & 30.81355 & 0.02915 & 2.442688 & $-0.2671763 \mathrm{E}-01$ & 2.645511 \\
\hline 20.52 & & 0.26 & 41.08 & & & & \\
\hline 4 & 100 & .0 .09145 & 50.79498 & 0.03010 & 2.402925 & $-0.2491242 \mathrm{E}-01$ & 2.639429 \\
\hline 18.17 & & 0.29 & 41.04 & & & & \\
\hline 4 & 80 & .0 .10155 & 50.77898 & 0.02906 & 2.459738 & $-0.2714995 \mathrm{E}-01$ & 2.752970 \\
\hline 16.06 & & 0.30 & 41.01 & & & & \\
\hline 4 & 50 & .0 .14341 & 10.71576 & 0.02949 & 2.479917 & $-0.2699084 \mathrm{E}-01$ & 3.053029 \\
\hline 11.32 & & 0.29 & 40.86 & & & & \\
\hline 4 & 40 & .0 .18780 & 0.65398 & 0.02947 & 2.540812 & $-0.2807300 \mathrm{E}-01$ & 3.470354 \\
\hline 7.58 & & 0.25 & 0.69 & & & & \\
\hline 4 & 30 & .0 .33857 & 70.47965 & 0.02947 & 2.868214 & $-0.3371206 \mathrm{E}-01$ & 5.432723 \\
\hline 3.57 & & 0.15 & 9.96 & & & & \\
\hline 4 & 25 & .0 .58941 & 10.26243 & 0.02865 & 4.338891 & $-0.5693929 \mathrm{E}-01$ & 12.96852 \\
\hline 0.00 & & 0.62 & 7.72 & & & & \\
\hline 4 & 20 & .0 .86248 & 30.03218 & 0.02873 & 2.328626 & $0.7384897 \mathrm{E}-01$ & -55.87772 \\
\hline 0.00 & & 0.00 & 4. 27 & & & & \\
\hline 5 & 300 & .0 .14500 & 0.60096 & 0.02946 & 2.677331 & $-0.3027066 \mathrm{E}-01$ & 4.050798 \\
\hline 10.99 & & 0.19 & 40.77 & & & & \\
\hline 5 & 200 & .0 .14500 & 0.60096 & 0.02946 & 2.677331 & $-0.3027066 \mathrm{E}-01$ & 4.050798 \\
\hline 10.99 & & 0.19 & 40.77 & & & & \\
\hline 5 & 150 & .0 .14500 & 0.60096 & 0.02946 & 2.677331 & $-0.3027066 \mathrm{E}-01$ & 4.050798 \\
\hline 10.99 & & 0.19 & 40.77 & & & & \\
\hline 5 & 100 & .0 .14500 & 0.60096 & 0.02946 & 2.677331 & $-0.3027066 \mathrm{E}-01$ & 4.050798 \\
\hline 10.99 & & 0.19 & 40.77 & & & & \\
\hline 5 & 80 & .0 .14500 & 0.60096 & 0.02946 & 2.677331 & $-0.3027066 \mathrm{E}-01$ & 4.050798 \\
\hline 10.99 & & 0.19 & 40.77 & & & & \\
\hline 5 & 50 & .0 .14500 & 0.57775 & 0.03009 & 2.672992 & $-0.2945804 \mathrm{E}-01$ & 4.169206 \\
\hline 10.97 & & 0.23 & 40.72 & & & & \\
\hline 5 & 40 & .0 .14500 & 0.55275 & 0.02938 & 2.766574 & $-0.3192579 E-01$ & 4.463585 \\
\hline 10.94 & & 0.27 & 40.66 & & & & \\
\hline 5 & 30 & .0 .14500 & 0.52051 & 0.02937 & 2.823690 & $-0.3289561 \mathrm{E}-01$ & 4.770657 \\
\hline 10.91 & & 0.33 & 40.58 & & & & \\
\hline 5 & 25 & .0 .14500 & 0.50008 & 0.02962 & 2.835485 & $-0.3272779 \mathrm{E}-01$ & 4.957386 \\
\hline 10.88 & & 0.36 & 40.52 & & & & \\
\hline 5 & 20 & 0.14500 & 0.47508 & 0.02939 & 2.963798 & $-0.3495865 E-01$ & 5.619157 \\
\hline 10.84 & & 0.19 & 40.44 & & & & \\
\hline 1 & 300 & .0 .07029 & 90.45195 & 0.02807 & 3.173107 & $-0.3827690 \mathrm{E}-01$ & 6.295038 \\
\hline 22.53 & & 0.18 & 41.53 & & & & \\
\hline 1 & 200 & .0 .07494 & 40.45660 & 0.02814 & 3.151491 & $-0.3782472 \mathrm{E}-01$ & 6.203522 \\
\hline 21.61 & & 0.17 & 41.57 & & & & \\
\hline 1 & 150 & 0.07998 & B 0.46164 & 0.02822 & 3.128604 & $-0.3734361 \mathrm{E}-01$ & 6.106895 \\
\hline 20.61 & & 0.16 & 41.61 & & & & \\
\hline 1 & 100 & .0 .09145 & 50.47311 & 0.02911 & 3.009674 & $-0.3430128 E-01$ & 5.766220 \\
\hline 18.29 & & 0.17 & 41.70 & & & & \\
\hline 1 & 80 & .0 .10155 & 50.48321 & 0.02953 & 2.928677 & $-0.3245092 \mathrm{E}-01$ & 5.477236 \\
\hline 16.19 & & 0.20 & 41.77 & & & & \\
\hline
\end{tabular}




\begin{tabular}{|c|c|c|c|c|c|c|c|}
\hline 1 & 50 & .0 .14341 & 10.52507 & 0.02932 & 2.845013 & $-0.3137165 E-01$ & 4.829613 \\
\hline 11.50 & & 0.28 & 42.05 & & & & \\
\hline 1 & 40 & .0 .18780 & 0.56945 & 0.02894 & 2.812172 & $-0.3118804 \mathrm{E}-01$ & 4.466991 \\
\hline 7.79 & & 0.21 & 2.30 & & & & \\
\hline 1 & 30. & .0 .33857 & 70.46336 & 0.02825 & 3.120885 & $-0.3718080 \mathrm{E}-01$ & 6.074362 \\
\hline 3.51 & & 0.16 & 1.62 & & & & \\
\hline 1 & 25 & .0 .58941 & 10.09198 & 0.02722 & 3610.466 & -2.808330 & 1245.116 \\
\hline 0.00 & & 0.26 & 3.17 & & & & \\
\hline 1 & 20 & .0 .86248 & 30.00000 & 0.00000 & 0.0000000 & 0.0000000 & 0.0000000 \\
\hline 0.00 & & 0.00 & 0.00 & & & & \\
\hline 2 & 300. & .0 .07029 & 90.38582 & 0.02805 & 3.462378 & $-0.4191734 \mathrm{E}-01$ & 7.806674 \\
\hline 22.52 & & 0.29 & 41.68 & & & & \\
\hline 2 & 200 & .0 .07494 & 40.39046 & 0.02805 & 3.438879 & $-0.4156519 E-01$ & 7.666971 \\
\hline 21.60 & & 0.29 & 41.73 & & & & \\
\hline 2 & 150 & .0 .07998 & 30.39551 & 0.02809 & 3.411464 & $-0.4109797 \mathrm{E}-01$ & 7.520333 \\
\hline 20.60 & & 0.29 & 41.79 & & & & \\
\hline 2 & 100 & .0 .09145 & 50.40698 & 0.02826 & 3.345922 & $-0.3986068 E-01$ & 7.204072 \\
\hline 18.27 & & 0.28 & 41.91 & & & & \\
\hline 2 & 80 & .0 .10155 & 50.41708 & 0.02846 & 3.287926 & $-0.3869227 E-01$ & 6.944306 \\
\hline 16.18 & & 0.27 & 42.02 & & & & \\
\hline 2 & 50 & .0 .14341 & 10.45894 & 0.02806 & 3.204469 & $-0.3776080 \mathrm{E}-01$ & 6.285129 \\
\hline 11.49 & & 0.17 & 42.40 & & & & \\
\hline 2 & 40 & . 0.18780 & 0.50332 & 0.02965 & 2.898017 & $-0.3089056 E-01$ & 5.124012 \\
\hline 7.78 & & 0.30 & 2.74 & & & & \\
\hline 2 & 30 & .0 .33857 & 70.46336 & 0.02812 & 3.184410 & $-0.3734549 E-01$ & 6.199853 \\
\hline 3.56 & & 0.16 & 2.44 & & & & \\
\hline 2 & 25 & .0 .58941 & 10.09198 & 0.02730 & 1552.599 & -1.811058 & 816.1611 \\
\hline 0.00 & & 0.31 & 3.40 & & & & \\
\hline 2 & 20 & .0 .86248 & 30.00000 & 0.00000 & 0.0000000 & 0.0000000 & 0.0000000 \\
\hline 0.00 & & 0.00 & 0.00 & & & & \\
\hline 3 & 300 & .0 .07029 & 90.50667 & 0.02979 & 2.826057 & $-0.3119942 \mathrm{E}-01$ & 4.927472 \\
\hline 22.55 & & 0.33 & 41.41 & & & & \\
\hline 3 & 200 & .0 .07494 & 40.51132 & 0.02899 & 2.884531 & $-0.3315166 \mathrm{E}-01$ & 4.985970 \\
\hline 21.63 & & 0.31 & 41.43 & & & & \\
\hline 3 & 150 & .0 .07998 & 30.51636 & 0.02912 & 2.865999 & $-0.3268946 E-01$ & 4.910909 \\
\hline 20.62 & & 0.31 & 41.46 & & & & \\
\hline 3 & 100 & .0 .09145 & 50.52784 & 0.02946 & 2.822073 & $-0.3155185 E-01$ & 4.746768 \\
\hline 18.30 & & 0.30 & 41.51 & & & & \\
\hline 3 & 80 & .0 .10155 & 50.53793 & 0.02977 & 2.782979 & $-0.3051055 E-01$ & 4.609594 \\
\hline 16.20 & & 0.29 & 41.56 & & & & \\
\hline 3 & 50 & .0 .14341 & 10.57979 & 0.02991 & 2.712021 & $-0.2909783 E-01$ & 4.233890 \\
\hline 11.51 & & 0.22 & 41.73 & & & & \\
\hline 3 & 40 & .0 .18780 & 0.62418 & 0.02940 & 2.675860 & $-0.2902573 E-01$ & 3.918372 \\
\hline 7.79 & & 0.18 & 1.88 & & & & \\
\hline 3 & 30 & .0 .33857 & 70.47965 & 0.02927 & 2.977709 & $-0.3422661 E-01$ & 5.633093 \\
\hline 3.71 & & 0.16 & 1.27 & & & & \\
\hline 3 & 25 & .0 .58941 & 10.26243 & 0.02846 & 4.541886 & $-0.5792575 E-01$ & 13.52588 \\
\hline 0.00 & $c$ & 0.65 & 9.05 & & & & \\
\hline 3 & 20 & 0.86248 & 30.03218 & 0.02872 & 2.139589 & $0.7058474 \mathrm{E}-01$ & -55.70502 \\
\hline 0.00 & & 0.00 & 4.59 & & & & \\
\hline 4 & 300 & .0 .08329 & 90.55450 & 0.02818 & 2.852068 & $-0.3361849 E-01$ & 4.627240 \\
\hline 19.97 & & 0.22 & 41.53 & & & & \\
\hline 4 & 200 & . 0.08794 & 40.55915 & 0.02828 & 2.837002 & $-0.3322966 \mathrm{E}-01$ & 4.572036 \\
\hline 19.03 & & 0.22 & 41.55 & & & & \\
\hline 4 & 150 & .0 .09298 & 30.56419 & 0.02893 & 2.780569 & $-0.3148460 \mathrm{E}-01$ & 4.448465 \\
\hline 17.99 & & 0.22 & 41.58 & & & & \\
\hline 4 & 100 & .0 .10445 & 50.57567 & 0.02978 & 2.702935 & $-0.2912363 \mathrm{E}-01$ & 4.254528 \\
\hline 14.82 & & 0.21 & 41.63 & & & & \\
\hline 4 & 80 & .0 .11455 & 50.58576 & 0.03005 & 2.671063 & $-0.2824027 E-01$ & 4.146077 \\
\hline 14.03 & & 0.20 & 41.68 & & & & \\
\hline 4 & 50 & .0 .15641 & 10.62763 & 0.02911 & 2.665629 & $-0.2917025 E-01$ & 3.871513 \\
\hline 9.33 & & 0.19 & 1.86 & & & & \\
\hline 4 & 40 & .0 .20080 & 0.66698 & 0.03038 & 2.539699 & $-0.2552110 \mathrm{E}-01$ & 3.414149 \\
\hline 7.18 & & 0.25 & 2.02 & & & & \\
\hline 4 & 30 & .0 .35157 & 70.49265 & 0.02944 & 2.852153 & $-0.3212024 E-01$ & 5.164587 \\
\hline
\end{tabular}




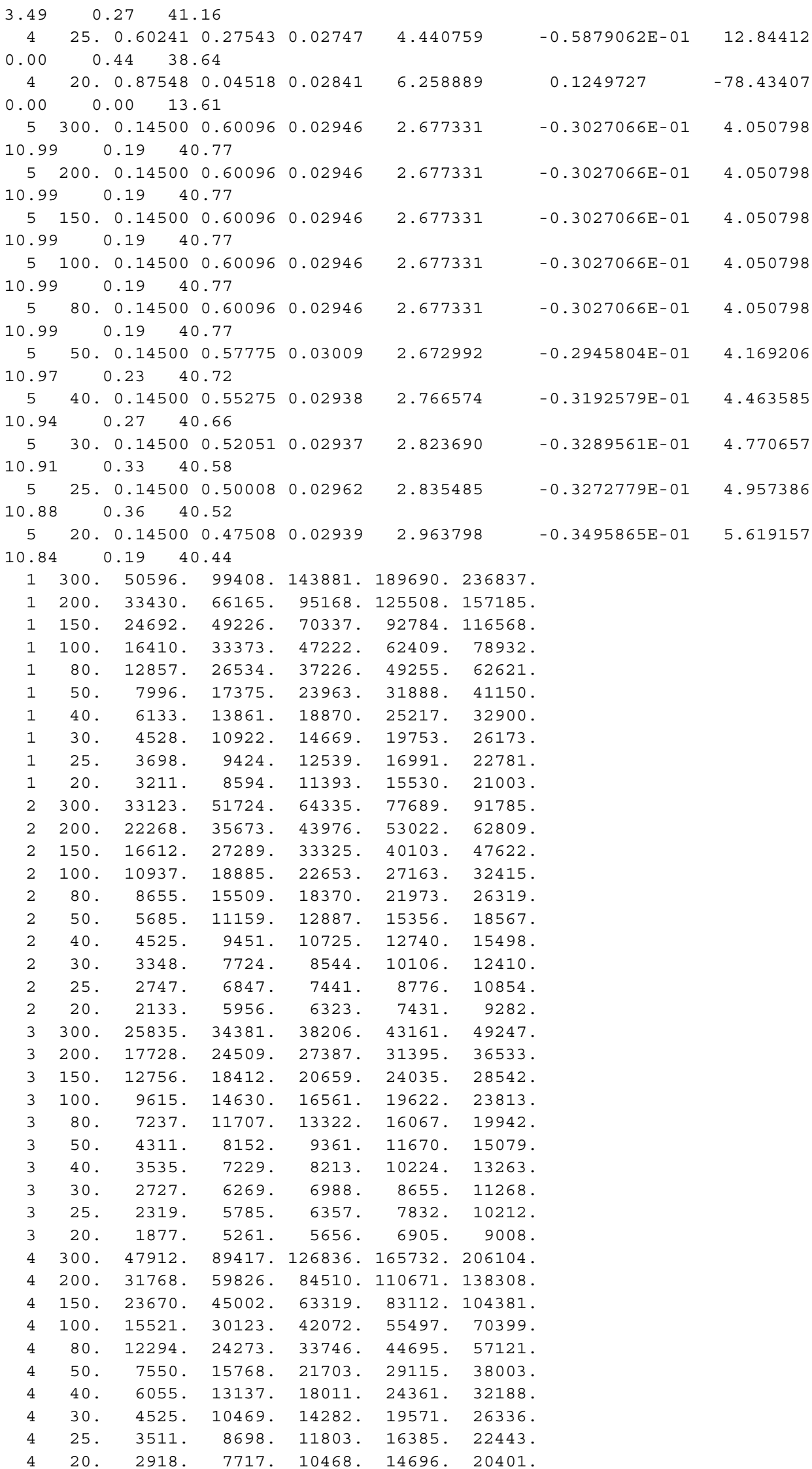




$\begin{array}{rrrrrr}300 . & 44901 . & 78946 . & 108850 . & 140477 . & 173829 . \\ 200 . & 29727 . & 52954 . & 72866 . & 94503 . & 117863 . \\ 150 . & 22112 . & 39929 . & 54845 . & 71486 . & 89850 . \\ 100 . & 14444 . & 26844 . & 36765 . & 48410 . & 61779 . \\ 80 . & 11428 . & 21738 . & 29738 . & 39461 . & 50909 . \\ 50 . & 7054 . & 14424 . & 19733 . & 26767 . & 35524 . \\ 40 . & 5724 . & 12246 . & 16787 . & 23052 . & 31041 . \\ 30 . & 4370 . & 10042 . & 13815 . & 19311 . & 26532 . \\ 25 . & 3677 . & 8923 . & 12311 . & 17423 . & 24260 . \\ 20 . & 2962 . & 7781 . & 10785 . & 15513 . & 21965 .\end{array}$




\section{Appendix C Real-Time Mobility DATA File for SAF}

GRIZZLY API Checkout Performance Data

! Grizzly performance results. 15 December 1998

! Power: 1500 hp, 125 Degrees, Sea-level, NBC-OFF

! Weight: 142760

! Plow data from Dr. Mason, WES

\&GRIZDATA

$\mathrm{DIAG}=$. FALSE.

$\mathrm{GCW}=127451 ., \mathrm{HPCOEF}=1.000, \mathrm{STCOEF}=1.000$

NSTREN $=10$

STRENS $=300.200 .150 .100 .80 .50 .40 .30 .25 .20$

NPSTREN $=10$

PSTRENS $=300.0200 .0 \quad 150.0100 .0 \quad 80.0 \quad 50.0 \quad 40.0 \quad 30.0 \quad 25.0 \quad 20.0$

$\mathrm{NPDEPTH}=5$

$\mathrm{PDEPTHS}=6.0 \quad 12.0 \quad 18.0 \quad 24.0 \quad 30.0$

I

1300.0 .060290 .830260 .030012 .386131

1 200. 0.064940 .834910 .030072 .380699

1 150. 0.069980 .837060 .030112 .377874

1 100. 0.081450 .820010 .030052 .392947

180.0 .091550 .805010 .030092 .425041

1 50. 0.133410 .742840 .029242 .483928

1 40. $0.177800 .676950 .02923 \quad 2.542589$

$130.0 .328570 .453360 .02834 \quad 3.062254$

1 25. $0.579410 .081980 .02712 \quad 39.60506$

1 20. $0.852480 .000000 .00000 \quad 0.0000000$

2 300. $0.060290 .830260 .03001 \quad 2.386131$

2 200. $0.064940 .834910 .03007 \quad 2.380699$

2 150. 0.069980 .837060 .030112 .377874

2 100. $0.081450 .820010 .03005 \quad 2.392947$

2 80. 0.091550 .805010 .030092 .425041

2 50. 0.133410 .742840 .029242 .483928

2 40. $0.177800 .676950 .02923 \quad 2.542589$

2 30. $0.328570 .453360 .02834 \quad 3.062254$

2 25. $0.579410 .081980 .02712 \quad 39.60506$

2 20. 0.852480 .000000 .000000 .0000000

3 300. $0.060290 .796970 .03017 \quad 2.399057$

3 200. 0.064940 .801610 .029732 .417768

$\begin{array}{llll}3 & 150.0 .06998 & 0.803550 .02921 & 2.471952\end{array}$

$\begin{array}{llll}3 & 100.0 .081450 .784980 .02922 & 2.449261\end{array}$

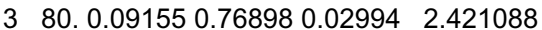

$\begin{array}{lllccc}-0.2477937 \mathrm{E}-01 & 2.503212 & 24.39 & 0.29 & 41.04 \\ -0.2461229 \mathrm{E}-01 & 2.482711 & 23.49 & 0.29 & 41.05 \\ -0.2451840 \mathrm{E}-01 & 2.473318 & 22.50 & 0.29 & 41.06 \\ -0.2486672 \mathrm{E}-01 & 2.549373 & 20.21 & 0.28 & 41.03 \\ -0.2542072 \mathrm{E}-01 & 2.683470 & 18.14 & 0.24 & 41.00 \\ -0.2743072 \mathrm{E}-01 & 2.951147 & 12.36 & 0.27 & 40.88 \\ -0.2844124 \mathrm{E}-01 & 3.360419 & 8.08 & 0.24 & 40.72 \\ -0.3837402 \mathrm{E}-01 & 6.035738 & 3.60 & 0.19 & 39.86 \\ 0.3328510 & -157.4801 & 0.00 & -0.39 & 27.94 \\ 0.0000000 & 0.0000000 & 0.00 & 0.00 & 0.00 \\ -0.2477937 \mathrm{E}-01 & 2.503212 & 24.39 & 0.29 & 41.04 \\ -0.2461229 \mathrm{E}-01 & 2.482711 & 23.49 & 0.29 & 41.05 \\ -0.2451840 \mathrm{E}-01 & 2.473318 & 22.50 & 0.29 & 41.06 \\ -0.2486672 \mathrm{E}-01 & 2.549373 & 20.21 & 0.28 & 41.03 \\ -0.2542072 \mathrm{E}-01 & 2.683470 & 18.14 & 0.24 & 41.00 \\ -0.2743072 \mathrm{E}-01 & 2.951147 & 12.36 & 0.27 & 40.88 \\ -0.2844124 \mathrm{E}-01 & 3.360419 & 8.08 & 0.24 & 40.72 \\ -0.3837402 \mathrm{E}-01 & 6.035738 & 3.60 & 0.19 & 39.86 \\ 0.3328510 & -157.4801 & 0.00 & -0.39 & 27.94 \\ 0.0000000 & 0.0000000 & 0.00 & 0.00 & 0.00 \\ -0.2476644 \mathrm{E}-01 & 2.629600 & 24.39 & 0.29 & 41.04 \\ -0.2560912 \mathrm{E}-01 & 2.638845 & 23.49 & 0.28 & 41.05 \\ -0.2721448 \mathrm{E}-01 & 2.756707 & 22.50 & 0.22 & 41.06 \\ -0.2677252 \mathrm{E}-01 & 2.721935 & 20.19 & 0.30 & 41.02 \\ -0.2543395 \mathrm{E}-01 & 2.741838 & 18.12 & 0.31 & 40.98\end{array}$


3 50. $0.133410 .705760 .02945 \quad 2.488902$

3 40. $0.177800 .643980 .02934 \quad 2.556455$

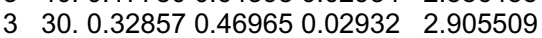

3 25. $0.579410 .252430 .02778 \quad 4.740184$

3 20. $0.852480 .022180 .00000 \quad 0.0000000$

4 300. $0.070290 .806970 .03101 \quad 2.372528$

4 200. 0.074940 .811610 .029292 .440238

4 150. 0.079980 .813550 .029152 .442688

4 100. 0.091450 .794980 .030102 .402925

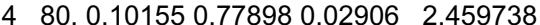

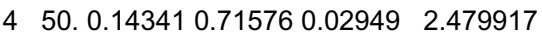

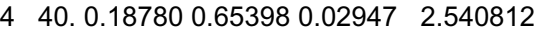

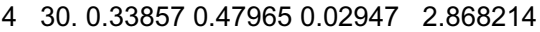

4 25. $0.589410 .262430 .02865 \quad 4.338891$

4 20. $0.862480 .032180 .02873 \quad 2.328626$

5 300. $0.145000 .600960 .02946 \quad 2.677331$

5 200. 0.145000 .600960 .029462 .677331

5 150. 0.145000 .600960 .029462 .677331

5 100. $0.145000 .600960 .02946 \quad 2.677331$

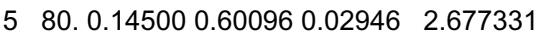

$\begin{array}{llll}5 & 50.0 .14500 & 0.577750 .03009 & 2.672992\end{array}$

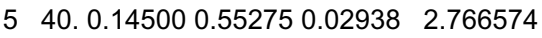

5 30. $0.145000 .520510 .02937 \quad 2.823690$

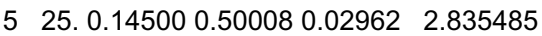

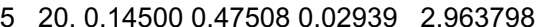

1 300. $0.070290 .451950 .02807 \quad 3.173107$

1 200. $0.074940 .456600 .02814 \quad 3.151491$

1 150. $0.079980 .461640 .02822 \quad 3.128604$

1 100. 0.091450 .473110 .029113 .009674

$\begin{array}{llll}1 & 80.0 .101550 .48321 & 0.02953 & 2.928677\end{array}$

$150.0 .143410 .525070 .02932 \quad 2.845013$

1 40. 0.187800 .569450 .028942 .812172

$130.0 .338570 .463360 .02825 \quad 3.120885$

1 25. $0.589410 .091980 .02722 \quad 3610.466$

1 20. $0.862480 .000000 .00000 \quad 0.0000000$

2 300. $0.070290 .385820 .02805 \quad 3.462378$

2 200. $0.074940 .390460 .02805 \quad 3.438879$

2 150. 0.079980 .395510 .028093 .411464

2 100. $0.091450 .406980 .02826 \quad 3.345922$

2 80. $0.101550 .417080 .02846 \quad 3.287926$

2 50. $0.143410 .458940 .02806 \quad 3.204469$

2 40. 0.187800 .503320 .029652 .898017

2 30. $0.338570 .463360 .02812 \quad 3.184410$

2 25. $0.589410 .091980 .02730 \quad 1552.599$

2 20. $0.862480 .000000 .00000 \quad 0.0000000$

3 300. 0.070290 .506670 .029792 .826057

$\begin{array}{llllll}3 & 200 & 0.07494 & 0.51132 & 0.02899 & 2.884531\end{array}$

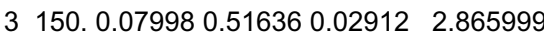

$\begin{array}{lll}3 & 100.0 .091450 .527840 .02946 & 2.822073\end{array}$

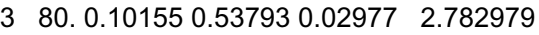

$\begin{array}{lllll}3 & 50.0 .14341 & 0.57979 & 0.02991 & 2.712021\end{array}$

3 40. $0.187800 .624180 .02940 \quad 2.675860$

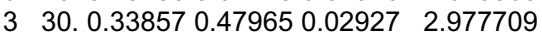

3 25. $0.589410 .262430 .02846 \quad 4.541886$

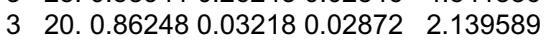

4 300. 0.083290 .554500 .028182 .852068

4 200. 0.087940 .559150 .028282 .837002

4 150. 0.092980 .564190 .028932 .780569

4 100. 0.104450 .575670 .029782 .702935

$\begin{array}{llll}4 & 80.0 .114550 .58576 & 0.03005 & 2.671063\end{array}$

4 50. 0.156410 .627630 .029112 .665629

$\begin{array}{lllll}4 & 40.0 .20080 & 0.66698 & 0.03038 & 2.539699\end{array}$

4 30. 0.351570 .492650 .029442 .852153

4 25. $0.602410 .275430 .02747 \quad 4.440759$

4 20. $0.875480 .045180 .02841 \quad 6.258889$

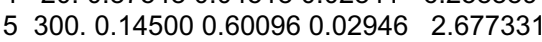

5 200. 0.145000 .600960 .029462 .677331

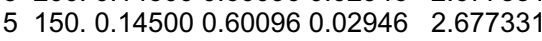

5 100. $0.145000 .600960 .02946 \quad 2.677331$

5 80. $0.145000 .600960 .02946 \quad 2.677331$

$\begin{array}{llll}5 & 50.0 .14500 & 0.577750 .03009 & 2.672992\end{array}$
$-0.2718630 \mathrm{E}-01 \quad 3.117707$ $-0.2848813 E-013.550984$ $-0.3455392 \mathrm{E}-01 \quad 5.585680$ $-0.6354313 E-01 \quad 14.37724$ $0.0000000 \quad 0.0000000$ $-0.2331115 \mathrm{E}-012.612162$ $-0.2652041 \mathrm{E}-01 \quad 2.654501$ $-0.2671763 \mathrm{E}-01 \quad 2.645511$ $-0.2491242 \mathrm{E}-012.639429$ $-0.2714995 \mathrm{E}-01 \quad 2.752970$ $-0.2699084 \mathrm{E}-01 \quad 3.053029$ $-0.2807300 \mathrm{E}-013.470354$ $-0.3371206 \mathrm{E}-01 \quad 5.432723$ $-0.5693929 E-01 \quad 12.96852$ $0.7384897 E-01-55.87772$ $-0.3027066 \mathrm{E}-01 \quad 4.050798$ $-0.3027066 \mathrm{E}-014.050798$ $-0.3027066 \mathrm{E}-01 \quad 4.050798$ $-0.3027066 \mathrm{E}-01 \quad 4.050798$ $-0.3027066 \mathrm{E}-01 \quad 4.050798$ $-0.2945804 \mathrm{E}-01 \quad 4.169206$ $-0.3192579 \mathrm{E}-01 \quad 4.463585$ $-0.3289561 E-01 \quad 4.770657$ $-0.3272779 \mathrm{E}-01 \quad 4.957386$ $-0.3495865 \mathrm{E}-01 \quad 5.619157$ $-0.3827690 \mathrm{E}-01 \quad 6.295038$ $-0.3782472 \mathrm{E}-01 \quad 6.203522$ $-0.3734361 \mathrm{E}-01 \quad 6.106895$ $-0.3430128 \mathrm{E}-01 \quad 5.766220$ $-0.3245092 \mathrm{E}-01 \quad 5.477236$ $-0.3137165 \mathrm{E}-01 \quad 4.829613$ $-0.3118804 \mathrm{E}-01 \quad 4.466991$ $-0.3718080 \mathrm{E}-01 \quad 6.074362$ $-2.808330 \quad 1245.116$ $0.0000000 \quad 0.0000000$ $-0.4191734 \mathrm{E}-01 \quad 7.806674$ $-0.4156519 \mathrm{E}-01 \quad 7.666971$ $-0.4109797 \mathrm{E}-01 \quad 7.520333$ $-0.3986068 \mathrm{E}-01 \quad 7.204072$ $-0.3869227 E-01 \quad 6.944306$ $-0.3776080 \mathrm{E}-01 \quad 6.285129$ $-0.3089056 \mathrm{E}-01 \quad 5.124012$ $-0.3734549 E-01 \quad 6.199853$ $-1.811058 \quad 816.1611$ $0.0000000 \quad 0.0000000$ $-0.3119942 \mathrm{E}-01 \quad 4.927472$ $-0.3315166 \mathrm{E}-01 \quad 4.985970$ $-0.3268946 \mathrm{E}-01 \quad 4.910909$ $-0.3155185 \mathrm{E}-01 \quad 4.746768$ $-0.3051055 E-01 \quad 4.609594$ $-0.2909783 E-01 \quad 4.233890$ $-0.2902573 E-01 \quad 3.918372$ $-0.3422661 \mathrm{E}-01 \quad 5.633093$ $-0.5792575 \mathrm{E}-01 \quad 13.52588$ $0.7058474 \mathrm{E}-01-55.70502$ $-0.3361849 \mathrm{E}-01 \quad 4.627240$ $-0.3322966 \mathrm{E}-01 \quad 4.572036$ $-0.3148460 \mathrm{E}-01 \quad 4.448465$ $-0.2912363 E-01 \quad 4.254528$ $-0.2824027 \mathrm{E}-01 \quad 4.146077$ $-0.2917025 \mathrm{E}-01 \quad 3.871513$ $-0.2552110 \mathrm{E}-01 \quad 3.414149$ $-0.3212024 \mathrm{E}-01 \quad 5.164587$ $-0.5879062 \mathrm{E}-0112.84412$ $0.1249727 \quad-78.43407$ $-0.3027066 \mathrm{E}-01 \quad 4.050798$ $-0.3027066 \mathrm{E}-014.050798$ $-0.3027066 \mathrm{E}-01 \quad 4.050798$ $-0.3027066 \mathrm{E}-01 \quad 4.050798$ $-0.3027066 \mathrm{E}-01 \quad 4.050798$ $-0.2945804 \mathrm{E}-01 \quad 4.169206$ $\begin{array}{lll}12.32 & 0.28 & 40.83\end{array}$

$\begin{array}{lll}8.05 & 0.25 & 40.65\end{array}$

$\begin{array}{lll}3.65 & 0.18 & 39.90\end{array}$

$\begin{array}{lll}0.00 & 0.62 & 37.53\end{array}$

$\begin{array}{lll}0.00 & 0.00 & 0.00\end{array}$

$\begin{array}{lll}22.44 & 0.25 & 41.06\end{array}$

$\begin{array}{lll}21.52 & 0.26 & 41.07\end{array}$

$\begin{array}{lll}20.52 & 0.26 & 41.08\end{array}$

$\begin{array}{lll}18.17 & 0.29 & 41.04\end{array}$

$\begin{array}{lll}16.06 & 0.30 & 41.01\end{array}$

$\begin{array}{lll}11.32 & 0.29 & 40.86\end{array}$

$\begin{array}{llll}7.58 & 0.25 & 40.69\end{array}$

$\begin{array}{lll}3.57 & 0.15 & 39.96\end{array}$

$\begin{array}{lll}0.00 & 0.62 & 37.72\end{array}$

$\begin{array}{lll}0.00 & 0.00 & 4.27\end{array}$

$\begin{array}{lll}10.99 & 0.19 & 40.77\end{array}$

$\begin{array}{lll}10.99 & 0.19 & 40.77\end{array}$

$\begin{array}{lll}10.99 & 0.19 & 40.77\end{array}$

$\begin{array}{lll}10.99 & 0.19 & 40.77\end{array}$

$\begin{array}{lll}10.99 & 0.19 & 40.77\end{array}$

$\begin{array}{lll}10.97 & 0.23 & 40.72\end{array}$

$\begin{array}{lll}10.94 & 0.27 & 40.66\end{array}$

$\begin{array}{lll}10.91 & 0.33 & 40.58\end{array}$

$\begin{array}{lll}10.88 & 0.36 & 40.52\end{array}$

$\begin{array}{lll}10.84 & 0.19 & 40.44\end{array}$

$\begin{array}{llll}22.53 & 0.18 & 41.53\end{array}$

$\begin{array}{lll}21.61 & 0.17 & 41.57\end{array}$

$\begin{array}{llll}20.61 & 0.16 & 41.61\end{array}$

$\begin{array}{lll}18.29 & 0.17 & 41.70\end{array}$

$\begin{array}{lll}16.19 & 0.20 & 41.77\end{array}$

$\begin{array}{lll}11.50 & 0.28 & 42.05\end{array}$

$\begin{array}{llll}7.79 & 0.21 & 42.30\end{array}$

$\begin{array}{lll}3.51 & 0.16 \quad 41.62\end{array}$

$\begin{array}{lll}0.00 & -0.26 & 28.17\end{array}$

$\begin{array}{lll}0.00 & 0.00 & 0.00\end{array}$

$\begin{array}{lll}22.52 & 0.29 & 41.68\end{array}$

$\begin{array}{lll}21.60 & 0.29 & 41.73\end{array}$

$\begin{array}{lll}20.60 & 0.29 & 41.79\end{array}$

$\begin{array}{lll}18.27 & 0.28 & 41.91\end{array}$

$\begin{array}{lll}16.18 & 0.27 & 42.02\end{array}$

$\begin{array}{lll}11.49 & 0.17 & 42.40\end{array}$

$\begin{array}{lll}7.78 & 0.30 & 42.74\end{array}$

$\begin{array}{lll}3.56 & 0.16 & 42.44\end{array}$

$\begin{array}{llll}0.00 & -0.31 & 28.40\end{array}$

$\begin{array}{lll}0.00 & 0.00 & 0.00\end{array}$

$\begin{array}{lll}22.55 & 0.33 & 41.41\end{array}$

$\begin{array}{llll}21.63 & 0.31 & 41.43\end{array}$

$\begin{array}{llll}20.62 & 0.31 & 41.46\end{array}$

$\begin{array}{lll}18.30 & 0.30 & 41.51\end{array}$

$\begin{array}{lll}16.20 & 0.29 & 41.56\end{array}$

$\begin{array}{lll}11.51 & 0.22 & 41.73\end{array}$

$\begin{array}{lll}7.79 & 0.18 & 41.88\end{array}$

$\begin{array}{lll}3.71 & 0.16 & 41.27\end{array}$

$\begin{array}{lll}0.00 & 0.65 & 39.05\end{array}$

$\begin{array}{lll}0.00 & 0.00 & 4.59\end{array}$

$\begin{array}{lll}19.97 & 0.22 & 41.53\end{array}$

$\begin{array}{lll}19.03 & 0.22 & 41.55\end{array}$

$\begin{array}{lll}17.99 & 0.22 & 41.58\end{array}$

$\begin{array}{lll}14.82 & 0.21 & 41.63\end{array}$

$\begin{array}{lll}14.03 & 0.20 & 41.68\end{array}$

$\begin{array}{lll}9.33 & 0.19 & 41.86\end{array}$

$\begin{array}{llll}7.18 & 0.25 & 42.02\end{array}$

$\begin{array}{lll}3.49 & 0.27 & 41.16\end{array}$

$\begin{array}{lll}0.00 & 0.44 & 38.64\end{array}$

$\begin{array}{lll}0.00 & 0.00 & 13.61\end{array}$

$\begin{array}{lll}10.99 & 0.19 & 40.77\end{array}$

$\begin{array}{lll}10.99 & 0.19 & 40.77\end{array}$

$\begin{array}{lll}10.99 & 0.19 & 40.77\end{array}$

$\begin{array}{lll}10.99 & 0.19 & 40.77\end{array}$

$\begin{array}{lll}10.99 & 0.19 & 40.77\end{array}$

$\begin{array}{lll}10.97 & 0.23 & 40.72\end{array}$ 


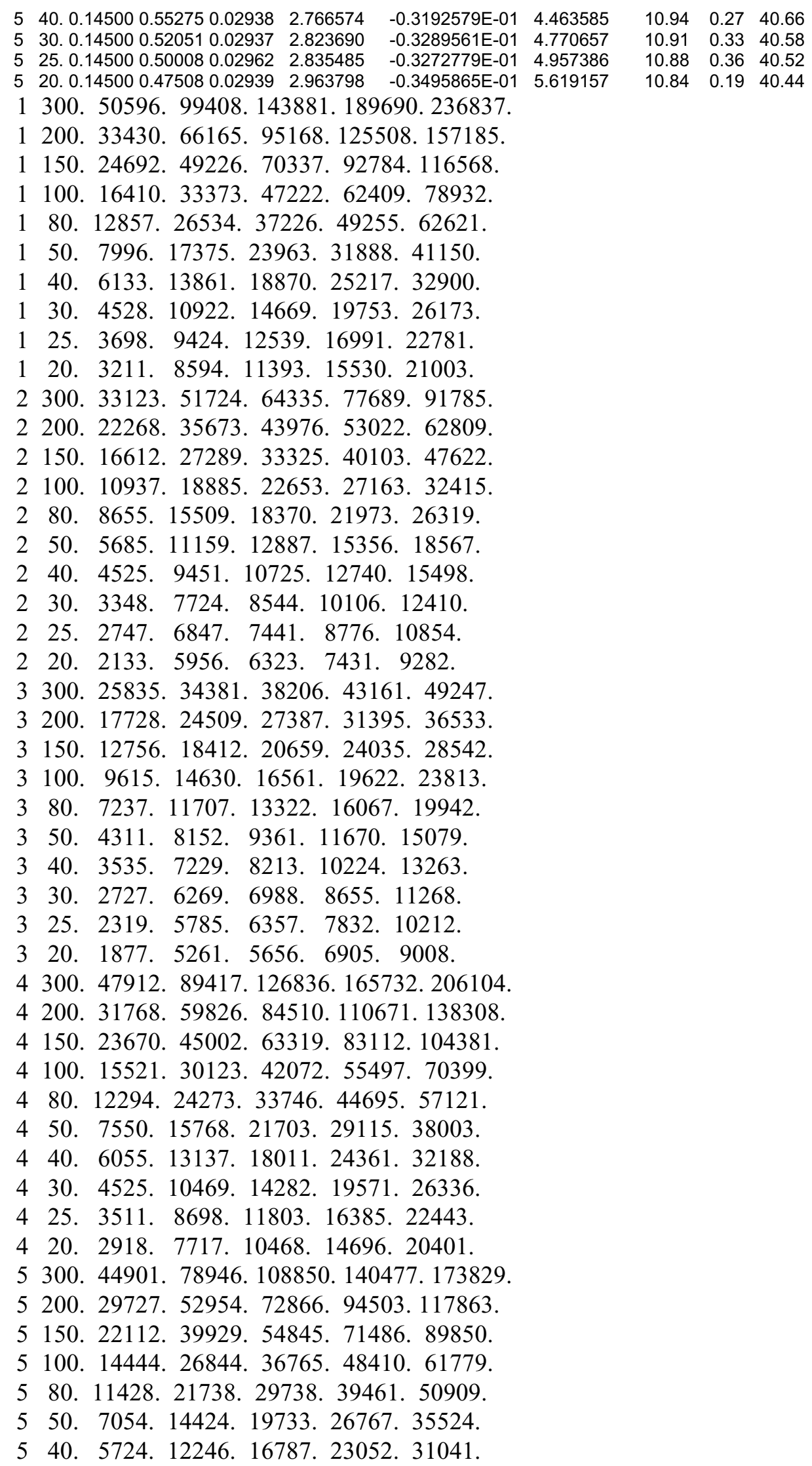


5 30. 4370. 10042. 13815. 19311. 26532.

5 25. 3677. 8923. 12311. 17423. 24260.

5 20. 2962. 7781. 10785. 15513. 21965. 


\section{Appendix D Laboratory Data}




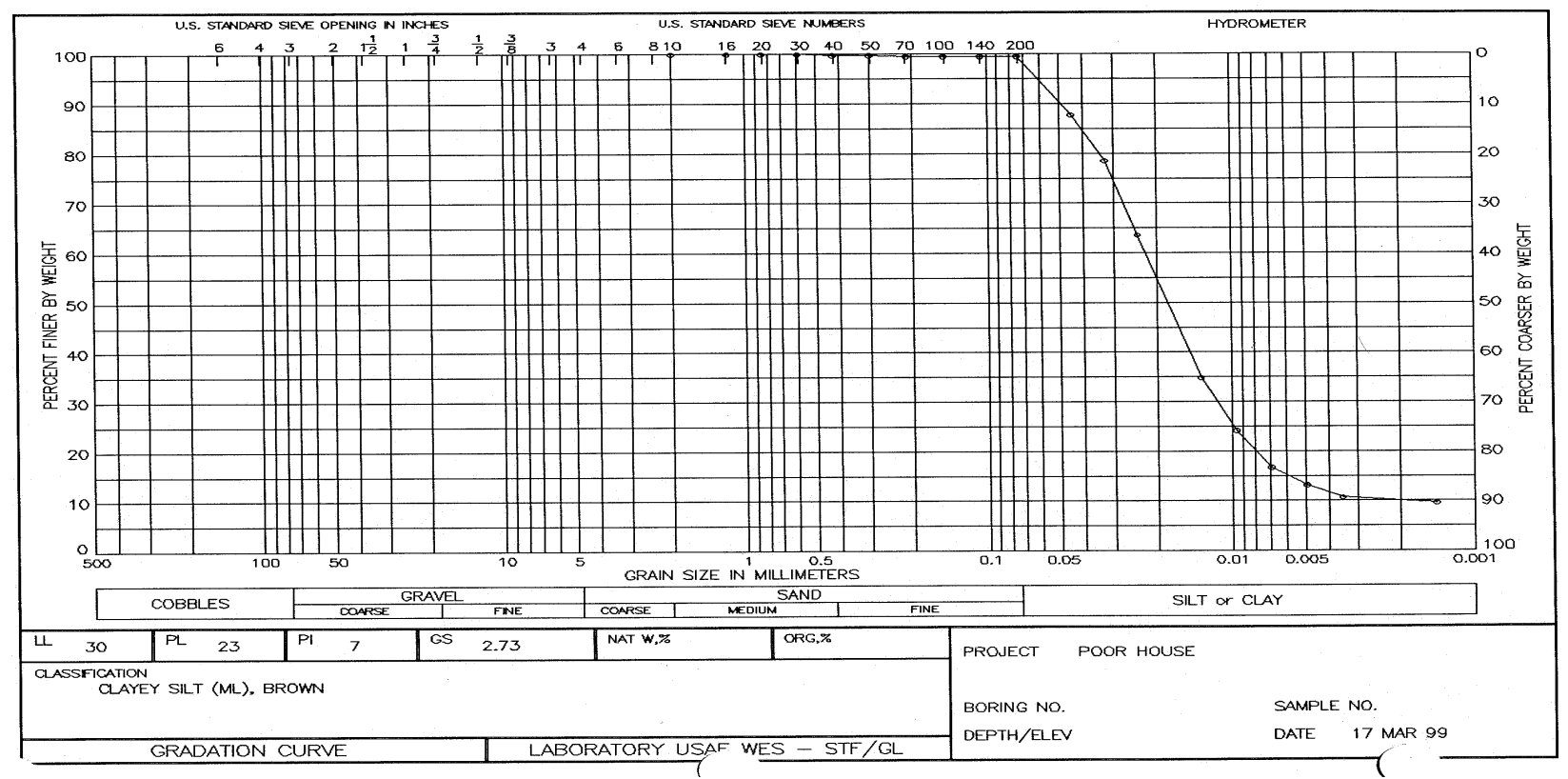

Figure D1. Gradation curves for Poor House property

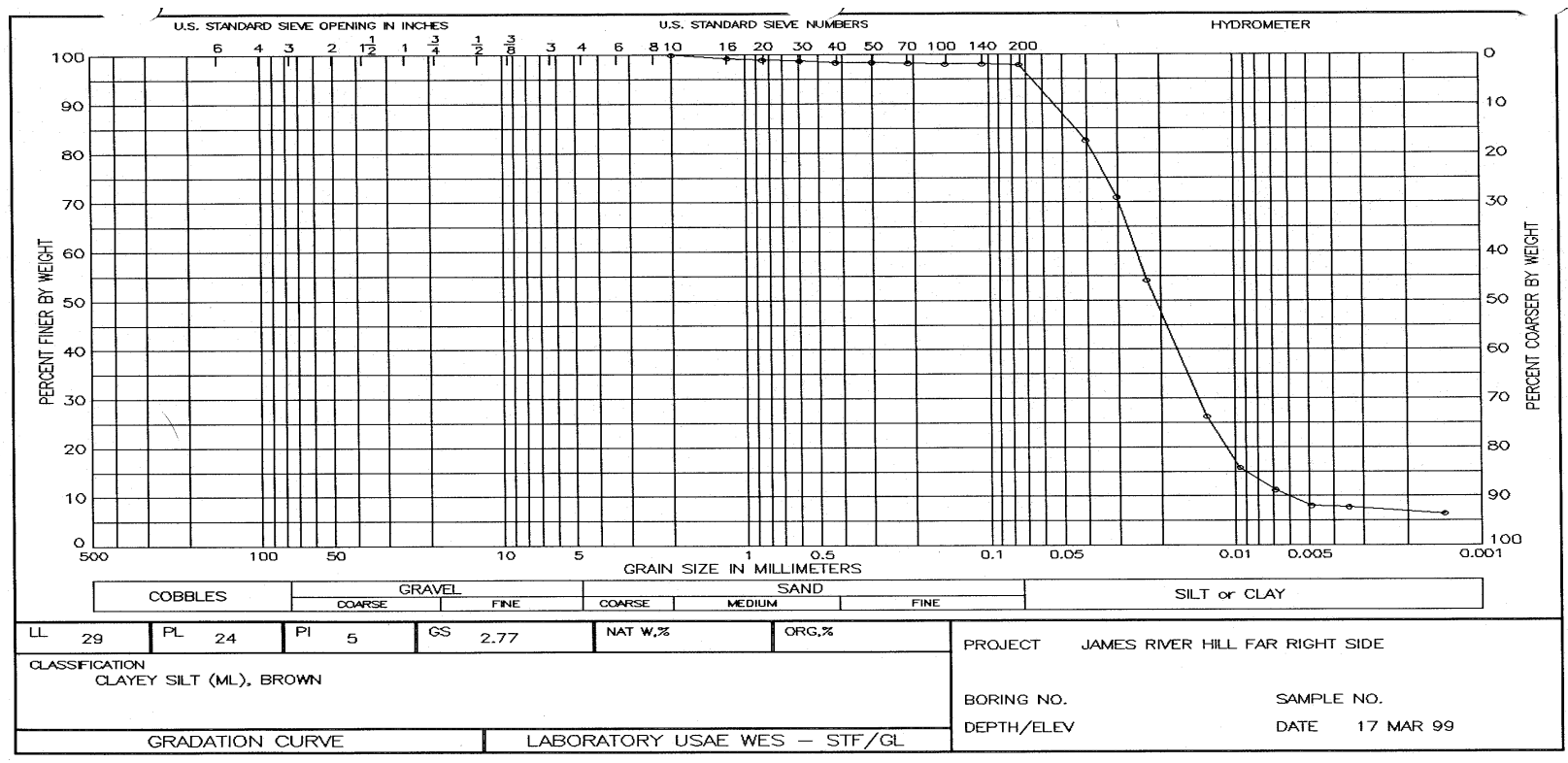

Figure D2. Gradation curve for Richards Hill 


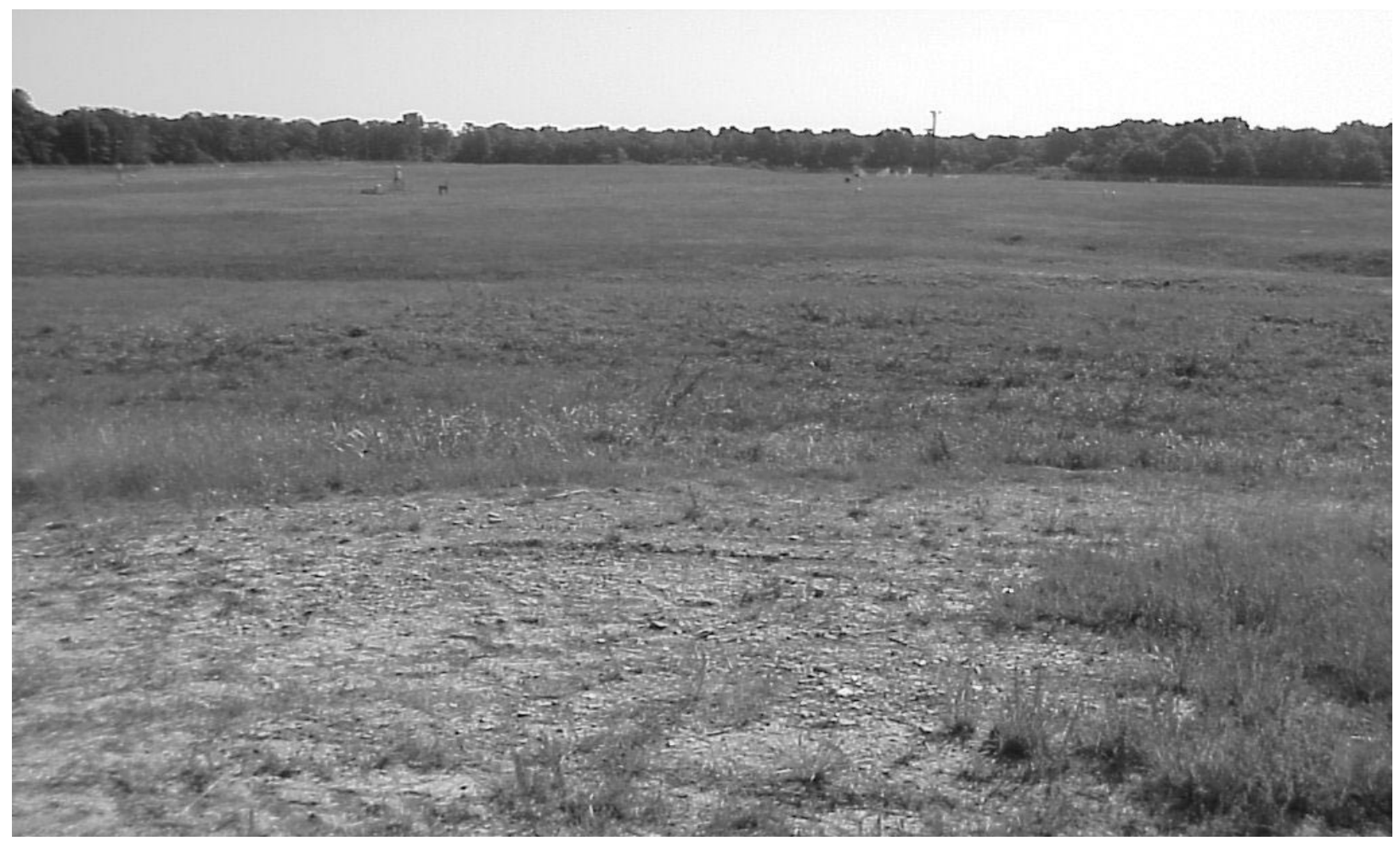

Figure D3. Photo of Fort Leonard Wood site

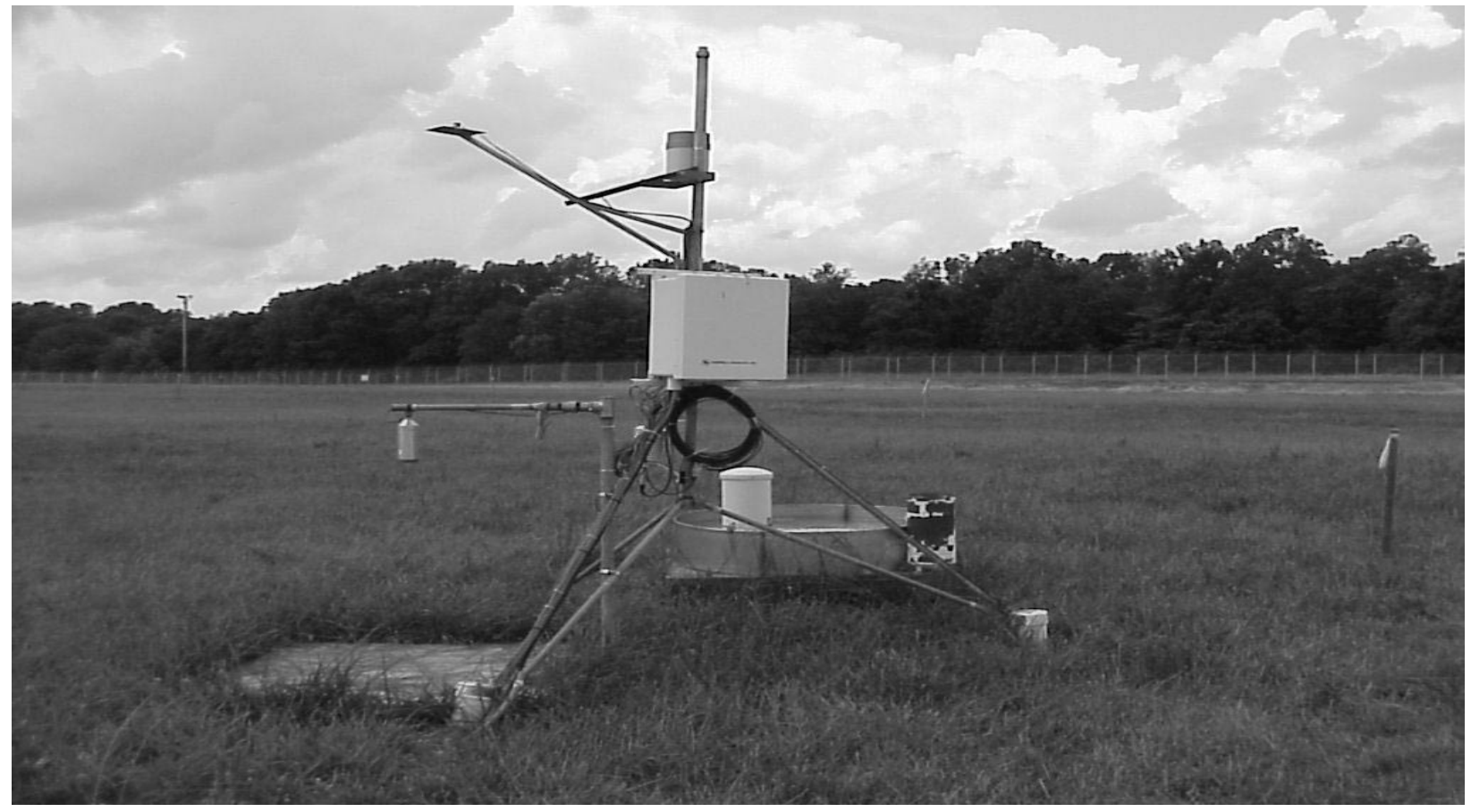

Figure D4. Photo of weather station 


\section{Appendix E Definitions}

Following are definitions of terrain and vehicle terms, which are pertinent to this study. Unless otherwise referenced, they are extracted from the International Society of Terrain-Vehicle Systems Standards (Meyer et al.1977). ${ }^{1}$

\section{Vehicle Terms}

All-drive. Indicates that all of the axles (i.e., tires) are powered.

Contact pressure factor (CPF). A factor that is loosely related to the average hard-surface contact pressure under a vehicle. It is one of eight factors used to calculate the Mobility Index.

Mobility Index (MI). A parameter that is related to the VCI performance of vehicles on fine-grained soils. It was developed in the United States.

Mean Maximum Pressure (MMP). A parameter that is related to the average ground contact pressure under a vehicle and is used to represent soft-soil performance potential. It was developed in the United Kingdom.

Gross vehicle weight (GVW). The total weight of a vehicle.

\section{Soil Terms}

Trafficability. The ability of terrain to support the passage of vehicles.

Cone Index (CI). An index of soil shear strength obtained using a trafficability cone penetrometer standardized by the U.S. Army Engineer Research and Development Center (ERDC).

Remold Index (RI). An index of the sensitivity of soil to strength losses under vehicular traffic obtained using remolding equipment standardized by ERDC.

\footnotetext{
${ }^{1}$ References are listed following main text.
} 
Rating Cone Index (RCI). An index of soil shear strength that includes consideration of the sensitivity of soil to strength losses under vehicular traffic. It is defined as the product of cone index and remold index for the particular layer of soil. For example, the 6-12 in. RCI equals the 6-12 in. RI times the 6-12 in. CI.

Cone penetrometer (see Figure E1). An instrument consisting of a circular cylindrical shaft (usually 18 to 36 in. in length) with a 30-deg right circular cone mounted on one end and a calibrated load-measuring device on the other end. For fine-grained soils, the shaft is 3/8-in.-diam steel (previously 5/8-in. aluminum) and the cone has a 0.5 -sq-in. base area. The output measurement (CI) is the average of pressure readings (typically in pounds per square inch) taken at specified depths of penetration of the base of the cone into the soil. The depths of penetration used in the measurement are usually those taken at the top, midheight, and bottom of the critical layer. The pressure readings are the result of the penetration force divided by the base area of the cone with a standard penetration rate of 72 in. per minute.

Remolding equipment (see Figure E1). Equipment consisting of a circular cylindrical tube mounted on a steel base and a drop hammer. The tube has 1-7/8-in. inside diameter. The drop hammer weighs $2-1 / 2 \mathrm{lb}$ and has $12 \mathrm{in}$. of drop travel. In use, soil samples approximately 6 in. in height are inserted into the tube using a trafficability (or Hvorslev) sampler. For fine-grained soils, cone index measurements are taken in the center of the sample before and after 100 blows of the drop hammer. The cone index measurements are based on readings taken in the sample at depths of $0,1,2,3$, and $4 \mathrm{in}$. The output measurement (RI) is the ratio of the cone index measurement after 100 blows over the cone index measurement before 100 blows. Trafficability (or Hvorslev) sampler (see Figure 2). A piston-type sampling device that is used to obtain an undisturbed sample in soft soils. It has a circular cylindrical tube with 1-7/8 in. inside diameter that is sharpened on the open end. The piston within the tube retracts during penetration into the soil such that a partial vacuum is maintained above the sample preserving the soil's in situ structure.

Critical layer. A layer of soil lying below the natural terrain surface that exerts the greatest influence on trafficability. The depth of the critical layer is dependent upon vehicle characteristics and the nature of the cone index (CI) profile with depth. A 6-in. layer of soil is typically used, but sometimes a 12-in. layer of soil is used. It is typically the 3- to 9-in. layer for light wheeled vehicles (wheel loads of 2,000 lb and less) and the 6- to 12-in. layer for normal wheeled vehicles (wheel loads up to about $10,000 \mathrm{lb}$ ).

Unified Soil Classification System (USCS). A system, which identifies (classifies) soils according to their textural and plasticity qualities and to their grouping with respect to their performances as engineering construction materials (Meyer et al. 1977). 


\section{Vehicle/Terrain Interaction Terms}

Traction. The process by which a ground-based vehicle develops tractive force and overcomes motion resistance to produce desired motion relative to the terrain.

Tractive force (T). The force developed at the vehicle/terrain interface by the traction elements as a result of applied torque from the power plant.

Motion resistance (R). Any force imposing resistance against desired motion. For element-level traction considerations, it is composed of rolling resistance forces only.

Rolling resistance. Motion resistance that arises from deformations in the terrain (external) and the traction elements (internal).

Traction element. Any element of a vehicle that is designed to provide support and/or traction for a vehicle traveling on a surface (e.g. tires, tracks, feet, screws, etc.).

Drawbar (D). The amount of sustained towing force a self-propelled vehicle can produce. It is the resultant of tractive force reduced by motion resistance.

Drawbar coefficient (D/W). Drawbar divided by gross vehicle weight.

Vehicle Cone Index (VCI). Minimum soil strength necessary for a vehicle to make a specified number of passes. Consideration is most often given to 1 pass $\left(\mathrm{VCI}_{1}\right)$ and 50 passes $\left(\mathrm{VCI}_{50}\right)$.

Sinkage (z). The depth to which the traction elements penetrate the terrain measured normal to the original, undisturbed surface.

Slip. An indication of how the speed of the traction elements differs from the forward speed of the vehicle. It is defined by the equation (Meyer et al. 1977):

$$
\begin{aligned}
& \text { Slip }=\left(\frac{r_{R} \omega-v}{r_{R} \omega}\right) \\
& \text { where: } \quad \begin{aligned}
r_{R}= & \text { rolling radius } \\
\omega & =\begin{array}{l}
\text { angular velocity of the wheel or number of revolutions per } \\
\text { unit time divided by } 2 \pi \text { for a track }
\end{array} \\
v & =\text { forward velocity of vehicle or wheel axle }
\end{aligned}
\end{aligned}
$$

Optimum slip. Slip at which maximum work index (WI) occurs.

Work Index (WI). A dimensionless number that represents the relative efficiency for a particular measure of drawbar. It is defined by the equation:

$$
\text { Work Index }=\frac{D}{W}\left(1-\frac{\text { Slip }(\%)}{100}\right)
$$


Maximum pull slip. Slip at which maximum drawbar occurs.

\section{Statistical Modeling Terms}

Coefficient of determination ( $R$ ). A measure of quality that indicates the amount of variation in the measurements $(Y)$ that is accounted for by the relationship predictions. It is defined as the ratio of the explained variation in $\mathrm{Y}$ (i.e., the variation explained by) over the total variation in $\mathrm{Y}$, and it is usually expressed in percent. It can be calculated using the equation:

$$
\begin{aligned}
& R^{2}=1-\frac{\sum_{i=1}^{n}\left(Y_{i}-\hat{Y}_{i}\right)^{2}}{\sum_{i=1}^{n}\left(Y_{i}-\bar{Y}\right)^{2}} \\
& \text { where: } \quad i=\text { increment counter for the observations } \\
& n=\text { total number of observations } \\
& Y_{i}=\text { measured value for } i \text {-th observation } \\
& \hat{Y}_{i}=\text { predicted value for } i=\text { th observation } \\
& \bar{Y}=\text { mean measurement for all observations }
\end{aligned}
$$

Degrees of freedom. A quantity related to quality that is equal to the total number of observations less the number of empirical constants.

Residual. The difference between measured $(\mathrm{Y})$ and predicted $(\mathrm{Y})$ values for an individual observation.

Standard error (S). A measure of quality that estimates the standard deviation of the measurements relative to the equation describing the relationship. It represents the amount of data scatter around the prediction equation. It can be calculated using the equation:

$$
S_{e}=\sqrt{\frac{\sum_{i=1}^{n}\left(Y_{i}-\hat{Y}_{i}\right)^{2}}{n-k}}
$$

where: $\quad i=$ increment counter for the observations

$$
\begin{aligned}
n & =\text { total number of observations } \\
k & =\text { number of empirical constants in the prediction equations } \\
Y_{i} & =\text { measured value for } i \text {-th observation } \\
\hat{Y}_{i} & =\text { predicted value for } i=\text { th observation }
\end{aligned}
$$

Adjusted coefficient of determination. A measure of quality that is identical to $\mathrm{R}_{2}$ with the exception that it takes the degrees of freedom associated with the relationship into account. This measure of quality is more appropriate when comparing various relationships that have different degrees of freedom. It can be calculated using the equation: 
Adj. $R^{2}=1-\frac{\sum_{i=1}^{n}\left(Y_{i}-\hat{Y}_{i}\right)^{2}}{\sum_{i=1}^{n}\left(Y_{i}-\bar{Y}\right)^{2}}\left(\frac{n-1}{n-k}\right)$

where: $\quad i=$ increment counter for the observations

$n=$ total number of observations

$k=$ number of empirical constants in the prediction equations

$Y_{i}=$ measured value for $i$-th observation

$\hat{Y}_{i}=$ predicted value for $i=$ th observation

$\bar{Y}=$ mean measurement for all observations

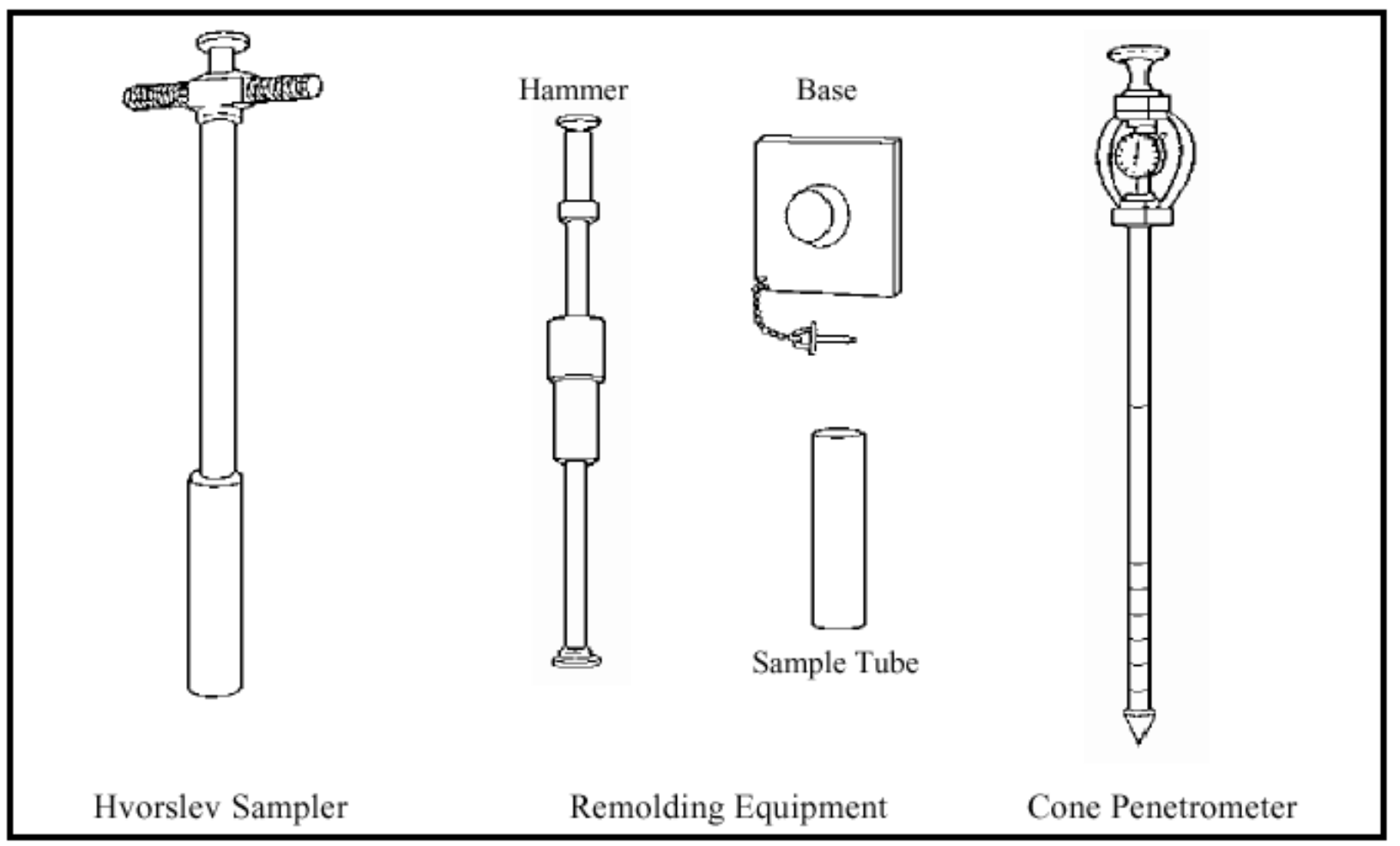

Figure E1. ERDC trafficability equipment 


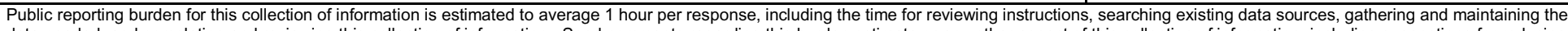

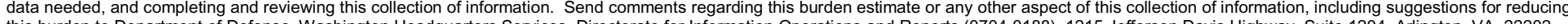

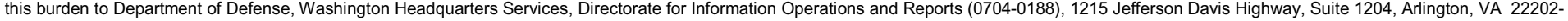

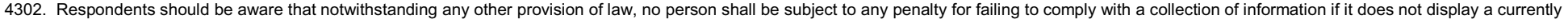
valid OMB control number. PLEASE DO NOT RETURN YOUR FORM TO THE ABOVE ADDRESS.

\begin{tabular}{l|l|l} 
1. REPORT DATE (DD-MM-YYYY) & 2. REPORT TYPE & 3. DATES COVERED (FrOm - To)
\end{tabular}

October 2001

\section{TITLE AND SUBTITLE}

Final Report

Short-Term Operational Forecasts of Trafficability

5a. CONTRACT NUMBER

\section{AUTHOR(S)}

George Mason, Richard Ahlvin, John Green

5b. GRANT NUMBER

5c. PROGRAM ELEMENT NUMBER

5d. PROJECT NUMBER

5e. TASK NUMBER

5f. WORK UNIT NUMBER

7. PERFORMING ORGANIZATION NAME(S) AND ADDRESS(ES)

8. PERFORMING ORGANIZATION REPORT NUMBER

U.S. Army Engineer Research and Development Center

ERDC/GSL TR-01-22

Geotechnical and Structures Laboratory

3909 Halls Ferry Road

Vicksburg, MS 39180-6199

\section{SPONSORING / MONITORING AGENCY NAME(S) AND ADDRESS(ES)}

10. SPONSOR/MONITOR'S ACRONYM(S)

U.S. Army Corps of Engineers

Washington, DC 20314-1000

11. SPONSOR/MONITOR'S REPORT NUMBER(S)

\section{DISTRIBUTION / AVAILABILITY STATEMENT}

Approved for public release; distribution is unlimited.

\section{SUPPLEMENTARY NOTES}

\section{ABSTRACT}

The primary objective of this study was to extend current state of the art for predicting temporal changes in soil strength with time as it relates to vehicle traction. A secondary objective was to develop an algorithm which could be included in high-resolution combat models for improvement of modeling mobility. To this end, the algorithms developed in this study were included in the Semiautomated Forces (SAF) models, specifically JointSAF 5.4. This provided an approach to evaluating combat models in the context of weather effects on mobility.

Two models are developed. The first is the Short-Term Operational Forecasts of Trafficability (SOFT) model. The second Real-Time Mobility (RTM) Model is a vehicle movement model which reacts to continuous changes in soil strength.

\section{SUBJECT TERMS}

Combat model Soft soil

Mobility Soil moisture

\begin{tabular}{|c|c|c|c|c|c|}
\hline \multicolumn{3}{|c|}{ 16. SECURITY CLASSIFICATION OF: } & \multirow{2}{*}{$\begin{array}{l}\text { 17. LIMITATION } \\
\text { OF ABSTRACT }\end{array}$} & \multirow{2}{*}{$\begin{array}{l}\text { 18. NUMBER } \\
\text { OF PAGES } \\
111\end{array}$} & 19a. NAME OF RESPONSIBLE PERSON \\
\hline $\begin{array}{l}\text { a. REPORT } \\
\text { UNCLASSIFIED }\end{array}$ & $\begin{array}{l}\text { c. ABSTRACT } \\
\text { UNCLASSIFIED }\end{array}$ & $\begin{array}{l}\text { c. THIS PAGE } \\
\text { UNCLASSIFIED }\end{array}$ & & & $\begin{array}{l}\text { 19b. TELEPHONE NUMBER (include area } \\
\text { code) }\end{array}$ \\
\hline
\end{tabular}

